\title{
Haemonchus contortus antigen identification and use of tropomyosin in ovine vaccine development
}

\author{
Brynnan P. Russ \\ West Virginia University, bpruss@hsc.wvu.edu
}

Follow this and additional works at: https://researchrepository.wvu.edu/etd

Part of the Immunity Commons, Immunoprophylaxis and Therapy Commons, Parasitology Commons, and the Sheep and Goat Science Commons

\section{Recommended Citation}

Russ, Brynnan P., "Haemonchus contortus antigen identification and use of tropomyosin in ovine vaccine development" (2020). Graduate Theses, Dissertations, and Problem Reports. 7944.

https://researchrepository.wvu.edu/etd/7944

This Dissertation is protected by copyright and/or related rights. It has been brought to you by the The Research Repository @ WVU with permission from the rights-holder(s). You are free to use this Dissertation in any way that is permitted by the copyright and related rights legislation that applies to your use. For other uses you must obtain permission from the rights-holder(s) directly, unless additional rights are indicated by a Creative Commons license in the record and/ or on the work itself. This Dissertation has been accepted for inclusion in WVU Graduate Theses, Dissertations, and Problem Reports collection by an authorized administrator of The Research Repository @ WVU.

For more information, please contact researchrepository@mail.wvu.edu. 
Graduate Theses, Dissertations, and Problem Reports

2020

Haemonchus contortus antigen identification and use of tropomyosin in ovine vaccine development

Brynnan P. Russ

Follow this and additional works at: https://researchrepository.wvu.edu/etd

Part of the Immunity Commons, Immunoprophylaxis and Therapy Commons, Parasitology Commons, and the Sheep and Goat Science Commons 
Haemonchus contortus antigen identification and use of tropomyosin in ovine vaccine development

\author{
Brynnan Paxton Russ
}

Dissertation submitted to the Davis College of Agriculture, Natural Resources and Design at West Virginia University

in partial fulfillment of the requirements for the degree of

Doctor of Philosophy in Animal and Food Science

Scott Bowdridge, PhD, Chair

Mariette Barbier, $\mathrm{PhD}$

Kimberly Barnes, $\mathrm{PhD}$

Jennifer Franko, PhD

Jianbo Yao, PhD

Division of Animal and Food Science

Morgantown, West Virginia

2020

Keywords: Haemonchus contortus, vaccine, antibody, antigen,

Copyright 2020 Brynnan Russ 


\section{Abstract \\ Haemonchus contortus antigen identification and use of tropomyosin in ovine vaccine development}

Brynnan Russ

Globally, the small ruminant industry loses hundreds of millions of dollars due to parasitism by the gastrointestinal nematode Haemonchus contortus. This parasite feeds on blood in the host's abomasum leading to disease including anemia, hypoproteinemia, lethargy, and death. There have been exhaustive efforts to manage this parasite including different management applications, anthelmintic treatment, and now integration of resistance genetics into a flock. Like antibiotics, overuse of anthelmintics has led to resistance of $H$. contortus to these drugs. Therefore, other methods of control are the main focuses of many research initiatives. St. Croix are a resistant breed of sheep that mount a Th2 immune response to third stage larvae (L3), preventing establishment of the parasite. Suffolk are susceptible to infection. In these studies, antibody from St. Croix and Suffolk were used to screen for $H$. contortus protein-sheep antibody binding that may contribute to the St. Croix immune response. This was carried out using immunoblotting technique and identified a $35 \mathrm{kDa} \mathrm{H}$. contortus L3 protein bound by St. Croix serum, but not by Suffolk serum. This protein was identified via Mass Spec as tropomyosin domain containing protein. Tropomyosin has been used in several parasite vaccine trials and is also the main allergen of several arthropods including shrimp and cockroaches. These studies led to the continued investigation of tropomyosin as a putative vaccine candidate in sheep. Peptides were selected and synthesized based on University of Nebraska epitope prediction software and from a study that used tropomyosin peptides in proliferation assays of $\mathrm{CD} 4^{+}$cells isolated from patients allergic to shrimp. After receiving these peptides, enzyme linked immunosorbent assays (ELISA) were performed to determine if there was a breed or infection effect on antibody specificity to these peptides. There were no differences in antibody binding between naïve or primed (previously infected), St. Croix or Suffolk (Nebraska: $P=0.3889$, 54: $P=0.1674,66: P=0.4110,80$ : $P=0.0527,81: P=0.3878)$. The second set of peptides was selected from the results of an epitope mapping experiment using overlapping $H c$ tropomyosin peptides screened with primed St. Croix antibody. Four peptides were selected from this experiment and were synthesized, a set with and without conjugation to keyhole limpet hemocyanin (KLH) for a vaccine trial. ELISA were performed with these peptides and showed no difference between groups (Peptide 1: $P=0.2501$, Peptide 2: $P=0.0732$, Peptide 3: $P=0.0900$, Peptide 4: $P=0.3250)$. However, results based on the epitope mapping experiment provided better expectations for these peptides in a vaccine trial. The vaccine trial 25 weeks and included 4 groups- 1) vaccinated (peptide cocktail of $62.5 \mu \mathrm{g}$ of each peptide + Montanide ISA 61 VG adjuvant), 2) adjuvant only, 3) infection only, and 4) naïve. Vaccinated and adjuvant only received an initial vaccination and a booster 4 weeks later. Six weeks later, animals in groups 1, 2, and 3 were challenged with 10,000 L3 $H$. contortus. The animals were dewormed 7 weeks later and rested for two weeks followed 
by a second challenge of 10,000 L3. Five weeks later, all animals were sacrificed. There were no differences in weekly or final infection parameters (fecal egg count: $P=0.8744$, packed cell volume: $P=0.7532$, adult worm burden: $P=0.8189$ ). However, the vaccinated group produced specific antibody to the peptide cocktail based on ELISA results. Gene expression revealed an adjuvant effect - increasing il17a expression. Although the vaccine was not protective, this experiment showed that Suffolk are able to respond to a vaccine and produce specific antibody to specific peptides. These experiments also provide a roadmap for future $H$. contortus vaccine development experiments. 


\section{Acknowledgments}

First, l'd like to thank Dr. Bowdridge. One of the first things he told me when I met him was "you can do anything you want in this lab," which turned out to be very true. He also encouraged me to apply for the Ruby Distinguished Doctoral Fellowship, wrote me a nomination letter, and helped me in writing my statement of purpose- which all led to my award. Dr. Bowdridge took a huge chance on me, taking in a PhD student straight from undergrad but I am thankful that he did. This position in his lab has led to me to meet incredible people, to take part in exciting research projects, and to expand my knowledge and confidence.

I also want to thank my lab mates throughout the time l've been here. First, Denzel Middleton has been one of the most supportive people I could have ever imagined. He has been there for me from day one of my PhD- both in and out of the lab with his humor and beautiful smile. Dr. Javier Garza has shown me how kind and fun the lab can be all while getting everything done and kicking butt in science; he also stuck with me during a 36-mile bike race even though he could have finished hours before me. Dr. Elizabeth Shepherd always was there if I needed help with experiments and for a talk if needed. She also is a phenomenal example of a strong, incredibly hard-working woman. Malia Berg, Andrew Weaver, Camren Maierle, Reese Tuckwiller, Roger Rohrbaugh, Curtis Patton, and Kelsey Bentley have all been imperative to helping with my animals and helping bring fun to the projects that otherwise would have been unbearable.

In addition, my committee members have been so patient with me in working to get everything put together and finished. They have found time in their busy days or work and home life to help me in whatever ways they can. Dr. Taylor was the first person I met here. I reached out to him first because he is an alumni of my alma mater as wellMississippi State University. He introduced me to Dr. Bowdridge and propelled this whole journey of the past 5 years. The faculty and staff of the Davis College have been more than welcoming throughout my time here and have been helpful in any way they could.

Lastly, my fiancé- Paul, mom- Beth, sister- Kathleen, Aunt- Becca, and grandparentsBarbara and Bernie have all been the most supportive family during my time up here in West Virginia. Even though they are distantly far away (except Paul), they always know how to help me through my downs and celebrate the ups. Clara, the newest addition to our family (my niece) has provided many smiles and pick-me ups when I needed them. Her little giggles bring such joy to us all. Although my dogs will never read this, Atlas and Fenrir have also kept me sane and comforted in times when nobody else could. My friends back home in Florida, whom have been there for me since elementary and high school deserve a million shoutouts- Chantal G., Zachary B., and Lauren M. have all been working to fulfill their passions as I work on mine and we are all seeing that work pay off. I'm so proud of us all. 


\section{Common Abbreviations}

$\mathrm{APC}=$ antigen presenting cell

$\mathrm{CD}=$ clusters of differentiation

Con $\mathrm{A}=$ Concanavalin $\mathrm{A}$

ELISA = enzyme-linked immunosorbent assay

FEC $=$ fecal egg count

$\mathrm{Hc}=$ Haemonchus contortus

HcLA = Haemonchus contortus larval antigen

IFNY = interferon gamma

$\lg =$ Immunoglobulin

IL- = interleukin

JAK = Janus Kinase

$\mathrm{KLH}=$ keyhole limpet hemocyanin

L3 = infective third stage

$\mathrm{MHC}=$ major histocompatibility complex

$\mathrm{PBMC}=$ peripheral blood mononuclear cells

$\mathrm{PCV}=$ packed cell volume $\mathrm{RT}=$ room temperature

STAT = signal transducer and activator of transduction

STC $=$ St. Croix sheep

SUF $=$ Suffolk sheep

TEM= transmission electron microscopy

$\mathrm{Th} 1=\mathrm{T}$ helper type 1

Th2 $=$ T helper type 2

TPM= tropomyosin 
Table of Contents

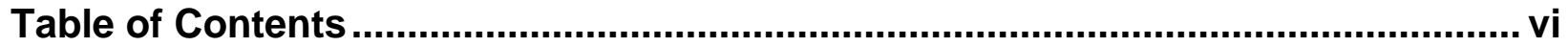

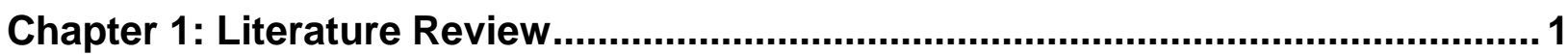

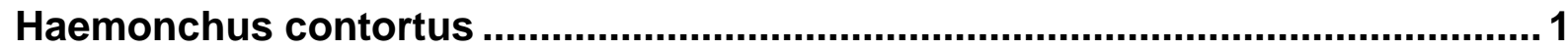

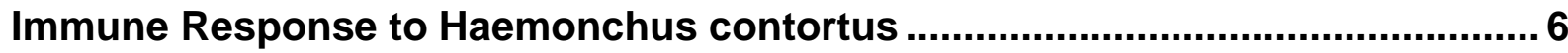

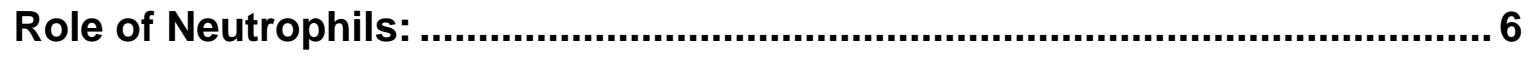

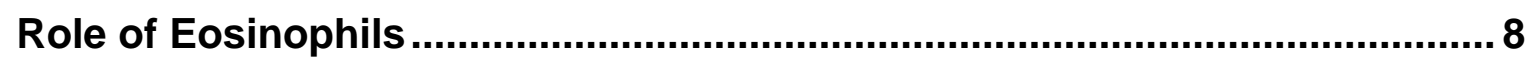

Role of $\mathrm{y} \delta \mathrm{T}$ cells and Epithelial Cells .............................................................

Role of Monocytes............................................................................................ 10

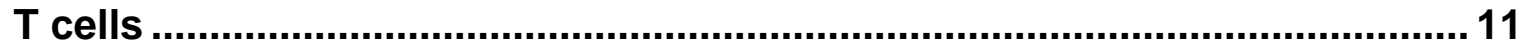

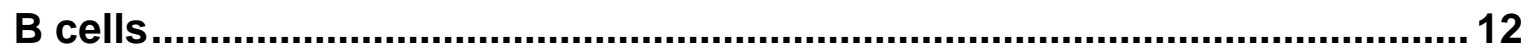

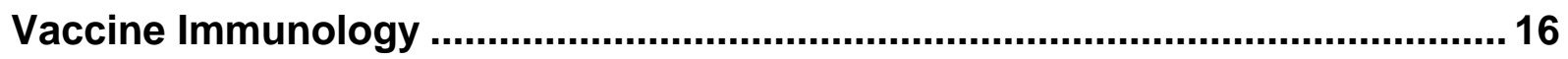

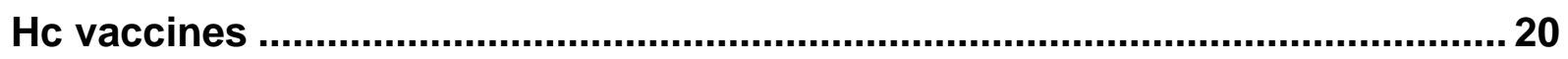

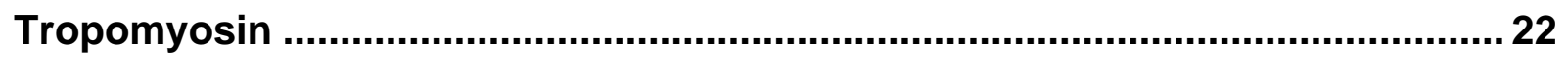

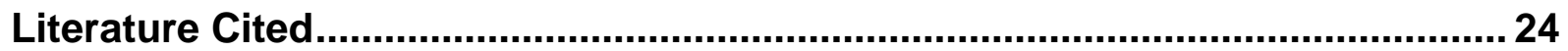

Chapter 2: Differential recognition of Haemonchus contortus protein by serum from parasite-resistant and -susceptible sheep ...................................................4 41

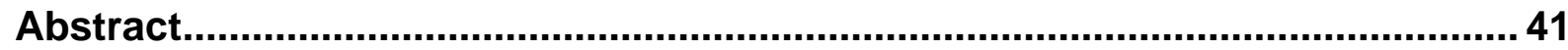

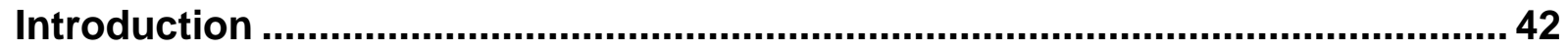

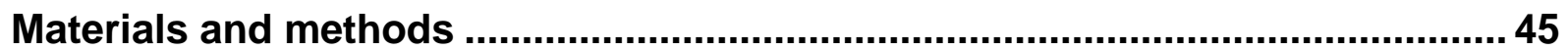

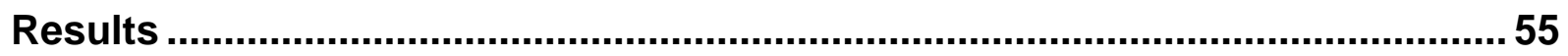

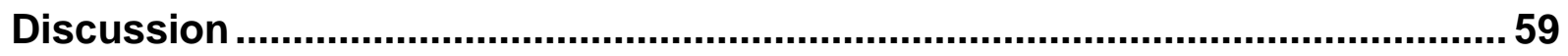

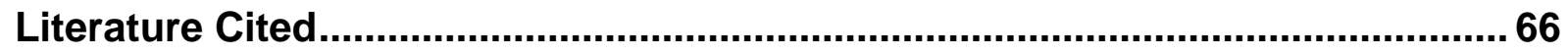

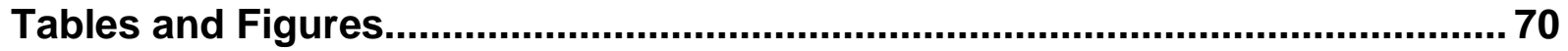

Table 2.1. Predicted antigenic tropomyosin peptides based off of epitope predictor and previous tropomyosin research ..............................................74

Table 2.2. Mapped antigenic tropomyosin peptides bound by St. Croix antibody in epitope mapping experiment........................................................ 76

Figure 2.1. Immunoblot of $\mathrm{H}$. contortus proteins with St. Croix or Suffolk serum and total circulating total immunoglobin.........................................70

Figure 2.2. Circulating levels of HcLA, XL3 -specific IgG. ........................... 71

Figure 2.3. Mass spectrometry analysis of $35 \mathrm{kDa}$ protein bound by St.

Croix antibody.

Figure 2.4. Western blot confirming tropomyosin presence in $\mathrm{H}$. contortus larval antigen at the same size as the immunoblot.

Figure 2.5. Comparisons of breed differences and infection status of predicted tropomyosin peptide-specific IgG................................................. 75 
Figure 2.6 Comparisons of breed differences and infection status of mapped tropomyosin peptide-specific IgG

Figure 2.7 Primed St. Croix IgG area under the curve of predicted vs mapped peptides 77

Figure 2.8. Proliferation of PBMC after 72-hour incubation with different antigens. 78 Chapter 3. Efficacy of vaccination with mapped peptides conjugated to KLH in susceptible sheep

Abstract. 79

Introduction 80

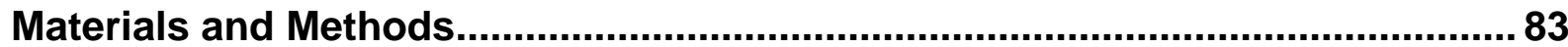

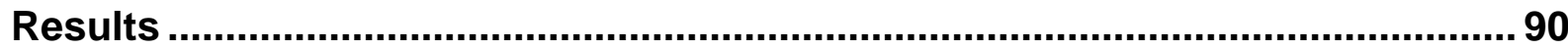

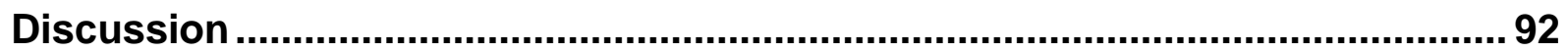

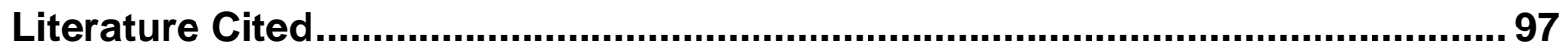

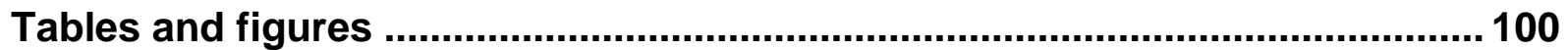

Table 3. 1. Peptides used in vaccine and their amino acid sequences ....... 87

Table 3. 2. Forward and reverse primers used in qRT-PCR ..........................90

Table 3. 3. Vaccine trial groups .................................................................100

Table 3. 4. Gene expression of abomasal lymph node sections.............104

Figure 3.1.Figure 3. 1. Vaccination and challenge schedule for vaccine trial.

Figure 3. 2. Weekly and final infection parameters. ................................. 101

Figure 3. 3. Abomasal lymph node weight and counts. ............................. 102

Figure 3. 4. Vaccine peptides- specific IgG............................................. 103

Chapter 5: Discussion..................................................................

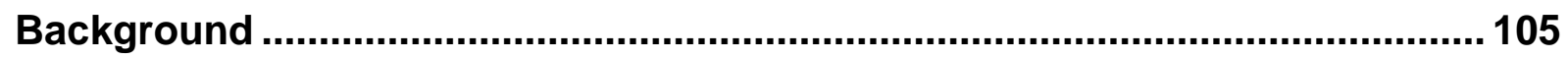

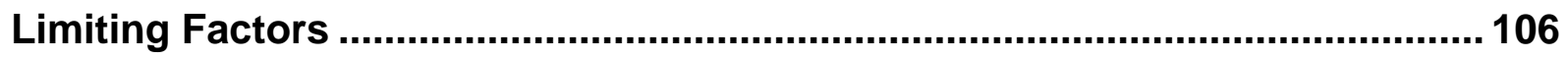

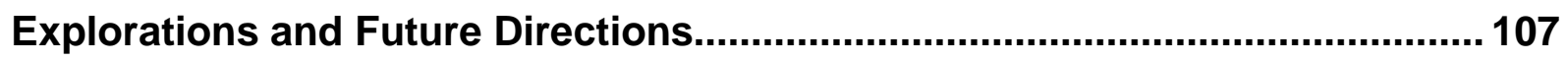

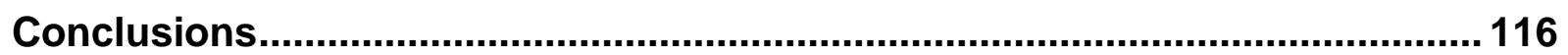

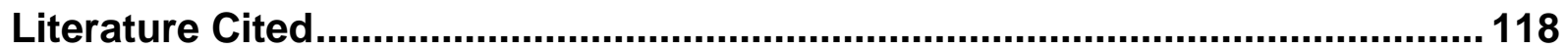




\section{Chapter 1: Literature Review}

\section{Haemonchus contortus}

\section{Lifecycle and pathogenic effects}

Haemonchus contortus $(\mathrm{Hc})$ is a hematophagic gastrointestinal nematode that affects small ruminants and has a direct lifecycle with no intermediate host. Adult females shed eggs while inhabiting the hosts abomasum and eggs enter the environment via host feces. After hatching, first stage larvae require approximately 7 days in favorable environmental conditions to develop into third stage larvae (HCL3). Third stage larvae travel up blades of grass in dew droplets where they are consumed by animals. L3 have a cuticle, that protects from environmental factors and maintains internal osmotic pressure. Once consumed by sheep, L3 travel with digesta to the abomasum where they shed their cuticles and molt, becoming blood-feeding fourth stage larvae (L4). L4 then develop into adults that reproduce sexually and release their eggs for continuation of the life cycle. $\mathrm{Hc}$ late stage larvae (L4) and adults use a buccal lancet to pierce the abomasal mucosa to produce a blood flow for feeding (Weise, 1977).

Female adult worms consume up to $0.05 \mathrm{ml}$ of blood per day (Clark et al., 1962)with an adult worm burden of 1000 , this leads to upwards of $50 \mathrm{ml}$ of blood loss per day. With an established infection of $H$. contortus, adult sheep can lose up to $1 / 10$ erythrocyte volume per day and lamb can lose up to 1/4 erythrocyte volume per day (Georgi and Whitlock, 1967). Blood loss caused by Hc often leads to anemia. Blood vessels throughout the body become leaky to replace fluid loss and leads to hypoproteinemia and edema. Disease caused by the gastrointestinal parasite, $H c$, is a leading source of economic loss in small ruminant industries worldwide. Australia, alone, in 2016 had over 
300 million USD in losses due to $H c$ infection (Emery et al., 2016). Costs include treatment with anthelmintics, increased feed and time to raise the animals, and animal death. In 2015 , the USDA estimated that $8.6 \%$ of sheep and lamb deaths in the United States were caused by internal parasites, including $\mathrm{Hc}$ (https://www.aphis.usda.gov/animal_health/nahms/sheep/downloads/sheepdeath/Shee pDeathLoss2015.pdf).

\section{Methods of Control}

One of the most important issues surrounding $\mathrm{Hc}$ is anthelmintic resistance. Resistance to anthelmintics has been reported as early as 1960 to classes including: Benzimidazoles, Organophosphates, and Imidazothiazoles (Drudge et al., 1964; Green et al., 1981). Factors that contribute to development anthelmintic resistance are high heritability and diversity of alleles associated with resistance, high fecundity of female adults (one female $\mathrm{Hc}$ can release up to 5000 eggs per day), and improper use of the anthelmintic treatments by producers (Silvestre and Humbert, 2002). The newest class of anthelmintic, monepantel, was released for use in 2009; by 2015 there were already two cases of resistance reported (Mederos et al., 2014; Van den Brom et al., 2015). Another concern surrounding drug resistance is multi-drug resistance strains of $\mathrm{Hc}$ leading to lack of effective chemical treatment options available to producers.

To mitigate development of anthelmintic resistance, the FAMACHA ${ }^{\mathrm{TM}}$ scoring system was developed. Using FAMACHA ${ }^{\text {TM }}$ to selectively deworm provides a refuge for drug-susceptible genes to be maintained. FAMACHA ${ }^{\mathrm{TM}}$ scoring utilizes the paleness of the conjunctivae as an indicator for anemia, with a score of 1 being red and healthy and 5 being pale and fatally anemic (Malan and Van Wyk, 1992). This allows producers to 
select individuals that are worst off for treatment with anthelmintic drugs, reducing treatment and lowering instance of resistance in Hc (Van Wyk and Bath, 2002; Wolstenholme et al., 2004; Ejlertsen et al., 2006).

Other alternative methods to help reduce the impact of $\mathrm{Hc}$ includes rotational grazing. Rotational grazing involves frequent movement of animals to different pastures in efforts to reduce exposure to larvae and limit adult parasite infection. The frequency of switching pastures depends on the climate and season as well as land availability and nutrition of the land that is available (Barger et al., 1994; Burke et al., 2009). In warmer, humid climates $L 3$ are more likely to survive in the pasture, leading to more regular rotations. However, in cooler, dryer climates, the frequency of rotating pastures is reduced.

Alternative methods of controlling $\mathrm{Hc}$ also include copper oxide wire particle bolus administration, nutritional management such as increasing protein availability, and grazing forages with condensed tannins (Bang et al., 1990; Steel, 2003; Burke and Miller, 2006; Lange et al., 2006; Heckendorn et al., 2007; Manolaraki et al., 2010; Vatta et al., 2012; Martínez-Ortíz-de-Montellano et al., 2013). While these methods are useful, there is one that continues to gain great interest and that is a genetic approach.

Selection for parasite resistance is one of two genetic approaches to manage the impact of $\mathrm{Hc}$ on economical sheep production. By identifying within breed variation in FEC, producers can incorporate parasite resistance in their selection strategy. This approach has been shown to impact parasite resistance on a flock-wide basis as best demonstrated by selection within the Katahdin breed. Estimated Breeding Values (EBV) is an estimate of an animals' genetic merit for a trait and is influenced by individual 
performance and that of relatives. By calculating an EBV for FEC reduction (FECR), the National Sheep Improvement Program (NSIP) has shown that US flock average FEC EBV has decreased from +20 in 2000 to -45 in 2016 (NSIP, 2016). These data indicate that significant, and reasonably rapid progress can be made within breed when selection emphasis is placed on parasite resistance which also supports data that indicate moderate heritability for this trait (Notter et al., 2018). While this type of selection has worked for Katahdin breeders, availability of this EBV in other breeds is scarce and will limit producer incorporation of this selection strategy.

The Katahdin Hair Sheep is currently the most popular sheep breed in the US based on annual new registrations but also due to producers experiencing more parasite problems nationwide. The breed that has contributed to parasite resistance in Katahdin Sheep is the St. Croix. This breed was developed in the Caribbean islands after their ancestors were brought from West Africa in the $16^{\text {th }}$ century (Thomas, 1991). Some of the benefits of the St. Croix breed include: low maintenance cost, ewe productivity is high, lamb survival rate is high, and they are known to have high resistance to internal parasites (Gamble and Zajac, 1992; Wildeus, 1997). These sheep adapt well in warm, humid environments such as the Southeastern, United States unlike other breeds such as Suffolk. They also can adapt to the cold by growing winter coats when raised in colder climates (Ward, 2017). However, St. Croix average daily gain and quality of meat is lower compared to wool breeds, such as Suffolk. Another downfall of the St. Croix is their small carcass size; mature rams on average weigh $90 \mathrm{~kg}$, while mature ewes weigh $68 \mathrm{~kg}$. In a production system, St. Croix ewes can play an important role to pass on hardiness when crossed with more heavily muscled breeds, such as the Dorper (Burke et al., 2003). 
Despite these flaws, this breed has worked to improve our knowledge of immune response to Hc infection.

Material reviewed in this section have illustrated that strategies meant to mitigate influence of parasitism on production must be those that incorporate a systems approach. This approach should address grazing method, selective deworming, nutritional supplementation and most of all genetic selection. Incorporating all of these management practices on top of managing everything else is a complicated task, therefore, a simpler approach is needed that would not absolve producers of their managerial duties but rather make their life just a bit easier. Thus, development of an effective, easy-to-use vaccine against $\mathrm{Hc}$ would be a desired approach to augment control strategies already in place. However, before this can start, knowledge of ovine immune response to $\mathrm{Hc}$ is critical. 


\section{Immune Response to Haemonchus contortus}

The immune system and immune response are key to protecting the body against pathogens. After infection, part of the immune response called the innate response is mounted and is largely unspecific. Cells associated with the innate immune response include neutrophils, eosinophils, monocytes, and in sheep, both $ү \delta$ T cells and epithelial cells also contribute. Innate immunity is important for mounting an initial response to pathogens as well as for recruiting other cells to the site of infection for further development. These other cells include adaptive immune cells such as $T$ cells and B cells. The adaptive immune response is developed specifically to the pathogen and ultimately helps clear it from the body. The adaptive immune response is also imperative in developing immune "memory" to prevent or reduce the impact of future infections of the same pathogen.

\section{Innate Immunity}

\section{Role of Neutrophils:}

Infective, HCL3 elicit immune responses as early as 3 days after infection. This delay in responsiveness reflects travel time to the abomasum which is the tissue niche for this parasitic infection of Hc (Adams, 1982; Balic et al., 2002). Early innate cell influx to the abomasum is a characteristic immune response expressed by parasite resistant sheep but not observed in parasite susceptible sheep until days later (Bowdridge et al., 2015). Authors of this paper found that innate cell influx is also associated with reduced larval burden. Neutrophils were found to exponentially increase from day 3 to day 7 after infection in parasite-resistant sheep, where no change in neutrophil influx was observed in parasite susceptible sheep. 
The role of neutrophils in the context of helminth infection is curious because they are traditionally associated with bacterial or viral responses and have a role in phagocytosis. Recent studies revealed new roles for neutrophils, particularly in memory responses, where these cells exhibit a different phenotype after challenge infection with the nematode, Nippostrongylus brasiliensis in mice. The authors of this study reported that neutrophils adopted an "N2" phenotype, upregulating Th2-associated cytokine genes IL-13, IL-33, Igf1, Retnla (RELMa) and Chi3l3 (Ym1) (Chen et al., 2014). Recent sheep studies revealed that neutrophils from St. Croix sheep produce IL-4 quickly in vitro in response to $H C L 3$ antigen (larval homogenate) but not to adult antigen (adult homogenate) (Middleton et al., 2020). These data support a role for neutrophils as an early source for IL-4 during Hc infection in sheep. However, de novo cytokine synthesis is not the only feature of these cells.

Current studies evaluating the role of neutrophils in sheep have revealed that these cells preferentially produce extracellular traps (NETs) in culture with L3 H. contortus, when derived from parasite-resistant sheep. The authors went on to demonstrate that NETs inhibit larval mobility and lead to larval clumping, presumably facilitating larval expulsion (Garza et al., 2018). This study also described how neutrophils from parasiteresistant sheep have a different type of NET activity called vital netosis, where neutrophils that have ejected cellular DNA are also still alive and have not begun apoptosis. Whereas neutrophils from Suffolk sheep experience classic netosis where once NETs are formed the cells are actively engaged in apoptosis. These data, coupled with early influx of neutrophils after $\mathrm{Hc}$ infection support a key role for neutrophils in early immune response (Bowdridge et al., 2013). 


\section{Role of Eosinophils}

Eosinophils respond to alarmins and have been implemented in mounting a protective immune response to Hc. Helminth studies have shown that IL-5 is imperative for eosinophil influx and differentiation (Coffman et al., 1989). Using Trichostrongylus colubriformis as a model for GI helminth infection in sheep, Bao et al., 1996 showed an upregulation of $I L-5$ gene expression in the small intestine lamina propria, mesenteric lymph node, and Peyer's patches of sheep (Bao et al., 1996).

In vitro, eosinophils primed with serum, complement, and IL-5 were able to directly bind and pull the cuticle away from the larval body. This binding caused larvae to remain immobile for 3 day and authors reported that these larvae were dead (Rainbird et al., 1998). Another role eosinophils play is the release of granules that damage different life stages of parasites, making them more susceptible to other facets of the immune response. Studies determining the composition of human eosinophil granules have identified charcot-leyden crystals, or galectin-10 as one of the granule proteins released (Ackerman et al., 2002). In sheep, the orthologue for eosinophil-released galectin-10 is galectin-14 (Young et al., 2009; Robinson et al., 2011a) which is released by eosinophils and is found in sheep Gl mucosal lining at rest and during $\mathrm{Hc}$ infection (Young et al., 2009; Robinson et al., 2011a). While the mechanism is yet to be elucidated, galectin-14 levels were negatively correlated with final worm burden, thus, indicating a potential role for eosinophil-released galectin-14 in reducing $H c$ infection (Robinson et al., 2011a). Galectin-11 is also found in sheep Gl epithelial lining during infection, and may also be released by eosinophils (Cummings and Liu, 2009; Preston et al., 2015). Galectin-11 is hypothesized to make the GI lining stickier, inhibiting free movement of the parasite and 
increasing larval expulsion. An in vitro study showed Galectin-11 bound to Hc L4 and adult pharynx regions but not L3 and prevented further development of the parasite.

\section{Role of $y \delta T$ cells and Epithelial Cells}

$T$ cell receptor phenotypes include $\alpha \beta$ heterodimers or $\gamma \delta$ heterodimers. While $\alpha \beta$ T cells are considered adaptive cells, $ү \delta$ T cells play a unique role in straddling the innate and adaptive immune responses. Most mammalian species see reductions of $y \delta$ T cell concentrations as they age, sheep and cattle maintain high concentrations of $y \delta$ T cells into adulthood. Concentrations as high as $50 \%$ of the T cell population have been reported in sheep (Evans et al., 1994). Rather than requiring external signals for maturation, yס T cells can leave the thymus with low-specificity TCRs able to bind and act against pathogens. In humans, there are reports of $y \delta$ T cell receptors recognizing pathogen associated molecular patterns (Holtmeier and Kabelitz, 2005; Parker and Ciofani, 2020).

Young ruminants have higher concentration of $y \delta \mathrm{T}$ cells than $\alpha \beta \mathrm{T}$ cells, presumably to allow development of an undeveloped immune system. The functions of үठ T cells include antigen presentation to $C D 4^{+}$cells, cytokine productions, and effectors as cytotoxic cells (Guerra-Maupome et al., 2019). To elucidate the role of $ү \delta ~ T$ cells during helminth infection, anti-WC1+ antibody was administered to Canaria Hair sheep to deplete $\gamma \delta T$ cells and determine the effect on adult worms. Without $W C 1^{+} \gamma \delta T$ cells, female worms grew longer and had higher number of eggs in utero. These results illustrate $W C 1^{+} \gamma \delta T$ cell roles in reducing adult female fecundity and thus affecting their ability to continue their life cycle (Hernández et al., 2017).

All life stages of $H c$ are large pathogens, particularly when compared to bacteria or viruses; HcL3 - the smallest of the infective life stages- measures an average of 750 
$\mu \mathrm{m}$ long (Anderson, 1995). All life stages also produce and excrete molecules known as excretory/secretory products $(E / S)$. Parasites elicit unique immune responses due to these multiple factors- size of the pathogen, E/S products, and antigens associated with the worm itself. The innate immune response is responsible for initiating the response against HcL3 and early prevention of establishment. In addition, all infective life stages of $H$. contortus must avoid being swept away by gastrointestinal peristalsis by constant movement, leading to epithelia and mucosal disturbance. These cells then release cytokines, alerting the immune system to the presence of large pathogens. During infection with Trichostrongylus colubriformis, another sheep GI nematode, sheep epithelial cells released alarmin cytokines IL-33, IL-25 and thymic stromal lymphopoietin (TSLP), leading to the recruitment of innate cells to the site of infection to initiate polarize the immune response towards a Th2 response (Humphreys et al., 2008; Wang et al., 2011; Andronicos et al., 2012; Lopes et al., 2015; Maizels and McSorley, 2016).

\section{Role of Monocytes}

Monocytes are plastic cells and can differentiate into either macrophages or dendritic cells. Macrophages and dendritic cells are known as bridges between innate and adaptive immune. Dendritic cells' main role is to collect antigen material, process it and present to adaptive immune cells via MHC (Chan et al., 2002). Depending on its derivation and local cytokine influence, macrophages have different functions. One function is to maintain tissue through phagocytosis of dead, infected, and dying cells (Gordon \& Martinez, 2010; Mantovani et al., 2013). Macrophages also mediate inflammation through cytokine production and shifting profiles when needed. In a 15-hour time period, isolated monocytes from either St. Croix or susceptible Suffolk, cultured with 
Hc L3 in vitro, showed different abilities to shift their immune profiles. St. Croix monocytes were able to shift from an inflammatory "M1" cytokine profile to an anti-inflammatory "M2" profile. However, Suffolk monocytes maintained M1 profiles, illustrating an ability of some monocytes to be "plastic" in their development (Shepherd, 2019). Monocytes act as a bridge between the innate and adaptive immune responses through presentation of antigen to $\mathrm{T}$ and $\mathrm{B}$ cells, eliciting a specific immune response.

\section{Adaptive immune response}

\section{T cells}

T cells develop in the thymus and either express $\alpha \beta$ T cell receptors (TCR) or $\gamma \delta t$ cell receptors. $ү \delta T$ cells are able to leave the thymus as effector cells, while $\alpha \beta T$ cell leave the thymus as naïve cells (Parker and Ciofani, 2020). As discussed earlier, yठ T cells act as both innate and adaptive cells. Alternatively, $\alpha \beta$ T cells require antigen to be presented to them through their TCR to mature. Antigen presenting cells deliver the processed antigen as peptide via MHC class I or class II, depending on the coreceptor present on the surface of the $T$ cell- CD8 or CD4, respectively. CD8 ${ }^{+} T$ cells are also known as cytotoxic T cells; their main function is to target infected cells and program them for apoptosis via transfer of cytotoxic proteins in lysosomes. Another function of CD8 ${ }^{+} \mathrm{T}$ cells is direct killing of pathogens including bacteria, viruses and parasites.

$\mathrm{CD} 4^{+}$cells are also referred to as $\mathrm{T}$ helper cells. Depending on the antigen presented to the cell and cytokine environment, naïve $\mathrm{CD} 4^{+} \mathrm{T}$ cells can develop into many population subsets. Janus kinase-signal transducer and activator of transcription (JAKSTAT) pathways play important roles in T helper cell polarization (Renauld, 2003). Cytokines surrounding the naïve $T$ helper cell binds the external portion of the 
transmembrane protein, JAK. After the cytokine binds, JAK dimerizes leading phosphorylation of STAT within the cytoplasm of the cell. Phosphorylation of different STAT proteins leads to transcription of polarizing genes. When activated, T helper cells generally induce a positive feedback loop to maintain their phenotype and maintain the cytokine environment.

T helper type 1 (Th1) cells are stimulated after the transcription factor, T-bet is activated via STAT1 and STAT4 which are activated by IFN-Y and IL-12. Th1 cells then produce IFN- $y$ themselves, leading to a pro-inflammatory immune response. Th2 cells are activated after IL-4 binds its JAK protein, phosphorylating STAT6. Th2 cells produce IL-4, IL-5 and IL-13, inducing an anti-parasitic immune response (O'Shea and Murray, 2008). Th17 cells are activates via STAT3 and induce IL-17 expression. The role of Th17 cells s still being elucidated. However, they are associated with neutrophils and bacterial infections(Harrington et al., 2005). Tregs are activated when TGF- $\beta$ activates STAT5 and thus, induces transcription of TGF- $\beta$ and IL-10. Tregs regulate immune responses to maintain a balance between pro-and anti-inflammatory pathways (Leung et al., 2010). T follicular helper cells (Tfh) are found in the lymph nodes within the germinal centers and are important in the development of specific antibody. These cells shuttle antigen between follicular dendritic cells and developing B cells to help produce specific antibodies.

\section{B cells}

B cells are named for the tissue in which they were discovered- bursa of fabricius. There, naïve B cells undergo somatic hypermutation to develop low-specificity b cell receptor $(\mathrm{BCR})$. B cell receptors $(\mathrm{BCR})$ are antibody structures expressed on the surface of B cells which are "Y" shaped proteins made up of a heavy and a light chain. The $C$ 
terminus of each chain is known as the "constant" domain and helps maintain the structure of the antibody. The $\mathrm{N}$ terminus of each chain goes through hypermutation to develop specificity to antigens and is known as the variable domain. During hypermutation, the heavy chain has three genetic regions ( $V, D$, and $J)$ that go through recombination to produce the strongest affinity for antigen. The light chain only has $V$ and $\mathrm{J}$ regions. The heavy chain also goes through class switching to generate the different antibody isotypes- $\lg (M, D, G, A$, and $E)$. Based on the signal provided by $T$ cells via $B$ cell CD40 and the microenvironment, antibody will switch its heavy chain constant region to change its effector function (Stavnezer and Schrader, 2014). During development, IgM and $\lg \mathrm{D}$ are the first antibodies present on the surface of the $\mathrm{B}$ cell. $\lg M$ and $\lg \mathrm{D}$ antibodies bind poorly but act as first response antibodies. IgG is the most abundant antibody found throughout the body and is highly specific to its target. IgA is found in mucosal surfaces and is important during infection that affects mucosal sites such as nasal passages, lungs, and stomach lining. IgE is associated with type 2 hypermutation, or an allergic response including mast cell degranulation via binding of $F c \varepsilon R$ on the cell surface (Schroeder and Cavacini, 2010).

B cells can mature into short-lived antibody producing plasma cells after encountering an antigen that binds poorly to its BCR. However, naïve B cells can mature in the germinal center of a lymph node where it interacts with $\mathrm{T}$ follicular helper cells and follicular dendritic cells to produce highly specific antibody. Follicular dendritic cells remain in the light zone of a germinal center and act as depots for antigen. There, Tfh's collect antigen and act as a secondary presenter of antigen to maturing B cells. When a $B$ cell has a BCR that binds the antigen, it retreats to the dark zone of GC and goes 
through further somatic hypermutation and isotype switching to produce highly specific antibody (McHeyzer-Williams and McHeyzer-Williams, 2005).

\section{Adaptive immune response to $\mathrm{Hc}$}

In $H c$ challenge infection studies, resistant sheep show a remarkable ability to avoid reinfection due to development of effective adaptive immune responses during primary infection that primes the immune system for future infections (Courtney et al., 1985; Gamble and Zajac, 1992; Shakya et al., 2011; Bowdridge et al., 2015; Hernández et al., 2016). Anti-CD4 monoclonal antibodies were used to experimentally deplete CD4+ cell populations in resistant sheep to determine their importance. After a challenge infection, these sheep without $\mathrm{CD} 4^{+}$cells had significantly higher fecal egg counts, decreased numbers of abomasal mucosal mast cells, and reduced eosinophilia. When compared to control infected randomly-bred sheep, there was no difference, illustrating the importance of $\mathrm{CD}^{+}$cells in an effective immune response against $\mathrm{Hc}$ infection. (Gill et al., 1993).

Helminth infections, including $\mathrm{Hc}$ infection, classically lead to a Th2 response including increased Th2 cells, M2 macrophages, $\lg \mathrm{A}, \lg \mathrm{E}$, and eosinophilia (Courtney et al., 1985; Gamble and Zajac, 1992; Gill et al., 2000; Bowdridge et al., 2015; MacKinnon et al., 2015; Estrada-Reyes et al., 2019). Multiple studies have shown IL-4 mRNA in abomasal tissues as early as 3 days in resistant breeds but not in susceptible breeds (Robinson et al., 2011b; Jacobs et al., 2016). IL-13, another important Th2 cytokine has recently been shown to bind and paralyze $\mathrm{Hc}$ larvae in vitro, expanding the role of Th2 cytokines in response to $\mathrm{Hc}$ infection (Shepherd et al., 2020). 
In vitro culture of L3 with St. Croix PBMC results in reduced motility of the larvae resulting from direct binding and potential damage to L3 by one or multiple cell types in the PBMC mixture (Holt et al., 2015). Further experiments showed that PBMC increase morbidity in addition to reducing motility. In these experiments, ATP was used to measure morbidity of L3 caused by PBMC, using heat-killed larvae as a control. Third stage larvae cultured with St. Croix PBMC plus autologous serum led to significantly increased morbidity compared to L3 cultured with Suffolk derived PBMC and serum. However, L3 cultured with PBMC alone from either breed led to larval death but not at the same level as heat-killed controls. These data indicate that although PBMC from Suffolk and St. Croix can affect larval morbidity, St. Croix humoral response enhances the killing (Shepherd et al., 2017)

Antibody development associated with Th2 response has been implicated in an effective immune response in resistant breeds. $\lg \mathrm{G} 1$ and $\lg A$ concentrations increase in serum during $H c$ infection and are positively correlated with resistance (Gill et al., 1993). Several other studies have also found increased levels of $\lg G$ and $\lg A$, along with $\lg E$ in resistant breeds compared to levels in susceptible breeds, indicating a role in effective immune responses (Lacroux et al., 2006; Terefe et al., 2007; Bowdridge et al., 2013; Hernández et al., 2016) In vitro culture of larvae with serum leads to clumping of larvae, which may play a role in expelling larvae and preventing establishment during infection (Garza et al., 2017). Th2 cytokines including IL-4, IL-5, CD40L bind their receptors on the surface of B cells, , providing signals to B cells to induce class switching both to $\lg A$ and $\lg E$, both of which are markers of anti-parasitic immune responses (Purkerson and Isakson, 1992; Morawetz, 1996; Cerutti, 2008). IgE binds the FcER1 of eosinophils, mast 
cells, and basophils leading to degranulation and potentially damaging incoming larvae or established adults. IgE can also bind its receptor on smooth muscle cells and epithelial cells leading to their contractility also bind to goblet cells leading to mucus secretions, all leading to the classic "weep and sweep" response to try and clear the parasite out of the gut. The "weep and sweep" mechanism is also enhanced by IL-4 and IL-13 binding and STAT6 activation of epithelial and smooth muscle cells (Anthony et al., 2007).

In most adaptive immune responses, antibody acts directly on a pathogen through binding and neutralizing functions or can target pathogens for destruction by other cells. The adaptive immune response including antibody and effector memory cells is the main target of vaccine development. Vaccines introduce a non-infective pathogen or pathogen molecule to the adaptive immune system without disease so that when that pathogen infects the body, it is easily recognized and eliminated.

\section{Vaccine Immunology}

Vaccines are made up two main components; antigen and adjuvant. Antigens are added in different forms including: live, attenuated pathogen, native antigen, toxoids derived from the pathogen, and recombinant protein or polysaccharide. Adjuvants are used to recruit cells to the site of vaccination to initiate an innate immune response. At the site of vaccination, dendritic cells mature after interacting with antigen and migrate to secondary lymph nodes where they present antigen to naive $\mathrm{T}$ and $\mathrm{B}$ cells, eliciting an adaptive immune response. The focus in vaccine development is to produce long-lasting, specific, and protective antibody. Early after vaccination, low-affinity antibodies circulate in the blood. In the germinal center of lymph nodes, $\mathrm{T}$ follicular helper cells act as intermediates, shuttling antigen between follicular dendritic cells and B cells. 
Administering the appropriate amount of antigen in the vaccine is imperative to have a long lasting and specific antibody response. During B cell maturation into antibody producing plasma cells, B cells shuttle antigen between the light and dark zone of germinal centers. This allows B cells in the dark zone to go through affinity maturation and produce specific antibodies. Another goal of vaccines is the production of memory B cells for a rapid response to the pathogen. In addition to activating $B$ cells, vaccines aid in protection through development and activation of memory $\mathrm{T}$ cell responses; this includes both $\mathrm{CD} 8^{+}$and $\mathrm{CD} 4^{+}$memory T cell populations (Plotkin and Orenstein, 2008).

Other factors considered during vaccine development are types of antigen. Whole cell vaccines including attenuated live and killed pathogens include multiple antigens, presenting multiple opportunities to induce protective immunity. However, pathogens are not always viable options as they can be expensive and difficult to grow (Jasmer et al., n.d.) or too dangerous to grow, thus, it is reasonable to utilize synthetically produced antigens to induce generation of protective humoral immunity.

\section{Adjuvants}

Adjuvants are mixed with the antigen or whole cell to enhance a specific immune response. Based on the adjuvants' chemical properties, different immune responses can be induced and contribute to protection against the targeted pathogen. Toll-like-receptors targets, such as $\mathrm{CpG}$, have been utilized in adjuvant mixes to elicit a specific type of immune response (Di Pasquale et al., 2015).

Aluminum salt (alum) adjuvants have been used in vaccines longer than any other adjuvant and are proven to induce antibody responses (Marrack et al., 2009). There are three mechanisms proposed for alum. The first mechanism of immunogenicity is initiating 
a strong innate immune response through an influx of dendritic cells, neutrophils, eosinophils, NK cells, and monocytes; these cells produce Th2 polarizing cytokines in response to alum. These cytokines direct $\mathrm{CD} 11 \mathrm{~b}^{+}$cells to differentiate into dendritic cells and "M2" phenotype macrophages (Seubert et al., 2008; Tritto et al., 2009; Calabro et al., 2011a). Dendritic cells then move antigen to draining lymph nodes where adaptive response can develop. Alum binds and slowly releases antigen, allowing follicular cells to sample antigen and develop a more specific antibody response (Shi et al., 2001). However, this "depot" mechanism is hypothesized to depend on site of injection and local cellular environment (Munks et al., 2010; Hutchison et al., 2012). The final proposed mechanism of alum is injection induces uric acid and cellular DNA release, both of which are danger signals leading to a Th2 response (Kool et al., 2008; Marichal et al., 2011).

Quil-A adjuvant is the A-Fraction of saponin from Quillaja saponaria Molina, a South American tree. Saponins are made up of an aglycone unit bound to carbohydrate chains. These chemicals also possess detergent properties and are produced by plants, lower marine animals, and some bacteria (Savage, 2003). Saponin adjuvants have been used in other sheep vaccine studies and other anti-parasite vaccine trials, including Taenia ovis, Taenia solium, and Echinococcus granulosus to attempt to induce a balanced response of Th1, Th2 and Treg (Lightowlers et al., 1996). Quil-A induces CD8+ lymphocyte proliferation, antibody specific humoral response, macrophage-oriented cytotoxicity, and cytokine production leading to a skewed Th1 response (Newman et al., 1992; Kensil, 1996; Behboudi et al., 1999; Yui et al., 2001). In a study looking at the effect of different adjuvants in an experimental infection of Fasciola hepatica, Quil-A induced B cell proliferation and antibody production, but also a Th1 response. These effects resulted 
in a reduced fluke infection in the lambs (Haçarız et al., 2009). Like many other popular adjuvants, the mechanism is not completely understood, but it is hypothesized that QuilA causes tissue damage leading to danger signals and deposition of the antigen with the response leads to a specific cytotoxic cellular response (Cibulski et al., 2018).

Other common adjuvants include water-in-oil (W/O) or oil-in-water (O/W) adjuvants, or emulsions. Some of the most common emulsion adjuvants are Freund's (complete or incomplete) Adjuvant, Montanide, and MF59. These types of adjuvants work by emulsifying the antigen into tiny droplets of either water or oil which then slowly release antigen. The emulsion itself also helps enhances appropriate vaccine response for the targeted pathogen. Incomplete Freund's adjuvant (IFA) is a W/O emulsion; when heatkilled Mycobacterium tuberculosis is included in the adjuvant, it becomes Complete Freund's adjuvant (CFA). CFA induces a Th1 response through activation of Macrophage-inducible C-type lectin (Mincle). Mincle activation leads to neutrophil infiltration, antigen-specific $\mathrm{T}$ cell responses, antibody production, and inflammatory chemokine, and cytokine production (Ishikawa et al., 2009; Werninghaus et al., 2009; Desel et al., 2013). CFA has such harsh local inflammatory side effects that it is not used in human vaccines. When it is used in vaccines, it is usually used for the initial vaccination and the subsequent boosters use IFA. IFA induces a Th2 response and slowly deposits the antigen, leading to stimulation and production of antibody-producing plasma cells

Montanide was developed by Seppic, in France, to enhance immune responses to recombinant antigens. While alum is good at inducing an antibody response, it is not good at eliciting a cellular response which is imperative when using recombinant antigens. Compared to Freund's adjuvant and alum, Montanide ISA 708,721 , and 70 was found to 
induce consistent adjuvant responses measured by antigen-specific antibody when used in a peptide vaccine administered to mice (Jones et al., 1990). Since this study, Seppic has developed several different Montanide ISA adjuvants to induce appropriate antibody and cellular responses when using synthetic peptides in vaccines in different species; these include Montanide ISA 720, Monanitde ISA 51, and Montanide ISA 61 VG (Aucouturier et al., 2002; Khorasani et al., 2016)

MF59 is a squalene-based emulsion adjuvant used in Influenza vaccines in over 20 countries (O'Hagan et al., 2012). It has been shown to increase antigenicity of influenza vaccines and increase seroconversion rates, which is important for vaccine

efficacy (Nicholson et al., 2001; O'Hagan, 2007; Pellegrini et al., 2009). There is also evidence of MF59 acting to enhance chemokine recruitment (CCL2, CCL3, CCL4, and CXCL8) to the site of vaccination leading to increased numbers of $C D 11 b^{+}$cell recruitment (Seubert et al., 2008). According to studies, the first cells to infiltrate the area are neutrophils followed by monocytes, eosinophils, and lastly dendritic cells. Recruitment of these cells increased interaction with antigen and transport of the antigen to the local draining lymph node for processing. Alum has been found to act similarly but with lower neutrophil recruitment and less efficient shuttling of antigen to the local draining $L N$ (Calabro et al., 2011b).

\section{$\underline{\text { Hc vaccines }}$}

There have been many efforts to produce vaccines against Hc. Urquhart et al.,1966 gave two doses of irradiated larvae 28 days apart followed by a challenge infection 30 days later to measure protection. This immunization provided no protection to sheep (Urquhart et al., 1966). Other targets for vaccine candidates include 
excretory/secretory proteins $(\mathrm{E} / \mathrm{S})$, native proteins, and recombinant proteins and peptides. Two adult worm E/S proteins ( $15 \mathrm{kDa}$ and $24 \mathrm{kDa}$ ) have been isolated and used in early vaccine trials. The biological function of these proteins remains unknown but are most likely associated with modulating the host immune response (Gadahi et al., 2016b). In the first trial, these proteins were emulsified in dimethyl dioctadecyl ammonium bromide (DDA) did not elicit protective antibodies (Vervelde et al., 2001). However, the same research group used whole E/S glycoprotein product and Alhydrogel as the adjuvant for their vaccine, leading to an $89 \%$ reduction in cumulative egg output (Vervelde et al., 2003). One issue affecting the viability of vaccine candidates is whether the antigens are recombinant or native. The group of proteins that has shown most efficacy has been native proteins, specifically hidden gut proteins $\mathrm{H} 11$ and H-gal-GP. These proteins are found in the gut wall of adult $H$. contortus. Therefore, the immune system would not normally have access to these proteins. After vaccination, antibody is produced to bind these proteins to block their function. When a blood meal is taken in, the conjugate antibody binds these proteins leading to disruption of blood digestion in the worm. This leads to starvation of the adult, reduced fecundity and expulsion of the worm from the host gut. These antigens are used in a commercial vaccine, Barbervax $\AA$, but is only available in Australia and New Zealand. Although this vaccine is effective, there are number of limitations such as maintaining infections in lambs to produce the native antigens of the vaccine, as well at the number of boosters needed for continued protection (Emery et al., 2016; Magalhães de Matos et al., 2017). These issues illustrate a need for improved understanding of the immune response to $H$. contortus. With a better understanding of which proteins are important for survival to the parasite as well as which 
proteins are targeted by the immune response, an improved vaccine could be studied and produced.

\section{$\underline{\text { Tropomyosin }}$}

Tropomyosin (TPM) is a highly conserved protein found in all eukaryotic cells. The function of this protein varies based on its isoform, but its main role is actin stabilization and regulation of actin/myosin interactions. Tropomyosin is normally found as a dimerized a-helical coiled-coil bound along actin. During muscle contraction and release, TPM regulates the $\mathrm{Ca}^{2+}$-mediated interactions between actin and myosin. It has also been found in non-muscle cells where it still interacts with actin, but plays a role in cell migration, cytokinesis and morphogenesis (Gunning et al., 2015).

Although tropomyosin is a conserved protein found in eukaryotic cells, invertebrate tropomyosins have been identified as main allergens in organisms such as shrimp, cockroaches, and dust mites (Witteman et al., 1994; Crespo et al., 1995; Rao et al., 1998; Ayuso et al., 2002). Parasite tropomyosins have also been studied as potential vaccine candidates in both ectopic and internal parasites (O'Donnell et al., 1989; Folkard et al., 1996; Taylor et al., 1996; Hartmann et al., 1997; Cao and Liu, 1998; Jenkins et al., 1998;

Nisbet et al., 2006; Nabian et al., 2013; Wright et al., 2016) . Taylor et al., 1996 found that $B A L B / c$ mice vaccinated with a 136 amino acid residue (MOv-14) from the $C$ terminus of Onchocerca volvulus tropomyosin led to $48-62 \%$ reduction in Onchocerca lienalis microfilaria after infection compared with the control group. Anti-MOv-14 antibodies levels increased in these mice and recognized Acanthocheilonema viteae product. In a follow up study, Jenkins et al., 1998 found high levels of anti-MOv-14 antibodies in mice vaccinated with MOv-14 and had serum-transferable protection. This study also used 
immunogold labeled anti-MOv-14 antibodies on different life stages of $O$. volvulus to identify the location of the antigen. Images were developed with TEM and showed tropomyosin throughout the different life stages' muscle, skin and cuticle. These results led the hypothesis that humoral exposure to TPM muscle isoform of dead and dying parasites may be leading to cross-reactions to cuticle TPM which further leads to protection from the parasite (Jenkins et al., 1998).

Currently, there is only one vaccine available to prevent $H$. contortus infectionBarbervax. However, this vaccine requires multiple boosters every season resulting in increased labor time and cost. Barbervax is only available for commercial use in Australia, New Zealand, and South Africa. Therefore, other countries including the United States of America still rely heavily on anthelmintics, resulting in anthelmintic resistance. Developing an efficacious vaccine against $H$. contortus requiring fewer boosters than Barbervax would reduce labor requirements, stress on the animals, and would further reduce the use of anthelmintics in the sheep industry.

When developing vaccines, understanding both innate and adaptive immune responses to the targeted pathogen is imperative. $H$. contortus-resistant sheep serve as models for developing an effective immune response. As we continue to investigate effective immune responses against $H$. contortus, vaccine candidates will continue to improve. 


\section{Literature Cited}

Ackerman, S. J., L. Liu, M. A. Kwatia, M. P. Savage, D. D. Leonidas, G. J. Swaminathan, and K. R. Acharya. 2002. Charcot-Leyden Crystal Protein (Galectin-10) Is Not a Dual Function Galectin with Lysophospholipase Activity but Binds a Lysophospholipase Inhibitor in a Novel Structural Fashion. J. Biol. Chem. 277:14859-14868. doi:10.1074/jbc.M200221200.

Adams, D. B. 1982. Time of onset and target of imune reactions in sheep with aquired immunity against Haemonchus contortus. Int J Parasitol. 12:439-443. doi:10.1016/00207519(82)90074-1.

Anderson, I. G. 1995. Observations on the life-cycles and larval morphogenesis of Haemonchus bedfordi, Impalaia tuberculoid and Longistrongylus sabie (Nematoda: Trichostrongyloidea) parasitic in impala, Aepyceros melampus. South Afr. J. Zool. 30:3745. doi:10.1080/02541858.1995.11448370.

Andronicos, N. M., J. McNally, A. C. Kotze, P. W. Hunt, and A. Ingham. 2012. Trichostrongylus colubriformis larvae induce necrosis and release of IL33 from intestinal epithelial cells in vitro: Implications for gastrointestinal nematode vaccine design. Int. J. Parasitol. 42:295-304. doi:10.1016/j.ijpara.2012.01.007.

Anthony, R. M., L. I. Rutitzky, J. F. Urban, M. J. Stadecker, and W. C. Gause. 2007. Protective immune mechanisms in helminth infection. Nat. Rev. Immunol. 7:975-987. doi:10.1038/nri2199.

Aucouturier, J., L. Dupuis, S. Deville, S. Ascarateil, and V. Ganne. 2002. Montanide ISA 720 and 51: a new generation of water in oil emulsions as adjuvants for human vaccines. Expert Rev. Vaccines. 1:111-118. doi:10.1586/14760584.1.1.111.

Ayuso, R., S. B. Lehrer, and G. Reese. 2002. Identification of continuous, allergenic regions of the major shrimp allergen Pen a 1 (tropomyosin). Int. Arch. Allergy Immunol. 127:27-37. doi:10.1159/000048166.

Baermann, G. 1917. A simple method for the detection of Ankylostomum (nematode) larvae in soil tests. Simple Method Detect. Ankylostomum Nematode Larvae Soil Tests. $41-47$.

Balic, A., V. M. Bowles, and E. N. T. Meeusen. 2002. Mechanisms of immunity to Haemonchus contortus infection in sheep. Parasite Immunol. 24:39-46. doi:10.1046/j.0141-9838.2001.00432.x. 
Bandukwala, H. S., B. S. Clay, J. Tong, P. D. Mody, J. L. Cannon, R. A. Shilling, J. S. Verbeek, J. V. Weinstock, J. Solway, and A. I. Sperling. 2007. Signaling through FcyRIII is required for optimal $\mathrm{T}$ helper type (Th)2 responses and Th2-mediated airway inflammation. J. Exp. Med. 204:1875-1889. doi:10.1084/jem.20061134.

Bang, K. S., A. S. Familton, and A. R. Sykes. 1990. Effect of copper oxide wire particle treatment on establishment of major gastrointestinal nematodes in lambs. Res. Vet. Sci. 49:132-137. doi:10.1016/S0034-5288(18)31065-8.

Bao, S., S. J. McClure, D. L. Emery, and A. J. Husband. 1996. Interleukin-5 mRNA expressed by eosinophils and $\gamma / \delta \mathrm{T}$ cells in parasite-immune sheep. Eur. J. Immunol. 26:552-556. doi:10.1002/eji.1830260308.

Barger, I. A., K. Siale, D. J. D. Banks, and L. F. Le Jambre. 1994. Rotational grazing for control of gastrointestinal nematodes of goats in a wet tropical environment. Vet. Parasitol. 53:109-116. doi:10.1016/0304-4017(94)90023-X.

Behboudi, Morein, and Villacres-Eriksson. 1999. Quillaja Saponin Formulations that Stimulate Proinflammatory Cytokines Elicit a Potent Acquired Cell-Mediated Immunity. Scand. J. Immunol. 50:371-377. doi:10.1046/j.1365-3083.1999.00603.x.

Boisvenue, R. J., M. I. Stiff, L. V. Tonkinson, and G. N. Cox. 1991. Protective studies in sheep immunized with cuticular collagen proteins and peptides of Haemonchus contortus. Parasite Immunol. 13:227-240. doi:10.1111/j.1365-3024.1991.tb00278.x.

Bowdridge, S. A., A. M. Zajac, and D. R. Notter. 2015. St. Croix sheep produce a rapid and greater cellular immune response contributing to reduced establishment of Haemonchus contortus. Vet. Parasitol. 208:204-210. doi:10.1016/j.vetpar.2015.01.019.

Bowdridge, S., K. MacKinnon, J. C. McCann, A. M. Zajac, and D. R. Notter. 2013. Hairtype sheep generate an accelerated and longer-lived humoral immune response to Haemonchus contortus infection. Vet. Parasitol. 196:172-178. doi:10.1016/j.vetpar.2013.01.008.

Burke, J. M., J. K. Apple, W. J. Roberts, C. B. Boger, and E. B. Kegley. 2003. Effect of breed-type on performance and carcass traits of intensively managed hair sheep. Meat Sci. 63:309-315. doi:10.1016/S0309-1740(02)00087-6.

Burke, J. M., and J. E. Miller. 2006. Control of Haemonchus contortus in goats with a sustained-release multi-trace element/vitamin ruminal bolus containing copper. Vet. Parasitol. 141:132-137. doi:10.1016/j.vetpar.2006.04.014. 
Burke, J. M., J. E. Miller, and T. H. Terrill. 2009. Impact of rotational grazing on management of gastrointestinal nematodes in weaned lambs. Vet. Parasitol. 163:67-72. doi:10.1016/j.vetpar.2009.03.054.

Calabro, S., M. Tortoli, B. C. Baudner, A. Pacitto, M. Cortese, D. T. O'Hagan, E. De Gregorio, A. Seubert, and A. Wack. 2011a. Vaccine adjuvants alum and MF59 induce rapid recruitment of neutrophils and monocytes that participate in antigen transport to draining lymph nodes. Vaccine. 29:1812-1823. doi:10.1016/j.vaccine.2010.12.090.

Calabro, S., M. Tortoli, B. C. Baudner, A. Pacitto, M. Cortese, D. T. O'Hagan, E. De Gregorio, A. Seubert, and A. Wack. 2011b. Vaccine adjuvants alum and MF59 induce rapid recruitment of neutrophils and monocytes that participate in antigen transport to draining lymph nodes. Vaccine. 29:1812-1823. doi:10.1016/j.vaccine.2010.12.090.

Cao, J., and S. Liu. 1998. [Immunization of mice with native tropomyosins from Schistosoma japonicum and Oncomelania hupensis]. Zhongguo Ji Sheng Chong Xue Yu Ji Sheng Chong Bing Za Zhi. 16:401-405.

Cerutti, A. 2008. The regulation of IgA class switching. Nat. Rev. Immunol. 8:421-434. doi:10.1038/nri2322.

Chan, S. S. M., I. McConnell, and B. A. Blacklaws. 2002. Generation and characterization of ovine dendritic cells derived from peripheral blood monocytes. Immunology. 107:366372. doi:10.1046/j.1365-2567.2002.01515.x.

Chen, F., W. Wu, A. Millman, J. F. Craft, E. Chen, N. Patel, J. L. Boucher, J. F. Urban, C. C. Kim, and W. C. Gause. 2014. Neutrophils prime a long-lived effector macrophage phenotype that mediates accelerated helminth expulsion. Nat. Immunol. 15:938-946. doi:10.1038/ni.2984.

Cibulski, S. P., M. Rivera-Patron, G. Mourglia-Ettlin, C. Casaravilla, A. C. A. Yendo, A. G. Fett-Neto, J. A. Chabalgoity, M. Moreno, P. M. Roehe, and F. Silveira. 2018. Quillaja brasiliensis saponin-based nanoparticulate adjuvants are capable of triggering early immune responses. Sci. Rep. 8. doi:10.1038/s41598-018-31995-1. Available from: https://www.ncbi.nlm.nih.gov/pmc/articles/PMC6134118/

Clark, C. H., G. K. Kiesel, and C. H. Goby. 1962. Measurements of blood loss caused by Haemonchus contortus infection in sheep. Am. J. Vet. Res. 23:977-980.

Coffman, R. L., B. W. Seymour, S. Hudak, J. Jackson, and D. Rennick. 1989. Antibody to interleukin-5 inhibits helminth-induced eosinophilia in mice. Science. 245:308-310. doi:10.1126/science.2787531. 
Conder, G. A., S. S. Johnson, A. D. Hall, M. W. Fleming, M. D. Mills, and P. M. Guimond. 1992. Growth and Development of Haemonchus contortus in Jirds, Meriones unguiculatus. J. Parasitol. 78:492-497. doi:10.2307/3283650.

Courtney, C. H., C. F. Parker, K. E. McClure, and R. P. Herd. 1985. Resistance of exotic and domestic lambs to experimental infection with Haemonchus contortus. Int. J. Parasitol. 15:101-109. doi:10.1016/0020-7519(85)90107-9.

Crespo, J. F., C. Pascual, R. Helm, S. Sanchez-Pastor, I. Ojeda, L. Romualdo, M. MartinEsteban, and J. A. Ojeda. 1995. Cross-reactivity of IgE-binding components between boiled Atlantic shrimp and German cockroach. Allergy. 50:918-924. doi:10.1111/j.13989995.1995.tb02499.x.

Cummings, R. D., and F.-T. Liu. 2009. Galectins. In: A. Varki, R. D. Cummings, J. D. Esko, H. H. Freeze, P. Stanley, C. R. Bertozzi, G. W. Hart, and M. E. Etzler, editors. Essentials of Glycobiology. 2nd ed. Cold Spring Harbor Laboratory Press, Cold Spring Harbor (NY). Available from: http://www.ncbi.nlm.nih.gov/books/NBK1944/

Desel, C., K. Werninghaus, M. Ritter, K. Jozefowski, J. Wenzel, N. Russkamp, U. Schleicher, D. Christensen, S. Wirtz, C. Kirschning, E. M. Agger, C. P. da Costa, and R. Lang. 2013. The Mincle-Activating Adjuvant TDB Induces MyD88-Dependent Th1 and Th17 Responses through IL-1R Signaling. PLoS ONE. 8. doi:10.1371/journal.pone.0053531. Available from: https://www.ncbi.nlm.nih.gov/pmc/articles/PMC3538599/

Di Pasquale, A., S. Preiss, F. Tavares Da Silva, and N. Garçon. 2015. Vaccine Adjuvants: from 1920 to 2015 and Beyond. Vaccines. 3:320-343. doi:10.3390/vaccines3020320.

Drudge, J. H., J. Szanto, Z. N. Wyant, and G. Elam. 1964. Field studies on parasite control in sheep: comparison of thia-bendazole, ruelene, and phenothiazine. Am. J. Vet. Res. 25:1512-1518.

Ejlertsen, M., S. M. Githigia, R. O. Otieno, and S. M. Thamsborg. 2006. Accuracy of an anaemia scoring chart applied on goats in sub-humid Kenya and its potential for control of Haemonchus contortus infections. Vet. Parasitol. 141:291-301. doi:10.1016/j.vetpar.2006.05.020.

Emery, D. L., P. W. Hunt, and L. F. Le Jambre. 2016. Haemonchus contortus: the then and now, and where to from here? Int. J. Parasitol. 46:755-769. doi:10.1016/j.ijpara.2016.07.001.

Estrada-Reyes, Z. M., Y. Tsukahara, R. R. Amadeu, A. L. Goetsch, T. A. Gipson, T. Sahlu, R. Puchala, Z. Wang, S. P. Hart, and R. G. Mateescu. 2019. Signatures of 
selection for resistance to Haemonchus contortus in sheep and goats. BMC Genomics. 20:735. doi:10.1186/s12864-019-6150-y.

Evans, C. W., B. T. Lund, I. McConnell, and R. Bujdoso. 1994. Antigen recognition and activation of ovine gamma delta T cells. Immunology. 82:229-237.

Fawzi, E. M., M. E. González-Sánchez, M. J. Corral, J. M. Alunda, and M. Cuquerella. 2015. Vaccination of lambs with the recombinant protein rHc23 elicits significant protection against Haemonchus contortus challenge. Vet. Parasitol. 211:54-59. doi:10.1016/j.vetpar.2015.04.029.

Fetterer, R. H. 1989. The cuticular proteins from free-living and parasitic stages of Haemonchus contortus-I. Isolation and partial characterization. Comp. Biochem. Physiol. Part B Comp. Biochem. 94:383-388. doi:10.1016/0305-0491(89)90360-X.

Folkard, S. G., R. E. Jenkins, and A. E. Bianco. 1996. Vaccination generates serummediated protection against Onchocerca lienalis microfilariae in the mouse. Trop. Med. Int. Health. 1:359-362. doi:10.1046/j.1365-3156.1996.d01-48.x.

Gadahi, J. A., M. Ehsan, S. Wang, Z. Zhang, Y. Wang, R. Yan, X. Song, L. Xu, and X. Li. 2016a. Recombinant protein of Haemonchus contortus 14-3-3 isoform 2 (rHcftt-2) decreased the production of IL-4 and suppressed the proliferation of goat PBMCs in vitro. Exp. Parasitol. 171:57-66. doi:10.1016/j.exppara.2016.10.014.

Gadahi, J. A., B. Li, M. Ehsan, S. Wang, Z. Zhang, Y. Wang, M. W. Hasan, R. Yan, X. Song, L. Xu, and X. Li. 2016b. Recombinant Haemonchus contortus $24 \mathrm{kDa}$ excretory/secretory protein ( $\mathrm{rHcES}-24$ ) modulate the immune functions of goat PBMCs in vitro. Oncotarget. 7:83926-83937. doi:10.18632/oncotarget.13487.

Gamble, H. R., and A. M. Zajac. 1992. Resistance of St. Croix lambs to Haemonchuscontortus in experimentally and naturally acquired infections. Vet. Parasitol. 41:211-225. doi:10.1016/0304-4017(92)90081-J.

Garza, J., S. P. Greiner, and S. A. Bowdridge. 2017. Serum-mediated Haemonchus contortus larval aggregation differs by larval stage and is enhanced by complement -. Parasite Immunol. $39 . \quad$ Available from: https://onlinelibrary.wiley.com/doi/abs/10.1111/pim.12409

Garza, J. J., S. P. Greiner, and S. A. Bowdridge. 2018. Ovine vital neutrophil extracellular traps bind and impair Haemonchus contortus L3 in a breed-dependent manner. Parasite Immunol. 40:e12572. doi:10.1111/pim.12572. 
Georgi, J. R., and J. H. Whitlock. 1967. Erythrocyte loss and restitution in ovine haemonchosis. Estimation of erythrocyte loss in lambs following natural exposure. Cornell Vet. 57:43-53.

Gill, H. S., K. Altmann, M. L. Cross, and A. J. Husband. 2000. Induction of T helper 1and Thelper 2-type immune responses during Haemonchus contortus infection in sheep. Immunology. 99:458-463. doi:10.1046/j.1365-2567.2000.00974.x.

Gill, H. S., G. D. Gray, D. L. Watson, and A. J. Husband. 1993. Isotype-specific antibody responses to Haemonchus contortus in genetically resistant sheep. Parasite Immunol. 15:61-67. doi:10.1111/j.1365-3024.1993.tb00585.x.

Gill, H S, D. L. Watson, and M. R. Brandon. 1993. Monoclonal antibody to CD4+ T cells abrogates genetic resistance to Haemonchus contortus in sheep. Immunology. 78:4349.

González-Sánchez, M. E., M. Cuquerella, and J. M. Alunda. 2018. Vaccination of lambs against Haemonchus contortus with the recombinant $\mathrm{rHc} 23$. Effect of adjuvant and antigen dose. P. L. Ho, editor. PLOS ONE. 13:e0193118. doi:10.1371/journal.pone.0193118.

Green, P. E., B. A. Forsyth, K. J. Rowan, and G. Payne. 1981. The Isolation of a Field Strain of Haemonchus Contortus in Queensland Showing Multiple Anthelmintic Resistance. Aust. Vet. J. 57:79-84. doi:10.1111/j.1751-0813.1981.tb00451.x.

Guerra-Maupome, M., J. R. Slate, and J. L. McGill. 2019. Gamma Delta T Cell Function in Ruminants. Vet. Clin. North Am. Food Anim. Pract. 35:453-469. doi:10.1016/j.cvfa.2019.08.001.

Gunning, P. W., E. C. Hardeman, P. Lappalainen, and D. P. Mulvihill. 2015. Tropomyosin - master regulator of actin filament function in the cytoskeleton. J. Cell Sci. 128:29652974. doi:10.1242/jcs.172502.

Guo, Z., J. F. González, J. N. Hernandez, T. N. McNeilly, Y. Corripio-Miyar, D. Frew, T. Morrison, P. Yu, and R. W. Li. 2016. Possible mechanisms of host resistance to Haemonchus contortus infection in sheep breeds native to the Canary Islands. Sci. Rep. 6. doi:10.1038/srep26200. Available from: https://www.ncbi.nlm.nih.gov/pmc/articles/PMC4873755/

Haçarız, O., G. Sayers, M. McCullough, M. Garrett, J. O'Donovan, and G. Mulcahy. 2009. The effect of Quil A adjuvant on the course of experimental Fasciola hepatica infection in sheep. Vaccine. 27:45-50. doi:10.1016/j.vaccine.2008.10.035. 
Harrington, L. E., R. D. Hatton, P. R. Mangan, H. Turner, T. L. Murphy, K. M. Murphy, and C. T. Weaver. 2005. Interleukin 17-producing CD4 + effector T cells develop via a lineage distinct from the $T$ helper type 1 and 2 lineages. Nat. Immunol. 6:1123-1132. doi:10.1038/ni1254.

Harrison, R., and A. Bianco. 2000. DNA immunization with Onchocerca volvulus genes, Ov-tmy-1 and OvB20: serological and parasitological outcomes following intramuscular or GeneGun delivery in a mouse model of onchocerciasis. - Abstract - Europe PMC. Parasite Immunol. 22:249-257.

Hartmann, S., R. Adam, T. Marti, C. Kirsten, S. Seidinger, and R. Lucius. 1997. A 41-kDa antigen of the rodent filaria Acanthocheilonema viteae with homologies to tropomyosin induces host-protective immune responses. Parasitol. Res. 83:390-393. doi:10.1007/s004360050269.

Hartmann, S., M. J. Sereda, A. Sollwedel, B. Kalinna, and R. Lucius. 2006. A nematode allergen elicits protection against challenge infection under specific conditions. Vaccine. 24:3581-3590. doi:10.1016/j.vaccine.2006.01.064.

Heckendorn, F., D. A. Häring, V. Maurer, M. Senn, and H. Hertzberg. 2007. Individual administration of three tanniferous forage plants to lambs artificially infected with Haemonchus contortus and Cooperia curticei. Vet. Parasitol. 146:123-134. doi:10.1016/j.vetpar.2007.01.009.

Hernández, J. N., A. Hernández, M. J. Stear, M. Conde-Felipe, E. Rodríguez, D. Piedrafita, and J. F. González. 2016. Potential role for mucosal $\lg A$ in modulating Haemonchus contortus adult worm infection in sheep. Vet. Parasitol. 223:153-158. doi:10.1016/j.vetpar.2016.04.022.

Hernández, J. N., E. Meeusen, M. Stear, F. Rodríguez, D. Piedrafita, and J. F. González. 2017. Modulation of Haemonchus contortus infection by depletion of $y \delta+T$ cells in parasite resistant Canaria Hair Breed sheep. Vet. Parasitol. 237:57-62. doi:10.1016/j.vetpar.2017.02.021.

Holt, R. M., E. A. Shepherd, A. G. Ammer, and S. A. Bowdridge. 2015. Effects of peripheral blood mononuclear cells on Haemonchus contortus larval motility in vitro. Parasite Immunol. 37:553-556. doi:10.1111/pim.12219.

Holtmeier, W., and D. Kabelitz. 2005. gammadelta T cells link innate and adaptive immune responses. Chem. Immunol. Allergy. 86:151-183. doi:10.1159/000086659.

House, R. 2010. Fundamentals of clinical immunotoxicology. In: Methods in Molecular Biology: Immunotoxicity Testing. Humana Press, Totowa, NJ, USA. 
Humphreys, N. E., D. Xu, M. R. Hepworth, F. Y. Liew, and R. K. Grencis. 2008. IL-33, a Potent Inducer of Adaptive Immunity to Intestinal Nematodes. J. Immunol. 180:24432449. doi:10.4049/jimmunol.180.4.2443.

Hutchison, S., R. A. Benson, V. B. Gibson, A. H. Pollock, P. Garside, and J. M. Brewer. 2012. Antigen depot is not required for alum adjuvanticity. FASEB J. Off. Publ. Fed. Am. Soc. Exp. Biol. 26:1272-1279. doi:10.1096/fj.11-184556.

Ishikawa, E., T. Ishikawa, Y. S. Morita, K. Toyonaga, H. Yamada, O. Takeuchi, T. Kinoshita, S. Akira, Y. Yoshikai, and S. Yamasaki. 2009. Direct recognition of the mycobacterial glycolipid, trehalose dimycolate, by C-type lectin Mincle. J. Exp. Med. 206:2879-2888. doi:10.1084/jem.20091750.

Jacobs, J. R. 2013. Characterizing Peripheral Cellular and Humoral Immune Responses to Haemonchus contortus in Sheep. Grad. Theses Diss. Probl. Rep. doi:https://doi.org/10.33915/etd.489. Available from: https://researchrepository.wvu.edu/etd/489

Jacobs, J. R., K. N. Sommers, A. M. Zajac, D. R. Notter, and S. A. Bowdridge. 2016. Early IL-4 gene expression in abomasum is associated with resistance to Haemonchus contortus in hair and wool sheep breeds. Parasite Immunol. 38:333-339. doi:10.1111/pim.12321.

Janeway, C. A., P. Travers, M. Walport, and M. J. Shlomchik. 2001. The distribution and functions of immunoglobulin isotypes. Immunobiol. Immune Syst. Health Dis. 5th Ed. Available from: https://www.ncbi.nlm.nih.gov/books/NBK27162/

Jenkins, R. E., M. J. Taylor, N. J. Gilvary, and A. E. Bianco. 1998. Tropomyosin implicated in host protective responses to microfilariae in onchocerciasis. Proc. Natl. Acad. Sci. 95:7550-7555. doi:10.1073/pnas.95.13.7550.

Jones, G. L., L. Spencer, R. Lord, R. Mollard, D. Pye, and A. Saul. 1990. Peptide vaccines derived from a malarial surface antigen: effects of dose and adjuvants on immunogenicity. Immunol. Lett. 24:253-260. doi:10.1016/0165-2478(90)90008-E.

Kandil, O. M., K. A. Abdelrahman, H. A. Shalaby, S. H. M. Hendawy, N. M. T. A. El Ezz, S. A. Nassar, and J. E. Miller. 2017. Evaluation of crude larval protein and recombinant somatic protein 26/23 (rHcp26/23) immunization against Haemonchus contortus in sheep. Vet. World. 10:758-763. doi:10.14202/vetworld.2017.758-763.

Keller, A., A. I. Nesvizhskii, E. Kolker, and R. Aebersold. 2002. Empirical statistical model to estimate the accuracy of peptide identifications made by MS/MS and database search. Anal. Chem. 74:5383-5392. doi:10.1021/ac025747h. 
Kensil, C. R. 1996. Saponins as vaccine adjuvants. Crit. Rev. Ther. Drug Carrier Syst. 13:1-55.

Khorasani, A., O. Madadgar, H. Soleimanjahi, H. Keyvanfar, and H. Mahravani. 2016. Evaluation of the efficacy of a new oil-based adjuvant ISA 61 VG FMD vaccine as a potential vaccine for cattle. Iran. J. Vet. Res. 17:8-12.

Kool, M., T. Soullié, M. van Nimwegen, M. A. M. Willart, F. Muskens, S. Jung, H. C. Hoogsteden, H. Hammad, and B. N. Lambrecht. 2008. Alum adjuvant boosts adaptive immunity by inducing uric acid and activating inflammatory dendritic cells. J. Exp. Med. 205:869-882. doi:10.1084/jem.20071087.

Lacroux, C., T. H. C. Nguyen, O. Andreoletti, F. Prevot, C. Grisez, J.-P. Bergeaud, L. Gruner, J.-C. Brunel, D. Francois, P. Dorchies, and P. Jacquiet. 2006. Haemonchus contortus (Nematoda: Trichostrongylidae) infection in lambs elicits an unequivocal Th2 immune response. Vet. Res. 37:607-622. doi:10.1051/vetres:2006022.

Lange, K. C., D. D. Olcott, J. E. Miller, J. A. Mosjidis, T. H. Terrill, J. M. Burke, and M. T. Kearney. 2006. Effect of sericea lespedeza (Lespedeza cuneata) fed as hay, on natural and experimental Haemonchus contortus infections in lambs. Vet. Parasitol. 141:273278. doi:10.1016/j.vetpar.2006.06.001.

LeJambre, L. F., R. G. Windon, and W. D. Smith. 2008. Vaccination against Haemonchus contortus: performance of native parasite gut membrane glycoproteins in Merino lambs grazing contaminated pasture. Vet. Parasitol. 153:302-312. doi:10.1016/j.vetpar.2008.01.032.

Leung, S., X. Liu, L. Fang, X. Chen, T. Guo, and J. Zhang. 2010. The cytokine milieu in the interplay of pathogenic Th1/Th17 cells and regulatory T cells in autoimmune disease. Cell. Mol. Immunol. 7:182-189. doi:10.1038/cmi.2010.22.

Lightowlers, M. W., J. G. Waterkeyn, J. S. Rothel, C. G. Gauci, and G. B. Harrison. 1996. Host-protective fragments and antibody binding epitopes of the Taenia ovis 45W recombinant antigen. Parasite Immunol. 18:507-513. doi:10.1046/j.13653024.1996.d01-20.x.

Lopes, F., J. L. Reyes, A. Wang, G. Leung, and D. M. McKay. 2015. Enteric epithelial cells support growth of Hymenolepis diminuta in vitro and trigger $\mathrm{TH} 2$-promoting events in a species-specific manner. Int. J. Parasitol. 45:691-696. doi:10.1016/j.ijpara.2015.05.004.

MacKinnon, K. M., S. A. Bowdridge, I. Kanevsky-Mullarky, A. M. Zajac, and D. R. Notter. 2015. Gene expression profiles of hair and wool sheep reveal importance of Th2 immune 
mechanisms for increased resistance to Haemonchus contortus. J. Anim. Sci. 93:20742082. doi:10.2527/jas.2014-8652.

MacKinnon, K. M., J. L. Burton, A. M. Zajac, and D. R. Notter. 2009. Microarray analysis reveals difference in gene expression profiles of hair and wool sheep infected with Haemonchus contortus. Vet. Immunol. Immunopathol. 130:210-220. doi:10.1016/j.vetimm.2009.02.013.

Magalhães de Matos, A. F. I., C. O. R. Nobre, J. P. Monteiro, C. M. L. Bevilaqua, W. D. Smith, and M. Teixeira. 2017. Attempt to control Haemonchus contortus in dairy goats with Barbervax $\AA$, a vaccine derived from the nematode gut membrane glycoproteins. Small Rumin. Res. 151:1-4. doi:10.1016/j.smallrumres.2017.03.016.

Maizels, R. M., and H. J. McSorley. 2016. Regulation of the host immune system by helminth parasites. J. Allergy Clin. Immunol. 138:666-675. doi:10.1016/j.jaci.2016.07.007.

Malan, F., and J. A. Van Wyk. 1992. The packed cell volume and colour of the conjunctivae as aids for monitoring Haemonchus contortus infestations in sheep. Proc SA Vet Assoc Bie Nat Vet Cong. 139.

Manolaraki, F., S. Sotiraki, A. Stefanakis, V. Skampardonis, M. Volanis, and H. Hoste. 2010. Anthelmintic activity of some Mediterranean browse plants against parasitic nematodes. Parasitology. 137:685-696. doi:10.1017/S0031182009991399.

Marichal, T., K. Ohata, D. Bedoret, C. Mesnil, C. Sabatel, K. Kobiyama, P. Lekeux, C. Coban, S. Akira, K. J. Ishii, F. Bureau, and C. J. Desmet. 2011. DNA released from dying host cells mediates aluminum adjuvant activity. Nat. Med. 17:996-1002. doi:10.1038/nm.2403.

Marrack, P., A. S. McKee, and M. W. Munks. 2009. Towards an understanding of the adjuvant action of aluminium. Nat. Rev. Immunol. 9:287-293. doi:10.1038/nri2510.

Martínez-Ortíz-de-Montellano, C., C. Arroyo-López, I. Fourquaux, J. F. J. Torres-Acosta, C. A. Sandoval-Castro, and H. Hoste. 2013. Scanning electron microscopy of Haemonchus contortus exposed to tannin-rich plants under in vivo and in vitro conditions. Exp. Parasitol. 133:281-286. doi:10.1016/j.exppara.2012.11.024.

McHeyzer-Williams, L. J., and M. G. McHeyzer-Williams. 2005. Antigen-Specific Memory B Cell Development. Annu. Rev. Immunol. 23:487-513. doi:10.1146/annurev.immunol.23.021704.115732. 
Mederos, A. E., Z. Ramos, and G. E. Banchero. 2014. First report of monepantel Haemonchus contortus resistance on sheep farms in Uruguay. Parasit. Vectors. 7:598. doi:10.1186/s13071-014-0598-z.

Middleton, D., J. J. Garza, S. P. Greiner, and S. A. Bowdridge. 2020. Neutrophils rapidly produce Th2 cytokines in response to larval but not adult helminth antigen. Parasite Immunol. 42:e12679. doi:10.1111/pim.12679.

Morawetz, R. 1996. Interleukin (IL)-4-independent immunoglobulin class switch to immunoglobulin (Ig)E in the mouse. J. Exp. Med. 184:1651-1661.

Munks, M. W., A. S. McKee, M. K. Macleod, R. L. Powell, J. L. Degen, N. A. Reisdorph, J. W. Kappler, and P. Marrack. 2010. Aluminum adjuvants elicit fibrin-dependent extracellular traps in vivo. Blood. 116:5191-5199. doi:10.1182/blood-2010-03-275529.

Nabian, S., M. Taheri, R. M. N. Fard, and M. Aramoon. 2013. Identification of Tropomyosin and Its Immunological Properties from Larvae of Cattle Tick, Boophilus annulatus. Iran. J. Parasitol. 8:242-248.

Nesvizhskii, A. I., A. Keller, E. Kolker, and R. Aebersold. 2003. A statistical model for identifying proteins by tandem mass spectrometry. Anal. Chem. 75:4646-4658. doi:10.1021/ac0341261.

Newman, M. J., J. Y. Wu, B. H. Gardner, K. J. Munroe, D. Leombruno, J. Recchia, C. R. Kensil, and R. T. Coughlin. 1992. Saponin adjuvant induction of ovalbumin-specific CD8+ cytotoxic T lymphocyte responses. J. Immunol. Baltim. Md 1950. 148:2357-2362.

Nicholson, K. G., A. E. Colegate, A. Podda, I. Stephenson, J. Wood, E. Ypma, and M. C. Zambon. 2001. Safety and antigenicity of non-adjuvanted and MF59-adjuvanted influenza A/Duck/Singapore/97 (H5N3) vaccine: a randomised trial of two potential vaccines against H5N1 influenza. The Lancet. 357:1937-1943. doi:10.1016/S01406736(00)05066-2.

Nisbet, A. J., A. Mackellar, H. W. Wright, G. P. Brennan, K. Y. Chua, N. Cheong, J. E. Thomas, and J. F. Huntley. 2006. Molecular characterization, expression and localization of tropomyosin and paramyosin immunodominant allergens from sheep scab mites ( Psoroptes ovis ). Parasitology. 133:515-523. doi:10.1017/S0031182006000631.

Notter, D. R., L. Ngere, J. M. Burke, J. E. Miller, and J. L. M. Morgan. 2018. Genetic parameters for ewe reproductive performance and peri-parturient fecal egg counts and their genetic relationships with lamb body weights and fecal egg counts in Katahdin sheep. J. Anim. Sci. 96:1579-1589. doi:10.1093/jas/sky100. 
O'Donnell, I. J., J. K. Dineen, B. M. Wagland, S. Letho, J. A. Werkmeister, and C. W. Ward. 1989. A novel host-protective antigen from Trichostrongylus colubriformis. Int. J. Parasitol. 19:327-335. doi:10.1016/0020-7519(89)90144-6.

O'Hagan, D. T. 2007. MF59 is a safe and potent vaccine adjuvant that enhances protection against influenza virus infection. Expert Rev. Vaccines. 6:699-710. doi:10.1586/14760584.6.5.699.

O'Hagan, D. T., G. S. Ott, E. De Gregorio, and A. Seubert. 2012. The mechanism of action of MF59 - An innately attractive adjuvant formulation. Vaccine. 30:4341-4348. doi:10.1016/j.vaccine.2011.09.061.

O'Shea, J. J., and P. J. Murray. 2008. Cytokine Signaling Modules in Inflammatory Responses. Immunity. 28:477-487. doi:10.1016/j.immuni.2008.03.002.

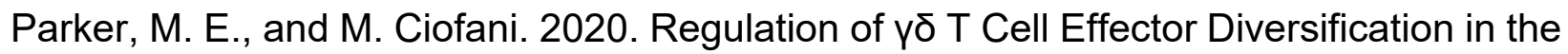
Thymus. Front. Immunol. 11. doi:10.3389/fimmu.2020.00042. Available from: https://www.frontiersin.org/articles/10.3389/fimmu.2020.00042/full

Pellegrini, M., U. Nicolay, K. Lindert, N. Groth, and G. Della Cioppa. 2009. MF59adjuvanted versus non-adjuvanted influenza vaccines: Integrated analysis from a large safety database. Vaccine. 27:6959-6965. doi:10.1016/j.vaccine.2009.08.101.

Piedrafita, D., S. Preston, J. Kemp, M. de Veer, J. Sherrard, T. Kraska, M. Elhay, and E. Meeusen. 2013. The effect of different adjuvants on immune parameters and protection following vaccination of sheep with a larval-specific antigen of the gastrointestinal nematode, Haemonchus contortus. PloS One. 8:e78357. doi:10.1371/journal.pone.0078357.

Plotkin, S. A., and W. A. Orenstein. 2008. Vaccines. Elsevier Health Sciences.

Preston, S. J. M., T. Beddoe, S. Walkden-Brown, E. Meeusen, and D. Piedrafita. 2015. Galectin-11: A novel host mediator targeting specific stages of the gastrointestinal nematode parasite, Haemonchus contortus. Int. J. Parasitol. 45:791-796. doi:10.1016/j.ijpara.2015.06.003.

Purcell, A. W., J. McCluskey, and J. Rossjohn. 2007. More than one reason to rethink the use of peptides in vaccine design. Nat. Rev. Drug Discov. 6:404-414. doi:10.1038/nrd2224.

Purkerson, J. M., and P. C. Isakson. 1992. Interleukin 5 (IL-5) provides a signal that is required in addition to IL-4 for isotype switching to immunoglobulin (Ig) G1 and IgE. J. Exp. Med. 175:973-982. doi:10.1084/jem.175.4.973. 
Rainbird, M. A., D. Macmillan, and E. N. T. Meeusen. 1998. Eosinophil-mediated killing of Haemonchus contortus larvar: effect of eosinophil activation and role of antobody, complement and interleukin-5. Parasite Immunol. 20:93-103. doi:10.1046/j.13653024.1998.00132.x.

Rao, P. V. S., D. Rajagopal, and K. A. Ganesh. 1998. B- and T-cell epitopes of tropomyosin, the major shrimp allergen. Allergy. 53:44-47. doi:10.1111/j.13989995.1998.tb04959.x.

Rappuoli, R., E. De Gregorio, and P. Costantino. 2019. On the mechanisms of conjugate vaccines. Proc. Natl. Acad. Sci. 116:14-16. doi:10.1073/pnas.1819612116.

Ravkov, E. V., I. Y. Pavlov, T. B. Martins, G. J. Gleich, L. A. Wagner, H. R. Hill, and J. C. Delgado. 2013. Identification and validation of shrimp-tropomyosin specific CD4 T cell epitopes. Hum. Immunol. 74. doi:10.1016/j.humimm.2013.08.276. Available from: https://www.ncbi.nlm.nih.gov/pmc/articles/PMC3870591/

Reese, G., R. Ayuso, and S. B. Lehrer. 1999. Tropomyosin: An Invertebrate PanAllergen. Int. Arch. Allergy Immunol. 119:247-258. doi:10.1159/000024201.

Renauld, J.-C. 2003. Class II cytokine receptors and their ligands: Key antiviral and inflammatory modulators. Nat. Rev. Immunol. 3:667-676. doi:10.1038/nri1153.

Robinson, N., J. Pleasance, D. Piedrafita, and E. N. Meeusen. 2011a. The kinetics of local cytokine and galectin expression after challenge infection with the gastrointestinal nematode, Haemonchus contortus. Int. J. Parasitol. 41:487-493. doi:10.1016/j.jpara.2010.11.006.

Robinson, N., J. Pleasance, D. Piedrafita, and E. N. Meeusen. 2011b. The kinetics of local cytokine and galectin expression after challenge infection with the gastrointestinal nematode, Haemonchus contortus. Int. J. Parasitol. 41:487-493. doi:10.1016/j.ijpara.2010.11.006.

Savage, G. P. 2003. SAPONINS. In: B. Caballero, editor. Encyclopedia of Food Sciences and Nutrition (Second Edition). Academic Press, Oxford. p. 5095-5098. Available from: http://www.sciencedirect.com/science/article/pii/B012227055X010506

Schroeder, H. W., and L. Cavacini. 2010. Structure and Function of Immunoglobulins. J. Allergy Clin. Immunol. 125:S41-S52. doi:10.1016/j.jaci.2009.09.046.

Sereda, M. J., S. Hartmann, D. W. Büttner, R. Volkmer, M. Hovestädt, N. Brattig, and R. Lucius. 2010. Characterization of the allergen filarial tropomyosin with an invertebrate 
specific monoclonal antibody. Acta Trop. 116:61-67. doi:10.1016/j.actatropica.2010.05.010.

Seubert, A., E. Monaci, M. Pizza, D. T. O'Hagan, and A. Wack. 2008. The Adjuvants Aluminum Hydroxide and MF59 Induce Monocyte and Granulocyte Chemoattractants and Enhance Monocyte Differentiation toward Dendritic Cells. J. Immunol. 180:54025412. doi:10.4049/jimmunol.180.8.5402.

Shakya, K. P., J. E. Miller, L. G. Lomax, and D. D. Burnett. 2011. Evaluation of immune response to artificial infections of Haemonchus contortus in Gulf Coast Native compared with Suffolk lambs. Vet. Parasitol. 181:239-247. doi:10.1016/j.vetpar.2011.03.051.

Sheep Production and Management: reproduction in sheep. Available from: https://aces.nmsu.edu/sheep/sheep_reproduction/breeding_habits.html

Shepherd, E. A. 2019. Characterization of Ovine Monocytes in Response to Haemonchus contortus Larvae in vitro and a Novel Role of Interleukin-13 Inducing Larval Paralysis [Ph.D.]. West Virginia University, United States -- West Virginia. Available from: https://search.proquest.com/pqdtglobal/docview/2401413094/abstract/F85EFDAB1A95 4F16PQ/1

Shepherd, E. A., J. J. Garza, S. P. Greiner, and S. A. Bowdridge. 2017. The effect of ovine peripheral blood mononuclear cells on Haemonchus contortus larval morbidity in vitro. Parasite Immunol. 39. doi:10.1111/pim.12424.

Shepherd, E., S. P. Greiner, B. Russ, and S. A. Bowdridge. 2020. Interleukin-13 induces paralysis of Haemonchus contortus larvae in vitro. Parasite Immunol. 42:e12758. doi:10.1111/pim.12758.

Shi, Y., H. HogenEsch, and S. L. Hem. 2001. Change in the degree of adsorption of proteins by aluminum-containing adjuvants following exposure to interstitial fluid: freshly prepared and aged model vaccines. Vaccine. 20:80-85. doi:10.1016/S0264410X(01)00313-9.

Silvestre, A., and J. F. Humbert. 2002. Diversity of benzimidazole-resistance alleles in populations of small ruminant parasites. Int. J. Parasitol. 32:921-928. doi:10.1016/S0020-7519(02)00032-2.

Stavnezer, J., and C. E. Schrader. 2014. Ig heavy chain class switch recombination: mechanism and regulation. J. Immunol. Baltim. Md 1950. 193:5370-5378. doi:10.4049/jimmunol.1401849. 
Steel, J. W. 2003. Effects of protein supplementation of young sheep on resistance development and resilience to parasitic nematodes. Aust. J. Exp. Agric. 43:1469-1476. doi:10.1071/ea03004.

Taylor, M. J., R. E. Jenkins, and A. E. Bianco. 1996. Protective immunity induced by vaccination with Onchocerca volvulus tropomyosin in rodents. Parasite Immunol. 18:219225. doi:10.1046/j.1365-3024.1996.d01-93.x.

Terefe, G., C. Lacroux, O. Andreoletti, C. Grisez, F. Prevot, J. P. Bergeaud, J. Penicaud, V. Rouillon, L. Gruner, J. C. Brunel, D. Francois, J. Bouix, P. Dorchies, and P. Jacquiet. 2007. Immune response to Haemonchus contortus infection in susceptible (INRA 401) and resistant (Barbados Black Belly) breeds of lambs. Parasite Immunol. 29:415-424. doi:10.1111/j.1365-3024.2007.00958.x.

Thomas, D. L. 1991. Hair Sheep Genetic Resources of the Americas. In: St. Croix, US Virgin Islands. p. 3-20.

Tritto, E., F. Mosca, and E. De Gregorio. 2009. Mechanism of action of licensed vaccine adjuvants. Vaccine. 27:3331-3334. doi:10.1016/j.vaccine.2009.01.084.

Urquhart, G. M., and E. Al. 1966. Immunity to Haemonchus contortus infection: relationship between age and successful vaccination with irradiated larvae. Am. J. Vet. Res. 27:1645-1648.

USDA-APHIS-VS-CEAH-NAHMS. 2014. Lambing Management Practices on U.S. Sheep Operations, 2011. APHIS USDA. Available from: https://www.aphis.usda.gov/animal_health/nahms/sheep/downloads/sheep11/Sheep11_ is_Lambing.pdf

Van den Brom, R., L. Moll, C. Kappert, and P. Vellema. 2015. Haemonchus contortus resistance to monepantel in sheep. Vet. Parasitol. 209:278-280. doi:10.1016/j.vetpar.2015.02.026.

Van Wyk, J. A. V., and G. F. Bath. 2002. The FAMACHA system for managing haemonchosis in sheep and goats by clinically identifying individual animals for treatment. Vet. Res. 33:509-529. doi:10.1051/vetres:2002036.

Vatta, A. F., P. J. Waller, J. B. Githiori, and G. F. Medley. 2012. Persistence of the efficacy of copper oxide wire particles against Haemonchus contortus in grazing South African goats. Vet. Parasitol. 190:159-166. doi:10.1016/j.vetpar.2012.06.018.

Vervelde, L., N. Bakker, F. N. J. Kooyman, A. W. C. A. Cornelissen, C. M. C. Bank, A. K. Nyame, R. D. Cummings, and I. van Die. 2003. Vaccination-induced protection of lambs 
against the parasitic nematode Haemonchus contortus correlates with high $\lg G$ antibody responses to the LDNF glycan antigen. Glycobiology. 13:795-804. doi:10.1093/glycob/cwg107.

Vervelde, L., F. N. J. Kooyman, M. A. W. V. Leeuwen, H. D. F. H. Schallig, A. Mackellar, J. F. Huntley, and A. W. C. A. Cornelissen. 2001. Age-related protective immunity after vaccination with Haemonchus contortus excretory/secretory proteins. Parasite Immunol. 23:419-426. doi:10.1046/j.1365-3024.2001.00391.x.

Wai, C. Y. Y., N. Y. H. Leung, M. H. K. Ho, L. J. Gershwin, S. A. Shu, P. S. C. Leung, and K. H. Chu. 2014. Immunization with Hypoallergens of Shrimp Allergen Tropomyosin Inhibits Shrimp Tropomyosin Specific IgE Reactivity. PLOS ONE. 9:e111649. doi:10.1371/journal.pone.0111649.

Wang, S., J. Delgado, E. Ravkov, D. Eckels, A. Georgelas, I. Pavlov, M. Cusick, S. K, G. GJ, and W. LA. 2012. Penaeus monodon tropomyosin induces CD4 T cell proliferation in shrimp allergic patients. Hum. Immunol. 73:426-431. doi:10.1016/j.humimm.2011.12.019.

Wang, S. W., Z. Q. Wang, and J. Cui. 2011. Protein change of intestinal epithelial cells induced in vitro by Trichinella spiralis infective larvae. Parasitol. Res. 108:593-599. doi:10.1007/s00436-010-2102-9.

Ward, M. 2017. NMSU: Sheep Breeds Best Suited for Arid Climates. N. M. Coll. Agric. Consum. Environ. Serv. Circular 684:1-8.

Weise, R. W. 1977. A Light and Electron Microscopic Study of the Dorsal Buccal Lancet of Haemonchus contortus. J. Parasitol. 63:854-857. doi:10.2307/3279892.

Werninghaus, K., A. Babiak, O. Groß, C. Hölscher, H. Dietrich, E. M. Agger, J. Mages, A. Mocsai, H. Schoenen, K. Finger, F. Nimmerjahn, G. D. Brown, C. Kirschning, A. Heit, P. Andersen, H. Wagner, J. Ruland, and R. Lang. 2009. Adjuvanticity of a synthetic cord factor analogue for subunit Mycobacterium tuberculosis vaccination requires FcRY-SykCard9-dependent innate immune activation. J. Exp. Med. 206:89-97. doi:10.1084/jem.20081445.

Wildeus, S. 1997. Hair sheep genetic resources and their contribution to diversified small ruminant production in the United States. J. Anim. Sci. 75:630-640. doi:10.2527/1997.753630x. 
Witteman, A. M., J. H. Akkerdaas, J. van Leeuwen, J. S. van der Zee, and R. C. Aalberse. 1994. Identification of a cross-reactive allergen (presumably tropomyosin) in shrimp, mite and insects. Int. Arch. Allergy Immunol. 105:56-61. doi:10.1159/000236803.

Wolstenholme, A. J., I. Fairweather, R. Prichard, G. von Samson-Himmelstjerna, and N. C. Sangster. 2004. Drug resistance in veterinary helminths. Trends Parasitol. 20:469476. doi:10.1016/j.pt.2004.07.010.

Wright, H. W., K. Bartley, J. F. Huntley, and A. J. Nisbet. 2016. Characterisation of tropomyosin and paramyosin as vaccine candidate molecules for the poultry red mite, Dermanyssus gallinae. Parasit. Vectors. 9:544. doi:10.1186/s13071-016-1831-8.

Young, A. R., G. J. Barcham, J. M. Kemp, J. L. Dunphy, A. Nash, and E. N. Meeusen. 2009. Functional characterization of an eosinophil-specific galectin, ovine galectin-14. Glycoconj. J. 26:423-432. doi:10.1007/s10719-008-9190-0.

Yui, S., K. Ubukata, K. Hodono, M. Kitahara, Y. Mimaki, M. Kuroda, Y. Sashida, and M. Yamazaki. 2001. Macrophage-oriented cytotoxic activity of novel triterpene saponins extracted from roots of Securidaca inappendiculata. Int. Immunopharmacol. 1:19892000. doi:10.1016/s1567-5769(01)00126-6. 


\section{Chapter 2: Differential recognition of Haemonchus contortus protein by serum from parasite-resistant and -susceptible sheep}

\section{$\underline{\text { Abstract }}$}

In this study, serum from parasite-susceptible and -resistant sheep was used to investigate differences in third stage larval (HcL3) antigen binding. Serum was blotted against Hc whole larvae homogenate (HcLA), L3 protective sheath (cuticle) and exsheathed L3 (XL3). These immunoblots revealed St. Croix IgG bound a $35 \mathrm{kDa}$ protein present in cuticle, HcLA, and XL3 antigens. Binding to this protein was not observed using Suffolk (SUF) serum. NanoLC-MS/MS identified this protein as H. contortus tropomyosincontaining domain. Analysis of HcLA, XL3 and cuticle-specific circulating IgG, determined by ELISA, revealed higher levels of antigen-specific IgG in Suffolk serum when compared to St. Croix (STC) serum. "Predicted" peptides within Hc-tropomyosin were selected using University of Nebraska online epitope predictor and from a study that used peptides to induce peripheral blood mononuclear cells (PBMC) proliferation in allergic patient cells. These peptides were synthesized for use in peptide-specific assays. Previously infected St. Croix had higher titres of peptide-specific $\lg G$ in circulation than Suffolk, but the differences were not significant. Epitope mapping was performed externally using overlapping tropomyosin peptides to determine which were bound best by St. Croix IgG. This experiment led to the selection of 4 "mapped" peptides $-1,2,3$, and 4 . These results suggest that St. Croix develop specific antibody to more Hc antigens, which may contribute to their resistance. These results further led to the selection of four peptides for use in a vaccine trial against $H c$. 


\section{Introduction}

Investigations into sheep breed responses to $\mathrm{Hc}$ have determined that St. Croix and other breeds are able to avoid early establishment through different immune mechanisms (Courtney et al., 1985; Gamble and Zajac, 1992; Burke et al., 2003). By day 7 after infection, there are differences in larval establishment of $\mathrm{Hc}$ in St. Croix when compared to composite wool crosses (Bowdridge et al., 2015). This indicates that there is an immune response occurring earlier than day 7 in the St. Croix to prevent establishment; this supports the idea that St. Croix are able to recognize cuticular components of $H C$ L3. Early responses in STC to Hc include il4 expression as early as 3 days while SUF do not respond even up to day 7 in abomasal mucosa (Jacobs et al., 2016).

Serum from primed sheep binds $\mathrm{Hc}$ life stages at varying levels. Garza et al. in 2017 measured antibody binding by counting the number of larvae swimming freely and dividing that be the number of larvae initially cultured in the well. The results showed a higher level of antibody binding to L3 when compared to XL3 or L4, suggesting an antigen recognized on the outer surface, or cuticle, of L3. Early antibody and complement binding to L3 may contribute to early larval expulsion (Garza et al., 2017).

While the exact protein makeup of the Hc cuticle has not been determined, researchers have determined there are both $2 \mathrm{ME}$-soluble and -insoluble fractions of protein. The $2 \mathrm{ME}$-soluble fraction was digested in collagenase, indicating collagen-like protein makeup. This study also determined a 1:0.8 ratio of hydroxyproline: proline, which may play a role in oxygen transportation from the blood across the cuticle (Fetterer, 1989). However, studies have yet to identify antigenic proteins in the cuticle, which may be 
playing a role in antibody binding and a role in immunity to $\mathrm{L} 3 \mathrm{H}$. contortus (Garza et al., 2017).

One major setback in discovering vaccine targets for gastrointestinal nematodes is their multi-stage life cycles within the host. While $\mathrm{Hc}$ has a simple life cycle, it goes through 3 different life stages inside the host, making identification of target antigens that will induce a protective response to difficult. In the 1989 study by Fetterer et al., characterization of proteins in the cuticle from second molt, L3, and adult, revealed that each life stage has different surface proteins. This result contributes to difficulty in identifying a potential vaccine target. To date, the most successful $H c$ vaccine candidates, proteins $\mathrm{H} 11$ and $\mathrm{H}$-gal-GP, have been found in the gut of adult $\mathrm{Hc}$ (LeJambre et al., 2008). Antibody binding "hidden" antigens requires a blood meal by fourth stage (L4) or adult $H$. contortus. Once inside the parasite the antibody in the blood can bind its target, disrupting blood metabolism. Rather than waiting for the larvae to molt and become hematophagous (L4) leading to damage in the abomasum, if an external L3 antigen is identified and targeted, the larvae would not develop any further, causing negative effects produced by L4 and adult life stage feeding. A vaccine target inducing high levels of antibody targeting the L3 cuticle may be optimal. Another advantage of identifying peptides associated with the cuticle is the ability to synthesize the peptides in vitro. Hidden gut antigens are extracted directly from adults, which means sheep have to be constantly infected and sacrificed for production of these antigens.

The aim of these experiments was to determine differences in specific Hc protein binding by antibody from Suffolk and St. Croix. After performing immunoblots with Suffolk and St. Croix serum binding different components of $H$. contortus antigens including 
whole third stage larval homogenate (HcLA), exsheathed L3 homogenate (XL3), and cuticle alone, tropomyosin was identified in all three samples as bound by St. Croix IgG but not by Suffolk IgG. These data indicate that St. Croix produce antibody specifically to proteins from $H$. contortus while Suffolk do not. Further, after minimal differences between St. Croix and Suffolk binding of "predicted" peptides, a more specific epitope mapping experiment using St. Croix antibody to bind overlapping tropomyosin peptides led to the selection of 4 peptides for use in a vaccine trial. These observations may help develop differences in St. Croix ability to clear $H$. contortus infection earlier than observed in Suffolk sheep. 


\section{Materials and methods}

\section{Animals and housing}

All sheep utilized in these studies were born at the West Virginia University Animal Husbandry Farm (Morgantown, WV, USA) and maintained on a raised and expanded metal floor in order to prevent unintended $\mathrm{Hc}$ infection. All animal protocols were approved by the West Virginia University Animal Care and Use Committee (ACUC-130308.1).

\section{Haemonchus contortus culture and collection}

Three SUF wethers were infected with $10,000 \mathrm{H}$. contortus $\mathrm{L} 3$ and served as the source for all larvae used in this study. Packed cell volumes (PCV) and fecal egg counts (FEC) were monitored weekly. Feces were collected and mixed with autoclaved peat moss and activated carbon, then incubated at $30^{\circ} \mathrm{C}$ for 7 days. Larvae were isolated using the Modified Baermann's apparatus (Baermann, 1917) then washed and stored in sterile PBS at $4^{\circ} \mathrm{C}$ until use.

\section{Ovine infection}

Five STC and SUF sheep were born and raised at the West Virginia University Animal Husbandry farm (Morgantown, WV, USA) and were kept on a raised, expanded metal floor to allow feces to fall through. These animals were infected orally with 10,000 third stage $H$. contortus larvae (L3) and infection was allowed to persist for 6 weeks. Infected animals were treated with levamisole (Agrilabs, St. Joseph, MO, USA) (8 mg/kg) and then were allowed to rest for 3 weeks. The animals were then given another dose of 10,000 L3 H. contortus, orally and the infection continued for another 6 weeks. The 
animals were then treated with another dose of levamisole in order to eliminate infection. Weekly FEC and PCV were collected to determine infection status. Animals were not infected when serum samples were collected for immunoblot and ELISA assays.

\section{Serum collection}

Blood was collected into 10-ml untreated vacutainer tubes (Tyco, Cork, Republic of Ireland) via jugular venipuncture and centrifuged at $750 \times g$ for 20 minutes at $4^{\circ} \mathrm{C}$. Serum was removed and pooled by treatment group. The serum was aliquoted and frozen at $-20^{\circ} \mathrm{C}$ until use.

\section{H. contortus L3 protein isolation (HcLA)}

Approximately 200,000 third stage $H$. contortus larvae were collected into a $15 \mathrm{ml}$ conical tube and centrifuged into a small pellet. Larvae in 2ml PBS (Corning, NY, USA) were transferred to a glass tube homogenizer on ice and were ground until homogenized. The sample was aliquoted into microcentrifuge tubes and centrifuged at $10,000 \times g$ for 20 minutes. Supernatant was collected and protein concentration were quantified using 660 nm protein assay (Pierce Biotechnology, Rockford, IL, USA).

\section{H. contortus $\mathrm{L} 3$ cuticle protein isolation}

This method is modified from (Boisvenue et al., 1991). Two hundred and twenty thousand total L3 were used to collect protein for cuticle protein per isolation. Twenty thousand L3 were pelleted and resuspended in 2 ml PBS were pipetted into each sealedtop T25 flask (11 flasks). Twenty-three $\mathrm{ml}$ of Earle's Balanced Salt Solution (GE Healthcare Bio-Sciences, Pittsburgh, PA, USA), and $250 \mu$ l Penicillin-streptomyosinneomyosin antibiotic (Sigma Aldrich, St. Louis, MO, USA) were added to reach total volume of $25 \mathrm{ml}$. Then, $\mathrm{CO}_{2}$ was "bubbled in" using flexible tubing for 30 seconds. The 
top was quickly sealed and the flasks were placed on a shaker overnight at $37^{\circ} \mathrm{C}$. Cuticles were collected by pouring flask content over a modified Baermann apparatus. The liquid containing the cuticles was collected from fluid above the filter, then re-filtered two more times. The cuticle solution was collected and centrifuged at $5000 \times g$ for 7 minutes. Volume was reduced to $4.5 \mathrm{~mL}$ of PBS and cuticle solution was further separated into 3 microcentrifuge tubes. Cuticles were pelleted by centrifugation and supernatant was taken off to $300 \mu \mathrm{l}$ of PBS, yielding approximately 50,000 cuticles per tube. $1.2 \mathrm{ml}$ of ST Buffer $(0.125 \mathrm{M}$ Tris- $\mathrm{HCl}, 1 \%$ SDS, $5 \% \beta$-mercaptoethanol) was added to each tube and heated at $98.4^{\circ} \mathrm{C}$ for 2 minutes. Contents were transferred to a BeadBug homogenizer tube filled with $0.5 \mathrm{~mm}$ triple pure zirconium beads (Benchmark Scientific, Edison, NJ, USA) and contents were homogenized 7 times for two minutes with 2 minutes of icing in between homogenizations (Benchmark Scientific, Edison, NJ, USA). Samples were centrifuged at $10,000 \times g$ for 20 minutes at $4^{\circ} \mathrm{C}$ and supernatants were collected and combined. Protein samples were then concentrated using TCA protein precipitation. The pellet was resuspended in ST Buffer and quantified using $660 \mathrm{~nm}$ Assay with Ionic Detergent Compatibility Reagent added (Pierce Biotechnology, Rockford, IL, USA).

\section{H. contortus exsheathed L3 (XL3) protein isolation}

One-hundred thousand L3 were suspended in $5 \mathrm{ml}$ of PBS in a T25 flask and mixed with bleach and deionized water for a $15 \%$ bleach solution. Larvae were mixed on a shaker for 5 minutes followed by 15 minutes in $37^{\circ} \mathrm{C}$ incubator. Exsheathed larvae were then washed twice in deionized water and suspended in $5 \mathrm{ml}$ of water. Larvae were then combined with $25 \mathrm{~mL}$ of Earle's Balanced Salt Solution (GE Healthcare Bio-Sciences, Pittsburgh, PA, USA) and $250 \mu \mathrm{l}$ of Pen/strep/neo (Sigma Aldrich, St. Louis, MO, USA) 
and incubated at $37^{\circ} \mathrm{C}$ with $5 \% \mathrm{CO}_{2}$ overnight. Exsheathed larvae were collected and washed two times in PBS and homogenized using BeadBug Homogenizer as mentioned in 2.5.2. Protein was quantified using $660 \mathrm{~nm}$ Protein assay (Pierce Biotechnology, Rockford, IL, USA).

\section{Immunoblots}

Laemmli Buffer 2X (Bio-Rad, Hercules, CA, USA) $+5 \% \beta$-mercaptoethanol was added at a 1:1 volumetric ratio to each sample $(2.32 \mu \mathrm{g}$ of each protein) and incubated at $95^{\circ} \mathrm{C}$ for 5 minutes. Each protein $(1.16 \mu \mathrm{g})$ at a volume of $15 \mu \mathrm{l}$ was added to respective well in a 4-15\% MiniProtean TGX 10 well gel (Bio-Rad, Hercules, CA, USA). $10 \mu$ of Dual Xtra Standards (Bio-Rad, Hercules, CA, USA) was used. SDS-PAGE was performed and proteins were transferred to PVDF membrane using iBlot 2 Dry Blotting System (ThermoFisher Scientific, Waltham, MA, USA). Following transfer, the membrane was blocked overnight at $4^{\circ} \mathrm{C}$ in Tris-Buffered Saline $+3.5 \%$ BSA. Primed STC and SUF serum were diluted $1: 50$ in TBS $+3.5 \%$ BSA $+1 \%$ Tween-20, added to its respective membrane, and incubated at room temperature for 1 hour on a shaker. The membranes were washed four times for 5 minutes in tris-buffered saline $+0.01 \%$ Tween-20. Secondary antibody, IRDye 680RD Donkey Anti-Goat IgG (Li-Cor, Lincoln, NE, USA) was diluted 1:15,000 in TBS $+3.5 \%$ BSA $+1 \%$ tween-20 and was added to respective membranes and incubated at room temperature for 1 hour. Membranes were washed four times with TBS-Tween-20 (0.1\%) followed by a single PBS wash for five minutes. All membranes were imaged with Li-Cor Odyssey Imager at their respective wavelengths (Li-Cor, Lincoln, NE, USA). 


\section{Antigen-Specific ELISAs}

Total ovine immunoglobulin ELISA was performed following protocol provided by the manufacturer (Sheep Total Immunoglobulin ELISA Kit, MyBioSource, San Diego, CA, USA). Cuticle, XL3, and HcLA antigens were diluted in 0.05M Carbonate/Bicarbonate buffer $\mathrm{pH} 9.4$ a concentrations of $5 \mu \mathrm{g} / \mathrm{ml}, 3 \mu \mathrm{g} / \mathrm{ml}$, and $4 \mu \mathrm{g} / \mathrm{ml}$, respectively, in $100 \mu \mathrm{l}$ per well of a 96 well 4 HBX plate (ThermoFisher Scientific, Waltham, MA, USA), and incubated overnight at $4^{\circ} \mathrm{C}$. Wells were washed five times with PBS-T and blocked PBS + BSA $(0.1 \%)$ for 1 hour at RT. STC or SUF serum was added and incubated at RT for one hour at 1:6400, 1:3200, or 1:1600 dilutions in PBS-B to wells coated with cuticle, XL3, and HcLA antigens, respectively. Wells were washed five times with PBS-T. Mouse antisheep IgG:HRP conjugated antibody (Sigma-Aldrich, St. Louis, MO, USA) was diluted in PBS-B at 1:6400, 1:800, or 1:3200 for cuticle, XL3, HcLA respectively and $100 \mu$ of each was incubated in its respective well for one hour at RT. Wells were washed ten times with PBS-T. TMB was added and reactions developed for 15 minutes followed by addition of 50uL of $2 \mathrm{M} \mathrm{H}_{2} \mathrm{SO}_{4}$. Absorbance was read at $450 \mathrm{~nm}$ using Epoch BioTek Plate Reader (BioTek, Winooski, VT, USA). Wells following the same protocol but with no serum were used as blank wells.

\section{Peptide-Specific ELISAs}

Nebraska peptide was synthesized based on an online antigenic prediction software based out of University of Nebraska (http://sysbio.unl.edu/SVMTriP/prediction.php). Peptides 54, 66, 80, and 81 were selected from a list of shrimp epitopes shown to induce proliferation of CD4 ${ }^{+} T$ cells in a study by Ravkov et al., (2013), and the amino acid sequences matched $H$. contortus 
amino acid sequences. "Predicted" peptides were synthesized by GenScript (Piscataway Township, NJ, USA) and peptide sequences are reported in Table 1. "Mapped" peptides selected from epitope mapping results were produced by BioMatik. These sequences can be found in Table 2.2. Peptides were diluted in 0.05M Carbonate/bicarbonate buffer $\mathrm{pH}$ 9.4 and plated at $5 \mu \mathrm{g} / \mathrm{ml}$ in a volume of $100 \mu \mathrm{l} /$ well in a 96 well $4 \mathrm{HBX}$ plate (ThermoFisher Scientific, Waltham, MA, USA). The plate was incubated overnight at $4^{\circ} \mathrm{C}$; the next day, the plates were set on the bench top to acclimate to room temperature followed by 5 washes with PBS-T. Wells were blocked with $200 \mu \mathrm{l}$ of $3 \%$ Powdered Skim Milk (Kroger, Cincinnati, OH, USA) in PBS-T for one hour at room temperature on a shaker. The wells were washed five times with PBS-T and coated with appropriate serum samples diluted 1:80 for predicted peptides and 1:50 for mapped peptides in 3\% Skim Milk PBS-T and serial diluted 1:1 down the plate, leaving the last row blank. The plate was incubated for two hours at RT on a shaker. After five more washes with PBS-T, wells were coated with $100 \mu \mathrm{l}$ mouse anti-sheep IgG:HRP conjugated antibody (Sigma-Aldrich, St. Louis, MO, USA ) diluted 1:2000 in 3\% Skim milk in PBS-T for one hour at room temperature RT on a shaker. Wells were washed ten times with PBS-T and developed with $100 \mu \mathrm{l}$ of TMB (ThermoFisher Scientific, Waltham, MA, USA) for 12 minutes and stopped with $100 \mu$ l of $2 \mathrm{M} \mathrm{H}_{2} \mathrm{SO}_{4}$. Absorbance was read at 450nm using Epoch BioTek Plate Reader (BioTek, Winooski, VT, USA).

\section{Tropomyosin Western Blot}

Laemmli Buffer 2X (Bio-Rad, Hercules, CA, USA) $+5 \% \beta$-mercaptoethanol was added at a 1:1 volumetric ratio to each sample $(2.32 \mu \mathrm{g}$ of each protein) and incubated at $95^{\circ} \mathrm{C}$ for 5 minutes. $1.16 \mu \mathrm{g}$ of each protein (at a volume of $15 \mu \mathrm{l}$ ) was added to its 
respective well in a 4-15\% MiniProtean TGX 10 well gel (Bio-Rad, Hercules, CA, USA). $10 \mu \mathrm{l}$ of Dual Xtra Standards (Bio-Rad, Hercules, CA, USA) was used. SDS-PAGE was performed and proteins were transferred to PVDF membrane using iBlot 2 Dry Blotting System (Thermo Fisher Scientific, Waltham, MA, USA). Following transfer, the membrane was blocked overnight at $4^{\circ} \mathrm{C}$ in Tris-Buffered Saline $+3 \%$ BSA (TBS-B). Primary antibody LS-C502037-50 Rabbit Polyclonal IgG anti-Charybdis feriata Tropomyosin (LSBio, Seattle, WA, USA) diluted 1:800 in TBS-B $+0.1 \%$ Tween20 and incubated at room temperature for one hour. The membrane was washed four times for five minutes in $3 \mathrm{ml}$ of TBS+ Tween20 (0.1\%). The Secondary antibody was added Ab6802 Donkey Anti-Rabbit IgG (HRP) (Abcam, Cambridge, United Kingdom) at a dilution of 1:1000 in TBS-B $+0.1 \%$ Tween20 and incubated at room temperature for one hour. The membrane was washed four times for five minutes in $4 \mathrm{ml}$ of TBS + Tween20 $(0.1 \%)$ followed by one final wash in PBS. 1-Step TMB-Blotting (Thermo Scientific, Waltham, MA, USA) was added to the membrane until the bands developed; the membrane was washed with water to stop the development.

\section{Mass Spectrometry}

Proteins were separated via 1D SDS-PAGE as mentioned previously and stained with Coomassie blue. The corresponding $35 \mathrm{kDa}$ band bound by IgG was excised and sent to the University of Nebraska, Lincoln for Mass Spectrometry analysis and identification. The gel band was washed 3 times with ammonium bicarbonate/acetonitrile to remove the stain and SDS, prior to shrinking of the clear gel pieces with $100 \%$ acetonitrile followed by air drying. Trypsin was then added and digestion was carried out overnight at $37^{\circ} \mathrm{C}$ overnight. The digests were then dried down and dissolved in $16 \mu \mathrm{L}$ of 
$2.5 \%$ acetonitrile and $0.1 \%$ formic acid. $5 \mu \mathrm{L}$ of the digest was processed by nanoLCMS/MS using a $1 \mathrm{~h}$ gradient on a $0.075 \mathrm{~mm} \times 250 \mathrm{~mm}$ C18 Waters $\mathrm{CSH}$ column feeding into a QExactive HF mass spectrometer. All MS/MS samples were analyzed using Mascot (Matrix Science, London, UK; version 2.5.1). Mascot was set up to search the CRAP_20150130 database and Uniprot (selected for Haemonchus contortus, 20170515, 21874 entries) assuming the digestion enzyme trypsin. Mascot was searched with a fragment ion mass tolerance of $0.060 \mathrm{Da}$ and a parent ion tolerance of 10.0 PPM. Deamidation of asparagine and glutamine, oxidation of methionine and carbamidomethyl of cysteine were specified in Mascot as variable modifications. Scaffold (version Scaffold_4.7.5, Proteome Software Inc., Portland, OR) was used to validate MS/MS based peptide and protein identifications. Peptide identifications were accepted if they could be established at greater than $80.0 \%$ probability by the Peptide Prophet algorithm (Keller, A et al Anal. Chem. 2002;74(20):5383-92) with Scaffold delta-mass correction. Protein identifications were accepted if they could be established at greater than $99.0 \%$ probability and contained at least 2 identified peptides. Protein probabilities were assigned by the Protein Prophet algorithm (Nesvizhskii, Al et al Anal. Chem. 2003;75(17):4646-58). Proteins that contained similar peptides and could not be differentiated based on MS/MS analysis alone were grouped to satisfy the principles of parsimony. Proteins sharing significant peptide evidence were grouped into clusters.

\section{PBMC isolation}

Whole blood was collected into 10-mL EDTA-treated vacutainer tubes (Tyco, Mansfield, MA, USA) via jugular venipuncture. Blood samples were centrifuged at 1,000 $x \mathrm{~g}$ for 20 minutes at room temperature (RT). Buffy coats containing white blood cells were transferred to sterile 15 
$\mathrm{mL}$ conical tubes and resuspended in $1 \mathrm{~mL}$ of sterile phosphate buffered saline (PBS). Red blood cells (RBC) were lysed with ACK lysis buffer (Lonza, Walkersville, MD). The remaining cell pellet in buffer was layered over sterile lymphocyte separation media (SPG $1.077 \mathrm{~g} / \mathrm{mL}$; Corning, Manassas, VA) and centrifuged at $400 \times \mathrm{g}$ for 20 minutes at RT. The middle layer containing PBMC was collected and washed two times in sterile PBS. PBMCs were collected and mixed 1:1 with trypan blue and counted using Bio-Rad TC-20 automated cell counter (Hercules, CA). The cells were then resuspended in complete media containing RPMI-1640 with 2mM L-gluatmine (GE Healthcare Life Sciences, Logan, UT), 10\% fetal bovine serum (FBS) (Corning, Corning, NY) and penicillin-streptomycin antibiotic (Sigma Aldrich, St. Louis MO, USA).

\section{Proliferation Assays}

PBMC from naïve and infected sheep were plated in complete media at 50,000 cells/well in 96 -well cell culture plates. Cells were incubated at $37^{\circ} \mathrm{C}$ with $5 \% \mathrm{CO}_{2}$ with peptides at $20 \mathrm{ug} / \mathrm{mL}$, ConA was added at $10 \mathrm{ug} / \mathrm{ml}$, LPS was added at $50 \mathrm{ug} / \mathrm{ml}$, and negative control cells were incubated without antigen in complete media. The plates were incubated $37^{\circ} \mathrm{C}$ with $5 \% \mathrm{CO}_{2}$ for 72 hours. CellTiter $96 \AA$ AQueous One Solution Cell Proliferation Assay (Promega, Madison, WI, USA) was added to each well for 1.5 hours before being read at 490nm using Epoch BioTek Plate Reader (BioTek, Winooski, VT, USA). Treated cell proliferation signals were corrected to the untreated control cells. Within naïve groups or infected groups, proliferation levels were compared between St. Croix and Suffolk. Within breed groups, infected groups were compared to naïve groups

\section{Epitope mapping for vaccine peptides}

LC Sciences produced the peptide chip and ran the epitope mapping service used in this experiment. The chip included 1158 unique 12 to 15 mer tiling peptides from the sequence of $H$. contortus tropomyosin with 3 to 4 redundancies. All peptide sequences were acetyl capped at $\mathrm{N}$ terminal. Multiple quality control probes were included on each chip. Blocking buffer (BB1) used 
was SuperBlock TBS (ThermoFisher, Waltham, MA, USA) with $0.05 \%$ Tween-20 and $0.05 \%$ Triton X-100, pH 7.0. Binding buffer (BB2) used was 1X PBS, pH 7.0. Washing buffer (WB) used was BB2 with $0.05 \%$ Tween-20 and $0.05 \%$ Triton X-100, pH 7.0. To block, BB1 was added to the chip and incubated at $4^{\circ} \mathrm{C}$ overnight. The chip was washed with $1 \mathrm{~mL}$ of TBS washing buffer. The chip was scanned at PMT700 in Cy5 channel. The chip was washed with $1 \mathrm{~mL}$ of BB2 at $25^{\circ} \mathrm{C}$ for 1 hour. 10X diluted St. Croix sheep serum was added to the chip in BB2 and incubated at $25^{\circ} \mathrm{C}$ for 2 hours. The chip was washed with BB2 at $25^{\circ} \mathrm{C}$ for 39 minutes followed by an incubation with $50 \mathrm{ng} / \mathrm{mL}$ donkey anti-sheep IgG Cy5 conjugate (Sigma Cat. \# AP184S) in BB2 at $25^{\circ} \mathrm{C}$ for 1 hour. The chip was washed with $0.5 \mathrm{~mL}$ WB at $25^{\circ} \mathrm{C}$ for 30 minutes and finally the chip was scanned for an image of binding at PMT 700 in Cy5 channel.

\section{Statistical Analysis}

Data in figures 2.1 and 2.2 were analyzed via one-way ANOVA performed with the Holm-Sidak Method for mean comparisons using SigmaPlot Software (Systat Software, San Jose, CA, USA). Peptide ELISA data were analyzed using one-way ANOVA using Geisser-Greenhouse correction in GraphPad Prism 8. Figure 2.7 data were analyzed via two-tailed unpaired t-test in GraphPad Prism 8. Proliferation assay data were analyzed using two-way ANOVA with Tukey multiple comparisons testing in GraphPad Prism 8 (GraphPad Software, CA, USA) . Significance was determined when $P \leq 0.05$. 


\section{$\underline{\text { Results }}$}

\section{IgG Immunoblot of $\boldsymbol{H}$. contortus L3 antigens and Total ovine immunoglobulin ELISA}

STC IgG bound many L3 proteins between the sizes of $35 \mathrm{kDa}$ and $250 \mathrm{kDa}$ (Fig. 2.1a). Of particular interest was the antigen with an apparent weight of $35 \mathrm{kDa}$ bound by STC IgG, but not by SUF IgG, in all three $H$. contortus homogenates including in the cuticle. Therefore, we decided to investigate the identity of this protein. In order to confirm that increased antigen binding by STC IgG was due to $\lg G$ specificity and not due to higher concentrations of antibody in STC serum used in the immunoblot, we performed a total ovine immunoglobulin ELISA on both STC and SUF serum (Fig. 2.1b). SUF serum contained a significantly higher concentration of total immunoglobulin in circulation when compared to STC serum, again confirming that the results of the immunoblot were not due to higher levels of immunoglobulin in STC serum $(19.417 \mathrm{mg} / \mathrm{ml} v \mathrm{vs} .15 .832 \mathrm{mg} / \mathrm{ml}$, respectively); $(P<0.05)$.

\section{Antigen-specific ELISAs}

Antigen-specific ELISA were performed using cuticle, HcLA, and XL3 antigens to determine IgG binding by STC and SUF antibody (Fig. 2.2). All three ELISAs resulted in higher levels of absorbance by SUF IgG when compared to STC IgG L3-specific IgG 1.249 vs 1.038 ( $P=0.002)$, XL3-specific IgG 1.893 vs.1.189 $(P<0.001)$, cuticle-specific lgG 0.204 vs. $0.114(P=0.001)$. These data combined with the immunoblot indicate that although SUF antibody bind whole homogenates at higher absorbances, the antibody may not be as specific as seen by STC antibody. 


\section{$35 \mathrm{kDa}$ antigen identification and confirmation}

H. contortus L3 protein was separated using 1D electrophoresis along a 4-15\% gradient TGX polyacrylamide gel and was stained with Coomassie blue. The band at 35 $\mathrm{kDa}$, matching the band bound by St. Croix serum, was extracted and sent to the University of Nebraska, Lincoln to be identified via mass spectrometry. The protein band was destained and digested using porcine trypsin and identified using LC-MS/MS. Mascot was used to analyze the results using CRAP_20150130 database and Uniprot databases (selected for Haemonchus contortus, 20170515, 21874 entries); (Fig. 2.3). The antigen identified by Mass Spec was $H$. contortus tropomyosin-domain containing protein U6PH16_HAECO. To confirm that tropomyosin was the identity of the $35 \mathrm{kDa}$ protein, a western blot was performed using HcLA and probed with anti-Charybdis feriata tropomyosin antibody. The results showed a band at both $35 \mathrm{kDa}$ and $40 \mathrm{kDa}$ (Fig 2.4).

\section{Predicted and mapped peptide-specific ELISAs}

The first set of peptides in Table 2.1 were selected based on epitope prediction software or from a publication that studied proliferation of PBMCs from patients allergic to shrimp tropomyosin. ELISAs were performed to detect antibody specific to these individual peptides with serum from naïve and primed STC and SUF. The serum samples in first row of the ELISA plate were diluted 1:50 and were serially diluted by half down the plate. Area under the curve analysis was performed to determine if there are antibody differences between primed or naïve St. Croix and Suffolk. Based on the results, there were no differences between groups- breed or infection status.

After the initial ELISAs showed no difference between groups to predicted peptides, new peptides were selected via epitope mapping. As mentioned in materials 
and methods, PSTC antibody was used in epitope mapping to screen for antigenic peptides of tropomyosin. These peptides were produced and screened with the same set of serums as "predicted" peptides. Figure 2.6 shows area under the curve analysis of the ELISA data. Again, there were no significant differences in antibody specific to peptides between breed or infection statuses. Average area under the curve was calculated for the PSTC group for both predicted and mapped peptides. There was no significant difference

\section{Proliferation assay of peptides}

In figure 2.8, PBMC were isolated from infected STC or SUF, or naïve STC or SUF. Infected animals had active infections and had been infected for 5 weeks. PBMC were incubated in triplicate with no antigen, $10 \mu \mathrm{g} / \mathrm{ml}$ ConA, $50 \mu \mathrm{g} / \mathrm{ml}$ LPS, or $20 \mu \mathrm{g} / \mathrm{ml}$ peptide at $37^{\circ} \mathrm{C}$ for 72 hours. These cells were then assessed to determine whether their cells were able to respond to the peptides without vaccination. Figure $2.8 \mathrm{a}$ shows the percent that stimulated PBMC proliferated more than PBMC with no antigen. PSTC cells proliferated significantly more than NSUF when cultures with all tested antigens and ConA except for when mixed with peptide 81. PSTC proliferated more than PSUF when incubated with ConA $(P<0.05)$, LPS $(P<0.01)$, and Nebraska peptide $(P<0.01)$. Lastly, PSTC proliferated more than the NSTC pool of cells only when incubated with Nebraska peptide $(P<0.0001)$ or peptide $80(P<0.05)$. Figure 2.8b used PBMC from the same pool of cells but were cultured with the mapped peptides. PSTC cells proliferated significantly more than NSUF $(P<0.01)$ when cultured with all tested antigens, LPS, and ConA except for when mixed with peptide $1(P=0.0512)$ and 4. PSTC proliferated more than PSUF and NSTC when incubated with LPS $(P<0.001, P<0.05$, respectively $)$, and 
peptide $2(P<0.001, P<0.05$, respectively) and $3(P<0.0001, P<0.01$, respectively). PBMC incubated with peptide 81,1 , and 4 did not significantly proliferate. 


\section{Discussion}

Results from this study provide evidence of St. Croix IgG, but not Suffolk IgG, recognition of a $35 \mathrm{kDa}$ protein found in $\mathrm{H}$. contortus larval homogenates. This protein was identified via nanoLC-MS/MS as $H$. contortus tropomyosin domain containing protein. After observing the differences in antibody binding, ELISAs were performed to confirm that the immunoblot results were not due to overall higher levels of circulating antibody in St. Croix serum. Interestingly, total immunoglobulin and antigen-specific IgG levels were significantly lower in St. Croix; serum used for these experiments was collected from animals that had two artificial infections but had been cleared of infection with Levamisole. Therefore, the antibody levels reflect that of circulating, resting levels.

Garza et al., (2017) performed an in vitro study in which St. Croix or Suffolk sheep serum was cultured with third (L3), exsheathed third (XL3), or fourth stage (L4) larvae. These experiments revealed L3 clumping around antibody and complement complexes, reducing larval ability to move independently. In theory, this mechanism would prevent larval escape of the "weep and sweep" mechanisms of IL-13 and IL-4, known to be produced in response to helminth infection. However, this clumping effect was not as prominent when tested with XL3 or L4's, indicating that there may be an antigen recognized on the surface of the L3 cuticle that was increasing this clumping. These data led to the investigation of antigens bound by sheep antibody using immunoblot techniques (sheep serum as primary antibody and anti-sheep $\lg G$ as the secondary antibody) and antigens from homogenized cuticle, larvae and exsheathed larvae. The $35 \mathrm{kDa}$ protein bound strongly by St. Croix IgG was identified as tropomyosin domain containing protein and was found in all three protein samples. Suffolk IgG bound different larval antigens 
from the homogenates, however none were as prominent as St. Croix IgG binding tropomyosin domain containing protein.

To confirm that the blot results were not due to higher levels of antibody in St. Croix serum, antigen-specific $\lg$ G and whole ovine immunoglobulin ELISAs were performed, with serum from both breeds taken while the sheep were cleared of infection. The data show that Suffolk had higher resting levels of circulating total immunoglobulins and antigen-specific lgG. Circulating IgG levels were higher in both naïve and infected Suffolkcrossed compared to St. Croix (Jacobs, 2013). Our western blot data indicate that although levels of circulating $\lg G$ were higher in Suffolk serum, St. Croix IgG was better able to bind proteins found in L3, XL3 and cuticle homogenates. Zajac et al. studied antigen-specific IgG levels in St. Croix compared to susceptible Dorset sheep. Contrary to our experiment, Zajac et al. found that St. Croix had higher levels of serum IgG specific to larval antigen, L3 exsheathing fluid, and $2^{\text {nd }}$ molt cuticle proteins (Gamble and Zajac, 1992). However, the differences in Zajac's study and this one included the age of the sheep when serum was collected as well as the breeds used in the experiment. Zajac's study used 9 week post-challenged 23 week- old lambs while our study used year old sheep that had been cleared of infection. Domestic breeds such as Suffolk sheep acquire protection to $\mathrm{H}$. contortus as they age and are exposed more often; this mechanism is not sufficient in younger lambs leading to higher incidences in death (Courtney et al., 1985).

Studies of the early cellular response to $H$. contortus have shown that by day 3 after a challenge infection, there are significantly higher numbers of neutrophils as well as expression of IL-13 and IL-4 in the abomasum in St. Croix when compared to susceptible wool breeds (Bowdridge et al., 2015; MacKinnon et al., 2015; Jacobs et al., 
2016). These studies illustrate the presence and implicate a need for a cellular response to clear infection early. The exact mechanism of cellular response and resistance is still being explored. Microarray analysis was used to find that 27 days after $H$. contortus infection, St. Croix sheep with Barbados blackbelly ancestry had greater expression of $F c$ $y$ receptor in abomasal lymph node tissue than the wool sheep used in this experiment; fecal egg counts in the St. Croix sheep were 2.5x lower than those found in the wool breed, although this difference was not statistically significant (MacKinnon et al., 2009). Although there are many isotypes of $F c \gamma R, F c y R I I I$ expression in mice has been found to augment Th2 responses depending on the antigen specificity of IgG1 (Bandukwala et al., 2007). Although we did not test the expression of sheep Fc $y$ receptor, based on these previous studies, the higher antigen specificity found in St. Croix serum tested in this experiment may could be associated with a higher expression of $F_{c} \gamma$ receptor and potentially contributing to an enhanced Th2 response needed to expel $H$. contortus to prevent establishment of L3's.

Currently, Barbervax is the only vaccine available against Haemonchus contortus, however it is only available in in Australia and Canada. This vaccine is made up of native antigens and saponin adjuvant to induce antibody production against hidden gut antigens $\mathrm{H}$-gal-GP and $\mathrm{H} 11$. Protection from infection requires five or six administrations during the highest risk season for infection; administration of this vaccine is also required in subsequent years but at lower doses (Reese et al., 1999) (http://www.wormboss.com.au/tests-tools/management-tools/the-barbervax-vaccineprogram.php). A vaccine comprised of the outer membrane protein of the infective stage may reduce number of treatments needed to maintain protection, as the animals would 
constantly encounter the antigen during grazing. Developing a vaccine using recombinant peptides would also reduce the use of infected animals for antigen collection.

The $H$. contortus protein bound highly by St. Croix IgG was identified as tropomyosin domain containing protein. Tropomyosin is a known antigen and the main allergen of other parasites and shellfish and is highly conserved among invertebrates. It has many different isoforms and is made up of two alpha helical subunits that twist around each other in a coiled-coil homodimer (Reese et al., 1999; Sereda et al., 2010) and plays a role in thin filament activation. In Figure 2.4, the two bands recognized by antitropomyosin antibody may be explained multiple isotypes of tropomyosin. One lab found an isoform of tropomyosin in Onchocerca volvulus infective and microfilarial life stage cuticles, supporting our findings of tropomyosin in L3 cuticle protein homogenate. Although the function of tropomyosin in the cuticle may be unknown, some have postulated that exposure to muscle tropomyosin from dead or dying microfilariae was leading to a humoral response that allowed for cross-reactivity with the cuticle tropomyosin(Jenkins et al., 1998). This may also be the case for $H$. contortus infections. In the current experiments, St. Croix IgG binding to tropomyosin in all three L3 homogenate samples warrants further studies regarding the location of tropomyosin on the cuticle as well as its presence in larval muscle.

Tropomyosin has been identified as a vaccine candidate for multiple helminth species such Trichostrongylus colubriformis, Onchocerca volvulus, Onchocerca lienalis, Acanthocheilonema viteae, and Schistosoma japonicum with varying levels of reductions in worm burden ((O’Donnell et al., 1989; Folkard et al., 1996; Taylor et al., 1996; Cao and Liu, 1998; Harrison and Bianco, 2000; Hartmann et al., 2006) Tropomyosin has also been 
identified as vaccine candidates for the poultry red mite, Dermanyssus gallinae with mortality of the mite at $19 \%$ (Wright et al., 2016) and larval stages of the cattle tick, Boophilus annulatus (Nabian et al., 2013). The $\mathrm{C}$ terminus of tropomyosin is also known to be well-conserved and therefore may act with cross-reactivity and protection against other invertebrate parasites. These studies indicate that invertebrate tropomyosin has been well-documented as vaccine candidates and should be investigated further to determine its efficacy in protecting against $H$. contortus infection in susceptible sheep.

The next set of experiments were focused on determining antigenic epitopes from tropomyosin. Initially, the first goal was to produce $H$. contortus tropomyosin in vitro through cloning. However, the initial PCR performed to amplify the gene for insertion into a vector was unfruitful. After one successful round of amplification of the correct size gene, it was inserted in a PGEM-T Easy vector and further amplified. However, when sequenced, the resulting gene was identified as $18 \mathrm{~S}$ ribosomal RNA of Pelodera cylindrica (a free-living nematode). These results led to investigations into tropomyosin epitopes that had been used in previous experiments.

The first peptide (Nebraska) selected for synthesis was predicted using online epitope prediction software from the University of Nebraska. The other 4 peptides (54, 66,80 , and 81 ) tested were selected from a list of shrimp tropomyosin peptides that experimentally caused proliferation of PBMC from patients with shrimp allergies (Wang et al., 2012; Ravkov et al., 2013). From this list, the sequences were blasted against $H$. contortus tropomyosin-domain containing protein and 4 were selected based on sequence homology. Peptide-specific ELISAs were performed. The primary antibody was serially diluted serum and the secondary antibody was anti-sheep IgG. The data showed 
that St. Croix had slightly higher resting levels of peptide-specific IgG when compared to Suffolk IgG for peptides Neb, 66, 80, and 81. Although not significant, STC had slightly higher titres of IgG specific to peptides Neb, 66, and 80. These results support the immunoblot results showing higher STC peptide-specific IgG than SUF.

The second group of "mapped" peptides were selected after the first set showed low IgG specificity. Epitope mapping technology is used to identify specific peptides from a protein that are bound by serum of a selected group. In this case, primed St. Croix serum was used in the epitope mapping experiment. 12-15 overlapping amino acid sequences of tropomyosin were printed on a glass slide. Next St. Croix serum coated the plate with the peptides followed by secondary fluorescently labeled antibody for detection. Results were sorted based on signal emitted by the fluorescent label. Four peptides were synthesized based on these results- peptides 1, 2, 3, and 4. ELISAs were performed with the same serum samples using the new peptides. Again, there was no significant difference between any of the groups. While IgG is the most abundant antibody produced, $\lg \mathrm{A}$ and $\lg \mathrm{E}$ are both associated with helminth infections and resistance and therefore antigen-specific $\lg A$ and $\lg E$ experiments may lead to more putative vaccine candidates as well.

Proliferation assays are used to narrowly measure the cellular immune response to a pathogen. In this experiment, the proliferation assay was performed to determine if cells from sheep that had been infected with $H$. contortus were able to respond to antigens if cultured directly. PBMCs are made up of lymphocytes, dendritic cells and monocytes. If a cellular response has been developed in vivo to a pathogen then these isolated cells should be able to respond and proliferate in response in vitro. Infected and naïve St. Croix 
and Suffolk PBMCs were isolated and cultured with each peptide at $20 \mu \mathrm{g} / \mathrm{ml}$. Cell cultures were incubated for 72 hours and proliferation was measured. PSTC cells proliferated significantly more than PSUF when cultured with peptides Nebraska, 80, 2, and 3. PSTC cells proliferated more than NSUF in response to Nebraska, 54, 66, 81, 2, and 3. Levels of proliferation were also greater in PSTC compared to NSTC after culture with Nebraska, and 3. In the first experiments of this chapter, serum from the "primed" animals was collected after the animals had received a primary and secondary infection. However, infected animals used in this experiment were actively infected, which may have affected the results. Their immune systems may not have been developed and therefore sensitivity to antigens and thus a propensity to proliferate may have been affected.

These results illustrate that infected St. Croix have better cellular recognition and response than naïve St. Croix or any infection status of Suffolk to tropomyosin peptides tested. Without a cytokine profile from the supernatant of the cells, these results can only show that there was a cellular response leading to proliferation. Some studies have shown that there is no difference in PBMC proliferation between St. Croix and other susceptible breeds (Gamble and Zajac, 1992) supporting our results, while other resistant breeds (Canaria Hair Breed) have been shown to have accelerated cell proliferation after infection (Guo et al., 2016).

What started as an immunoblot to determine differences in breed-specific protein binding led to the selection of 4 peptides for testing in a vaccine trial against $H$. contortus. These peptides have been conjugated to KLH to enhance their immunogenicity and will be mixed with adjuvant for vaccination. Overall, this research has revealed a distinct breed difference in antibody specificity to different components of $H$. controtus L3. 


\section{Literature Cited}

Baermann, G. 1917. A simple method for the detection of Ankylostomum (nematode) larvae in soil tests. Simple Method Detect. Ankylostomum Nematode Larvae Soil Tests. $41-47$.

Bandukwala, H. S., B. S. Clay, J. Tong, P. D. Mody, J. L. Cannon, R. A. Shilling, J. S. Verbeek, J. V. Weinstock, J. Solway, and A. I. Sperling. 2007. Signaling through FcyRIII is required for optimal $\mathrm{T}$ helper type (Th)2 responses and Th2-mediated airway inflammation. J. Exp. Med. 204:1875-1889. doi:10.1084/jem.20061134.

Boisvenue, R. J., M. I. Stiff, L. V. Tonkinson, and G. N. Cox. 1991. Protective studies in sheep immunized with cuticular collagen proteins and peptides of Haemonchus contortus. Parasite Immunol. 13:227-240. doi:10.1111/j.1365-3024.1991.tb00278.x.

Bowdridge, S. A., A. M. Zajac, and D. R. Notter. 2015. St. Croix sheep produce a rapid and greater cellular immune response contributing to reduced establishment of Haemonchus contortus. Vet. Parasitol. 208:204-210. doi:10.1016/j.vetpar.2015.01.019.

Burke, J. M., J. K. Apple, W. J. Roberts, C. B. Boger, and E. B. Kegley. 2003. Effect of breed-type on performance and carcass traits of intensively managed hair sheep. Meat Sci. 63:309-315. doi:10.1016/S0309-1740(02)00087-6.

Cao, J., and S. Liu. 1998. [Immunization of mice with native tropomyosins from Schistosoma japonicum and Oncomelania hupensis]. Zhongguo Ji Sheng Chong Xue Yu Ji Sheng Chong Bing Za Zhi. 16:401-405.

Courtney, C. H., C. F. Parker, K. E. McClure, and R. P. Herd. 1985. Resistance of exotic and domestic lambs to experimental infection with Haemonchus contortus. Int. J. Parasitol. 15:101-109. doi:10.1016/0020-7519(85)90107-9.

Fetterer, R. H. 1989. The cuticular proteins from free-living and parasitic stages of Haemonchus contortus-I. Isolation and partial characterization. Comp. Biochem. Physiol. Part B Comp. Biochem. 94:383-388. doi:10.1016/0305-0491(89)90360-X. 
Folkard, S. G., R. E. Jenkins, and A. E. Bianco. 1996. Vaccination generates serummediated protection against Onchocerca lienalis microfilariae in the mouse. Trop. Med. Int. Health. 1:359-362. doi:10.1046/j.1365-3156.1996.d01-48.x.

Gamble, H. R., and A. M. Zajac. 1992. Resistance of St. Croix lambs to Haemonchuscontortus in experimentally and naturally acquired infections. Vet. Parasitol. 41:211-225. doi:10.1016/0304-4017(92)90081-J.

Garza, J., S. P. Greiner, and S. A. Bowdridge. 2017. Serum-mediated Haemonchus contortus larval aggregation differs by larval stage and is enhanced by complement -. $\begin{array}{llll}\text { Parasite } & \text { Immunol. } & \text { Available } & \text { from: }\end{array}$ https://onlinelibrary.wiley.com/doi/abs/10.1111/pim.12409

Gill, H. S., K. Altmann, M. L. Cross, and A. J. Husband. 2000. Induction of T helper 1and Thelper 2-type immune responses during Haemonchus contortus infection in sheep. Immunology. 99:458-463. doi:10.1046/j.1365-2567.2000.00974.x.

Guo, Z., J. F. González, J. N. Hernandez, T. N. McNeilly, Y. Corripio-Miyar, D. Frew, T. Morrison, P. Yu, and R. W. Li. 2016. Possible mechanisms of host resistance to Haemonchus contortus infection in sheep breeds native to the Canary Islands. Sci. Rep. 6. doi:10.1038/srep26200. Available from: https://www.ncbi.nlm.nih.gov/pmc/articles/PMC4873755/

Harrison, R., and A. Bianco. 2000. DNA immunization with Onchocerca volvulus genes, Ov-tmy-1 and OvB20: serological and parasitological outcomes following intramuscular or GeneGun delivery in a mouse model of onchocerciasis. - Abstract - Europe PMC. Parasite Immunol. 22:249-257.

Hartmann, S., M. J. Sereda, A. Sollwedel, B. Kalinna, and R. Lucius. 2006. A nematode allergen elicits protection against challenge infection under specific conditions. Vaccine. 24:3581-3590. doi:10.1016/j.vaccine.2006.01.064.

Jacobs, J. R. 2013. Characterizing Peripheral Cellular and Humoral Immune Responses to Haemonchus contortus in Sheep. Grad. Theses Diss. Probl. Rep. 
doi:https://doi.org/10.33915/etd.489.

Available

from:

https://researchrepository.wvu.edu/etd/489

Jacobs, J. R., K. N. Sommers, A. M. Zajac, D. R. Notter, and S. A. Bowdridge. 2016. Early IL-4 gene expression in abomasum is associated with resistance to Haemonchus contortus in hair and wool sheep breeds. Parasite Immunol. 38:333-339. doi:10.1111/pim.12321.

Jenkins, R. E., M. J. Taylor, N. J. Gilvary, and A. E. Bianco. 1998. Tropomyosin implicated in host protective responses to microfilariae in onchocerciasis. Proc. Natl. Acad. Sci. 95:7550-7555. doi:10.1073/pnas.95.13.7550.

LeJambre, L. F., R. G. Windon, and W. D. Smith. 2008. Vaccination against Haemonchus contortus: performance of native parasite gut membrane glycoproteins in Merino lambs grazing contaminated pasture. Vet. Parasitol. 153:302-312. doi:10.1016/j.vetpar.2008.01.032.

MacKinnon, K. M., S. A. Bowdridge, I. Kanevsky-Mullarky, A. M. Zajac, and D. R. Notter. 2015. Gene expression profiles of hair and wool sheep reveal importance of Th2 immune mechanisms for increased resistance to Haemonchus contortus. J. Anim. Sci. 93:20742082. doi:10.2527/jas.2014-8652.

MacKinnon, K. M., J. L. Burton, A. M. Zajac, and D. R. Notter. 2009. Microarray analysis reveals difference in gene expression profiles of hair and wool sheep infected with Haemonchus contortus. Vet. Immunol. Immunopathol. 130:210-220. doi:10.1016/j.vetimm.2009.02.013.

Nabian, S., M. Taheri, R. M. N. Fard, and M. Aramoon. 2013. Identification of Tropomyosin and Its Immunological Properties from Larvae of Cattle Tick, Boophilus annulatus. Iran. J. Parasitol. 8:242-248.

O'Donnell, I. J., J. K. Dineen, B. M. Wagland, S. Letho, J. A. Werkmeister, and C. W. Ward. 1989. A novel host-protective antigen from Trichostrongylus colubriformis. Int. J. Parasitol. 19:327-335. doi:10.1016/0020-7519(89)90144-6. 
Ravkov, E. V., I. Y. Pavlov, T. B. Martins, G. J. Gleich, L. A. Wagner, H. R. Hill, and J. C. Delgado. 2013. Identification and validation of shrimp-tropomyosin specific CD4 T cell epitopes. Hum. Immunol. 74. doi:10.1016/j.humimm.2013.08.276. Available from: https://www.ncbi.nlm.nih.gov/pmc/articles/PMC3870591/

Reese, G., R. Ayuso, and S. B. Lehrer. 1999. Tropomyosin: An Invertebrate PanAllergen. Int. Arch. Allergy Immunol. 119:247-258. doi:10.1159/000024201.

S, W., D. JC, R. E, E. DD, G. A, P. IY, C. M, S. K, G. GJ, and W. LA. 2012. Penaeus monodon tropomyosin induces CD4 T cell proliferation in shrimp allergic patients. Hum. Immunol. 73:426-431. doi:10.1016/j.humimm.2011.12.019.

Sereda, M. J., S. Hartmann, D. W. Büttner, R. Volkmer, M. Hovestädt, N. Brattig, and R. Lucius. 2010. Characterization of the allergen filarial tropomyosin with an invertebrate specific monoclonal antibody. Acta Trop. 116:61-67. doi:10.1016/j.actatropica.2010.05.010.

Taylor, M. J., R. E. Jenkins, and A. E. Bianco. 1996. Protective immunity induced by vaccination with Onchocerca volvulus tropomyosin in rodents. Parasite Immunol. 18:219225. doi:10.1046/j.1365-3024.1996.d01-93.x.

Wright, H. W., K. Bartley, J. F. Huntley, and A. J. Nisbet. 2016. Characterisation of tropomyosin and paramyosin as vaccine candidate molecules for the poultry red mite, Dermanyssus gallinae. Parasit. Vectors. 9:544. doi:10.1186/s13071-016-1831-8.

http://www.wormboss.com.au/tests-tools/management-tools/the-barbervax-vaccineprogram.php, last accessed 03/14/18 


\section{$\underline{\text { Tables and Figures }}$}

a.
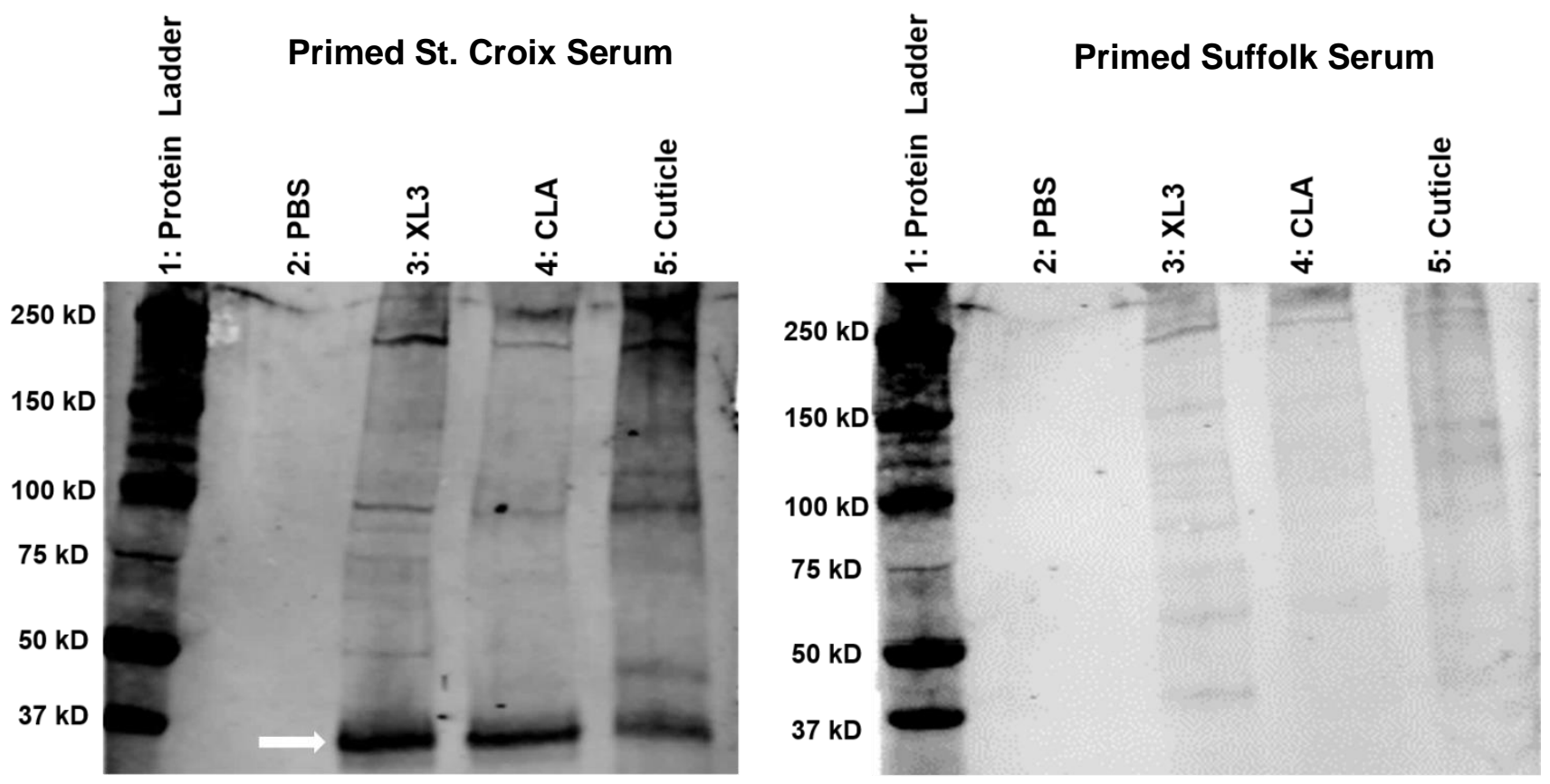

b.

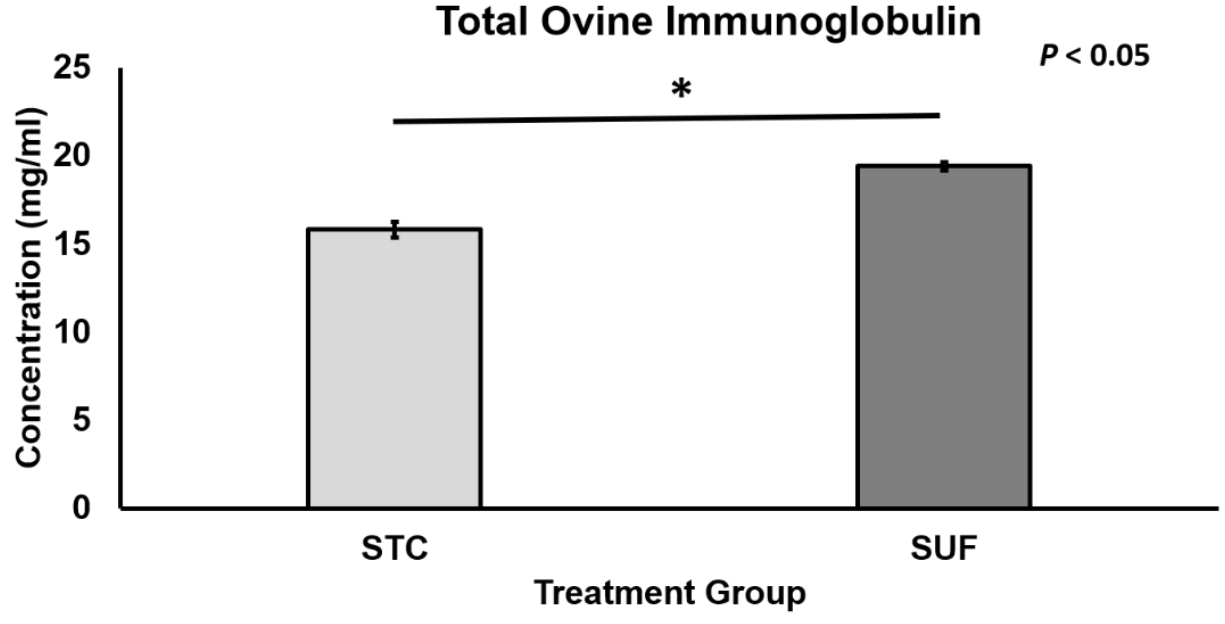

Figure 2.1. Immunoblot of $\boldsymbol{H}$. contortus proteins with St. Croix or Suffolk serum and total circulating total immunoglobin

(a) SDS-PAGE using 4-15\% MiniProtean TGX gels were used to separate the proteins; lane 1: Dual Xtra Protein ladder lane 2: PBS- negative control; lanes 3, 4, 5 contained1.16 $\mu \mathrm{g}$ of XL3, HcLA, Cuticle protein separated respectively. Primed STC and primed SUF serum were used as the primary antibodies and anti-sheep $\lg G$ was used as the secondary antibody. Immunoblots of $\mathrm{Hc}$ antigens recognized by STC IgG and SUF IgG. Arrow indicating $35 \mathrm{kDa}$ band recognized by STC $\operatorname{lgG}$ but not SUF IgG. (b) Total circulating immunoglobulin levels in serum from STC and SUF at resting levels after challenge infection were measured using total ovine immunoglobulin ELISA kit (MyBioSource). ( $\left.{ }^{\star} P<0.05\right)$. 


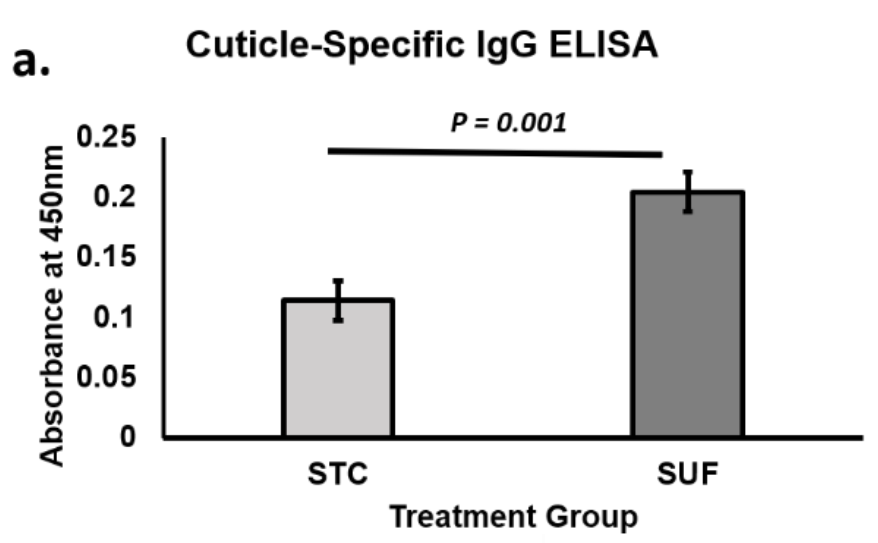

b.

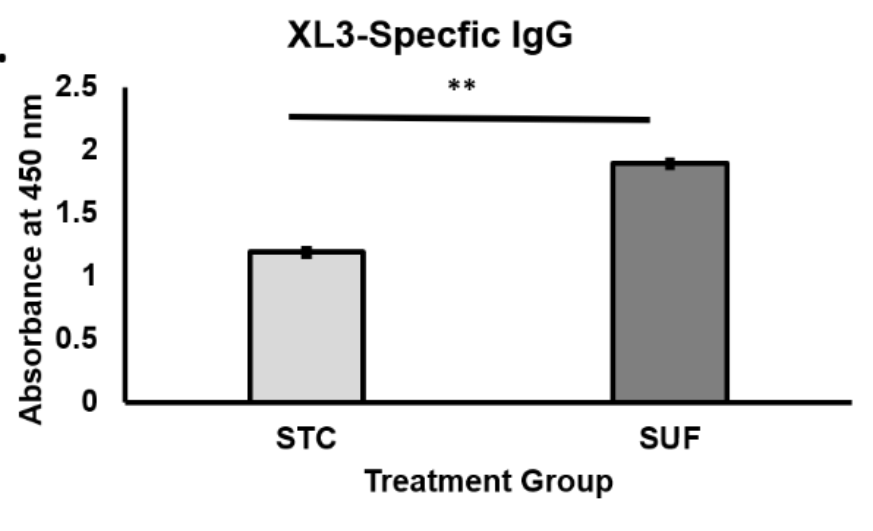

c.

HcLA-Specific IgG

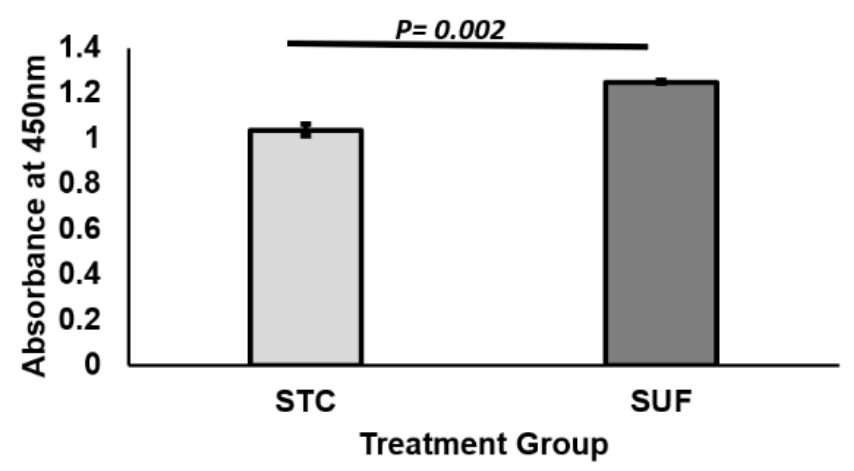

Figure 2.2. Circulating levels of HcLA, XL3 -specific IgG

SUF had significantly higher levels of circulating HcLA -specific IgG ( $P=0.001)$ $\mathrm{XL3}(P<0.01)$, and cuticle-specific $\operatorname{lgG}(P=0.002)$ when compared to STC resting levels of antigen-specific lgG. Antibody levels were measured at $450 \mathrm{~nm}$. $\left({ }^{\star *} P<0.01\right)$ 
a.

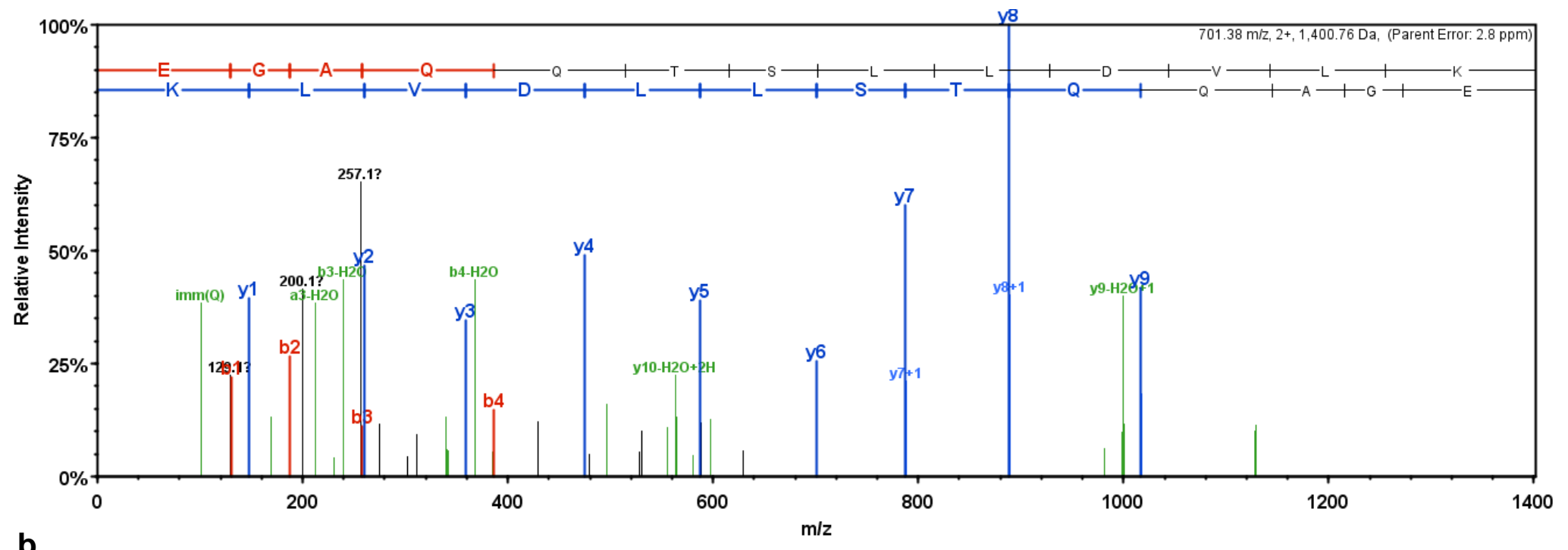

b.

U6PH16_HAECO (100\%), 35,034.0 Da

Tropomyosin domain containing protein OS=Haemonchus contortus $\mathrm{GN}=\mathrm{HCOI} 01534500 \mathrm{PE}=3 \mathrm{SV}=1$

18 exclusive unique peptides, 27 exclusive unique spectra, 33 total spectra, 162/302 amino acids (54\% coverage)

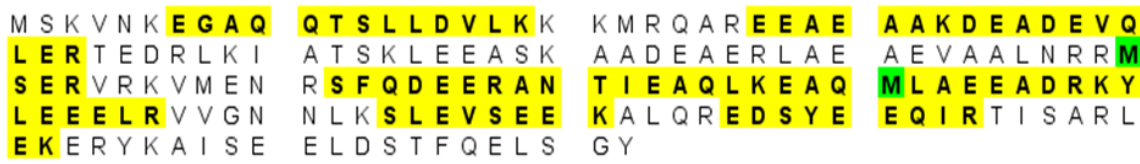

Q T S L L D V L K K A A DEAERLAE RSF Q DEERAN

N LKS LEVSEE ELDSTFQELS

A A V D A ADEVR

M

KALQREDSYE EQIRTISARL G Y

Figure 2.3. Mass spectrometry analysis of $35 \mathrm{kDa}$ protein bound by St. Croix antibody.

$35 \mathrm{kDa}$ protein identified as $H$. contortus tropomyosin domain containing protein. SDSPAGE was performed to separate HcLA. The $35 \mathrm{kDa}$ band was excised and sent to the University of Nebraska, Lincoln for mass spec analysis. After trypsin digestion of the 35 $\mathrm{kDa}$ band, nanoLC-MS/MS was performed to identify the peptide. (a) Mass spectra peptide peaks and (b) peptide coverage compared to known $H$. contortus tropomyosin domain containing protein analysis of peptides detected during nanoLC-MS/MS. 


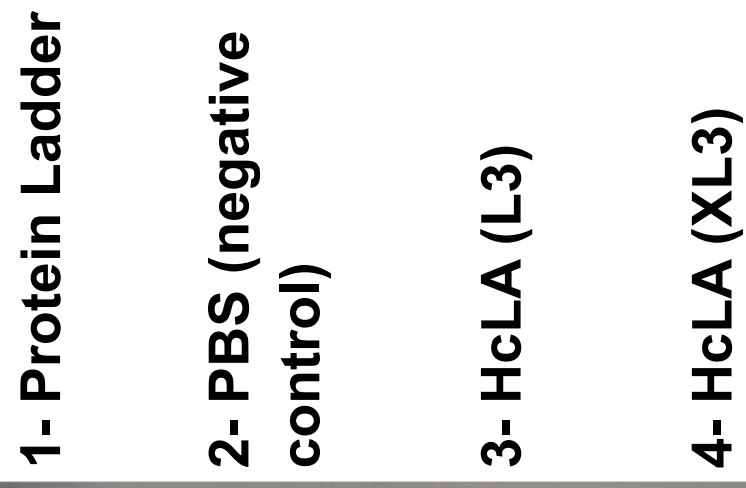

\section{0 kD}

$150 \mathrm{kD}$

$100 \mathrm{kD}$

$75 \mathrm{kD}$

$50 \mathrm{kD}$

37 kD

25 kD

Figure 2.4. Western blot confirming tropomyosin presence in $\mathrm{H}$. contortus larval antigen at the same size as the immunoblot.

Western blot was used to confirm tropomyosin in HcLA sample. SDS-PAGE was performed to separate protein samples. The protein was transferred to a PVDF membrane and blotted with rabbit anti-Charybdis feriata tropomyosin. The secondary antibody used anti-rabbit IgG-peroxidase labeled. The membrane was developed with one-step TMB (Thermo Scientific). 
Table 2.1. Predicted antigenic tropomyosin peptides based off of epitope predictor and previous tropomyosin research

\begin{tabular}{ccc}
\hline $\begin{array}{c}\text { Peptide } \\
\text { Name }\end{array}$ & Amino Acid Sequence & Reference \\
\hline $\begin{array}{c}\text { Nebraska } \\
\text { Peptide (Neb) }\end{array}$ & AERSVQKLQKEVDRLEDELV & $\begin{array}{c}\text { University of Nebraska } \\
\text { http://sysbio.unl.edu/SVMTriP/prediction.php }\end{array}$ \\
\hline 54 & RYKDEVARKLAMVEA & Ravkov et al. (2013) \\
\hline 66 & ELRVVGNNLKSLEVS & Ravkov et al. (2013) \\
80 & RAEFAERSVQKLQKE & Ravkov et al. (2013) \\
\hline 81 & FEARSVQKLQKEVDR & Ravkov et al. (2013) \\
\hline
\end{tabular}




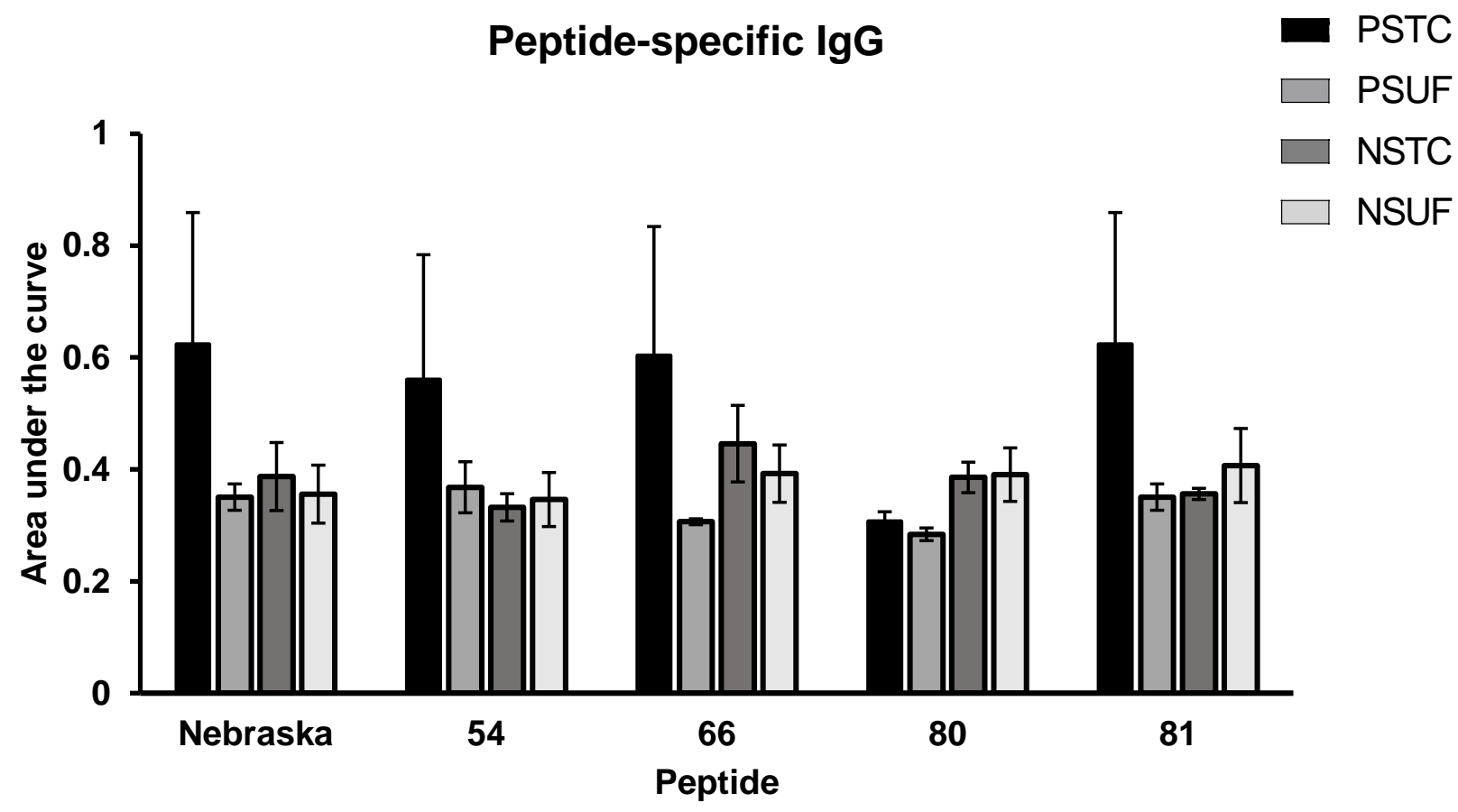

Figure 2.5. Comparisons of breed differences and infection status of predicted tropomyosin peptide-specific IgG

Area under the curve analysis was performed on antibody titres starting at a 1:80 dilution and serially diluted down the plate $1: 1$ to determine differences based on breed and infection status. (Nebraska: $P=0.3889,54: P=0.1674,66: P=0.4110,80: P=$ 0.0527, 81: $P=0.3878)$. 
Table 2.2. Mapped antigenic tropomyosin peptides bound by St. Croix antibody in epitope mapping experiment

\begin{tabular}{cc}
\hline $\begin{array}{c}\text { Peptide } \\
\text { Name }\end{array}$ & Amino Acid Sequence \\
\hline 1 & LERAEERAEAGENKIVELC \\
\hline 2 & VDESERVRKVMENRSFQDC \\
\hline 3 & ADEVQRQLEEERKKREDAEC \\
\hline 4 & EADRKYDEVARKLAMVC \\
\hline
\end{tabular}




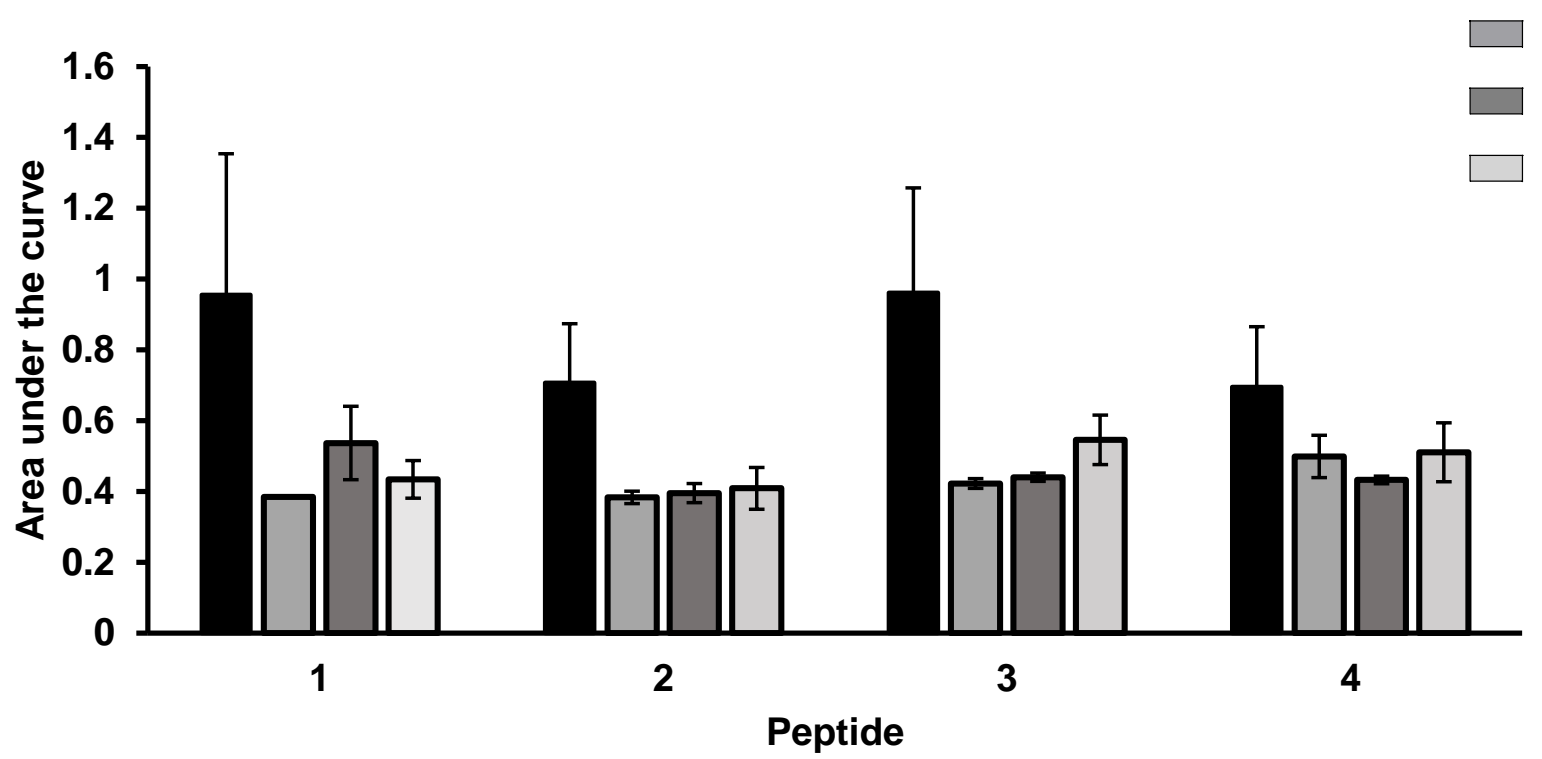

Figure 2.6 Comparisons of breed differences and infection status of mapped tropomyosin peptide-specific Ig $G$

Area under the curve analysis was performed on antibody titres starting at 1:50 serialdiluted 1:1 starting at a to determine differences based on breed and infection status. (Peptide 1: $P=0.2501$, Peptide 2: $P=0.0732$, Peptide 3: $P=0.0900$, Peptide 4: $P=$ 0.3250).

\section{Average AUC of PSTC Group}

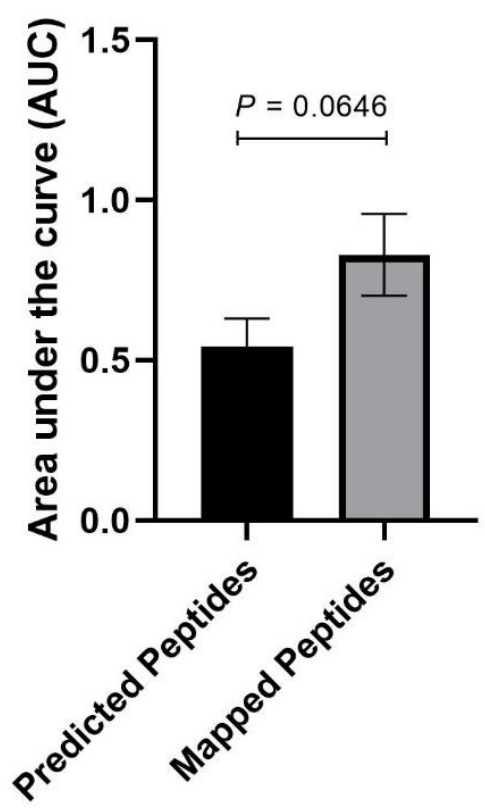

- Predicted Peptides

口 Mapped Peptides

Figure 2.7 Primed St. Croix IgG area under the curve of predicted vs mapped peptides

Average area under the curve was determined for the STC IgG of grouped predicted vs mapped peptides to help select which group to use in vaccine $(P=0.0646)$. 
a.

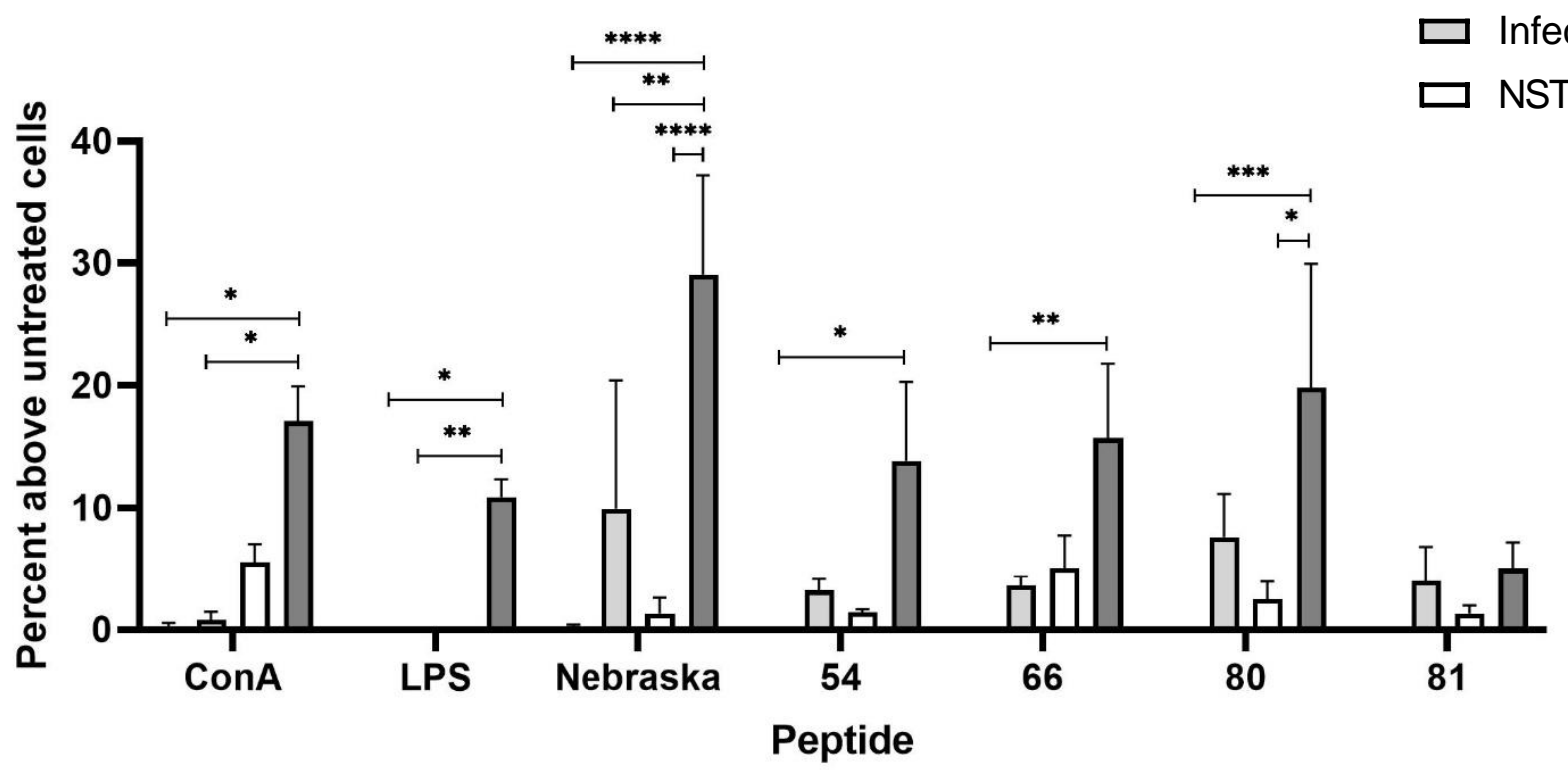

\section{PBMC Proliferation}

b.

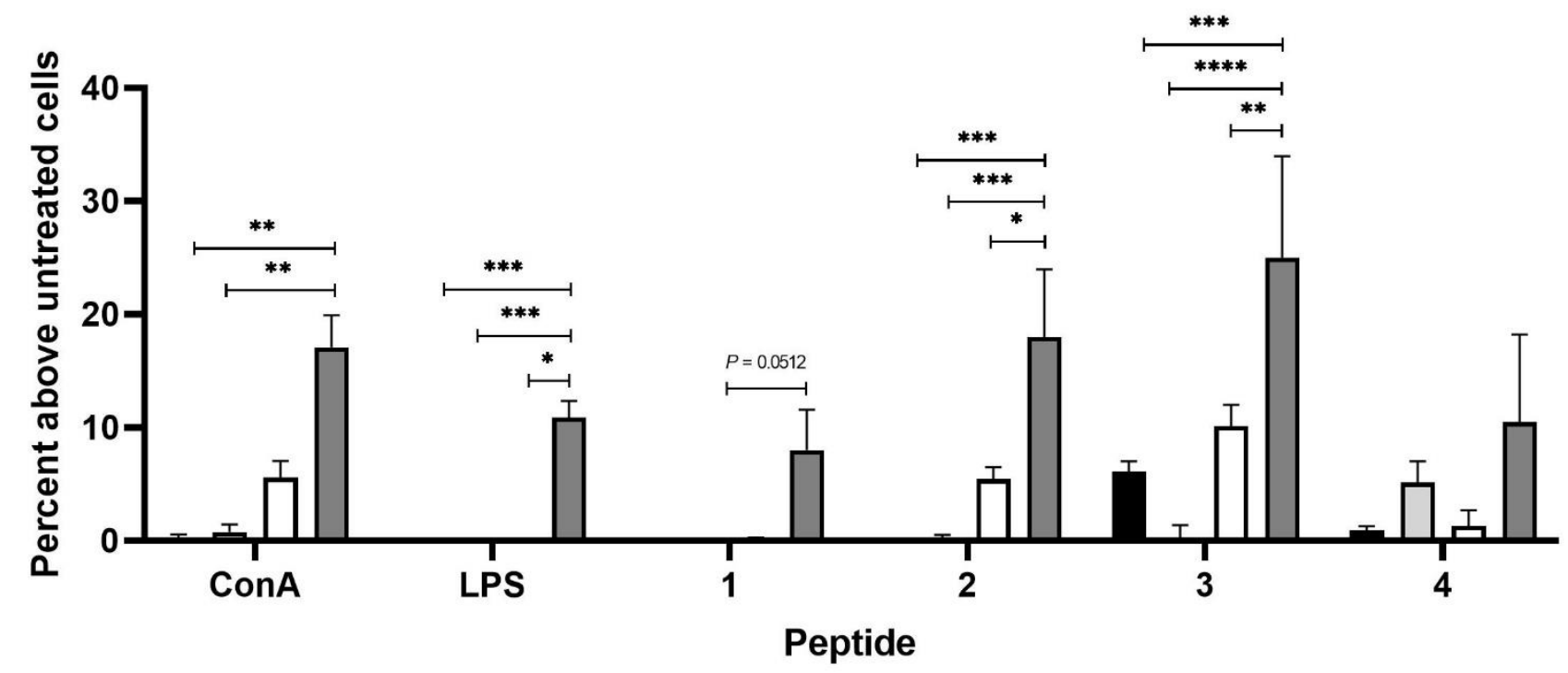

Figure 2.8. Proliferation of PBMC after 72-hour incubation with $20 \mu \mathrm{g} / \mathrm{ml}$ ConA, $5 \mu \mathrm{g} / \mathrm{ml} \mathrm{LPS}$, and $20 \mu \mathrm{g} / \mathrm{ml}$ peptides reported as percent above untreated cell proliferation.

PBMC were isolated from infected or naïve STC and SUF and were cultured with T cell mitogen ConA $(10 \mu \mathrm{g} / \mathrm{ml})$, B cell mitogen LPS $(50 \mu \mathrm{g} / \mathrm{ml})$, and each of the potential vaccine peptides $(20 \mu \mathrm{g} / \mathrm{ml})$. Proliferation results were corrected to antigen-free PBMC wells before statistical analysis. ${ }^{*}: P<0.05,{ }^{* *}: P<0.01,{ }^{* * *}: P<0.001,{ }^{* * * *}: P<0.0001$. 


\section{Chapter 3. Efficacy of vaccination with mapped peptides conjugated to KLH in susceptible sheep}

\section{$\underline{\text { Abstract }}$}

An effective vaccine for use against $H$. contortus would mean reduced used of anthelmintic and improved animal health. Development of an effective vaccine using synthetic peptides would improve the rate of vaccine production, as the current vaccine requires live larvae. Four peptides based on the epitope mapping assay (1, 2, 3, and 4) were conjugated to carrier protein $\mathrm{KLH}$. $\mathrm{KLH}$ was used to enhance the antigenicity of the peptides. Montanide ISA 61 VG was the adjuvant used in this vaccine to promote an appropriate immune response. SUF sheep were used in this vaccine trial, as they are a known susceptible breed. Four groups of $\mathrm{N}=6$ sheep each were used in this experimentvaccinated, adjuvant only, infection only, and naïve (uninfected). Vaccinated and adjuvant only groups were immunized and boosted with adjuvant + peptides, or adjuvant only. Other than to naïve, all groups received a primary infection of 10,000 Hc L3. Six weeks after primary infection, animals were dewormed with Levamisole and given a two-week

rest period followed by a secondary infection with $10,000 \mathrm{Hc}$ L3. Weekly fecal and blood samples were collected to monitor infection and to monitor antibody production specific to vaccine peptides. In the vaccinated group, antibodies specific to vaccine peptides were detectible one week after vaccination and remained high throughout the experiment; the other groups had no detectible antibody to the peptides $(p<0.01)$. However, there was no significant difference in infection outcome between the infected groups during primary or secondary infections- FEC, PCV or adult worm count. GPCR results showed that the infection only group had higher gene expression levels of foxp3 $(p<0.05)$, while both the vaccinated and adjuvant only groups had higher levels of il17a $(p<0.05)$, indicating a 
potential effect of the adjuvant. This vaccine trial revealed that SUF can respond to a peptide vaccine in this peptide +adjuvant construct despite the lack of protection provided. Gene expression revealed elevated levels of IL-17A which may have affected the overall vaccine efficacy. Future vaccine formulations should include a different adjuvant to promote a stronger Th2 response to ultimately reduce fecal egg count.

\section{Introduction}

Vaccines are used to elicit an adaptive immune response that are meant to protect an organism from future infections or reduce the severity of a pathogen. In most vaccines, there are two components- the adjuvant and the antigen. Adjuvants are substances used to elicit a specific type of immune response. Developing a vaccine in sheep has produced some difficulties, including which adjuvant is best. This is especially true in the case of developing a vaccine against $H$. contortus. Although there are multiple studies that have used different adjuvants, there is not a clear best choice. Adjuvants used in previous studies include alum (Alhydrogel), saponin (QuilA), Diethylaminoethyl dextran (DEAE), Freund's Complete Adjuvant, and Fruend's Incomplete Adjuvant (Vervelde et al., 2003; Piedrafita et al., 2013; Fawzi et al., 2015; Gadahi et al., 2016a; Kandil et al., 2017; González-Sánchez et al., 2018). Therefore, in this experiment a different, newer adjutant was used- Montanide ISA 61 VG. Montanide ISA vaccines are water in oil emulsions designed to slowly release antigen for a long-lived antibody response as well as a cellular response. The goal of this adjuvant in context of our vaccine was to induce a long-lasting antibody response and contribute cells to an appropriate cellular response.

Antigens are imperative to vaccines, as they are the target of the specific immune response built during vaccination. If the antigen is located in a region of the pathogen that 
is not accessible by the immune response, it would not be an appropriate selection for vaccination. In the case of commonly tested $\mathrm{Hc}$ antigens, the most successful vaccine antigens have been "hidden" gut antigens that are involved in blood metabolism. Antibodies are produced to recognize these antigens, bind the proteins when a blood meal is taken by $L 4 s$ and adults, and the worms cannot process their meals- starving the worms (Fawzi et al., 2015; Magalhães de Matos et al., 2017; González-Sánchez et al., 2018). Antigen production is also important in terms of vaccine development, recombinant proteins do not always fold properly and therefore have to be screened for antigenicity, native proteins and whole cell require production of the pathogen in large volumes, and peptides are not always antigenic enough and have to be bound to carrier proteins. For this vaccine, we selected peptides after unsuccessful production of recombinant protein. The specific peptides were selected based off epitope mapping results.

Previous vaccine trials for $\mathrm{Hc}$ focus largely on adult antigens. This means that for the vaccine to work, larval stages have to establish and develop. Therefore, this study focused on targeting $L 3$ and $L 3$ cuticle proteins to prevent establishment of $H$. contortus in the abomasum. There are advantages of both preventing L3 establishment and killing adult worms after establishment. In the case of targeting $L 3$, the goal would be to prevent any pathogenesis from occurring caused by L4 and adults feeding. An added benefit of preventing adult establishment would be to prevent egg production and shedding into the environment.

Vaccinations against $H$. contortus do not have to be $100 \%$ effective to be helpful to producers. If a one-time vaccine achieves partial protection, then other management practices can be utilized for preventing and treating infection. In this study, 24 SUF lambs 
were separated into 4 groups- vaccinated with antigen and adjuvant, adjuvant only control, infection only control and naïve. 


\section{Materials and Methods}

\section{Animals and housing}

All sheep utilized in these studies were born at the West Virginia University Animal Husbandry Farm (Morgantown, WV, USA) and raised on clean concrete floors order to prevent parasite infection. All animal protocols were approved by the West Virginia University Animal Care and Use Committee (IACUC-191002974.1).

\section{Haemonchus contortus culture and collection}

Three SUF were infected with 10,000 $\mathrm{H}$. contortus L3 and served as the source for all larvae used in this study. Packed cell volumes (PCV) and fecal egg counts (FEC) were monitored weekly. The feces of these animals were collected using cloth apparatus secured over the sheep's rear end. These feces were collected, broken up, mixed with autoclaved peat moss and activated carbon, and allowed to incubate at $37^{\circ} \mathrm{C}$ for 7 days. Larvae were collected via modified Baermann's apparatus, washed in PBS and stored in sterile PBS at $4^{\circ} \mathrm{C}$ until use.

\section{Generation of $\mathrm{Hc}$ infective larvae and experimental infection procedure}

Twenty-four SUF sheep were born and raised at the West Virginia University Animal Husbandry farm (Morgantown, WV, USA) and were raised parasite-free on a concrete floor. 18 of these animals were infected orally with 10,000 third stage $H$. contortus larvae (L3) while 6 remained naïve. Infection levels were monitored via fecal egg counts and packed cell volume. This infection continued for 7 weeks. Infected animals were treated with levamisole (Agrilabs, St. Joseph, MO, USA) (8 mg/kg) and rested for 2 weeks. The same animals were infected with another 10,000 L3 H. contortus and the infection continued until sacrificing the animals 5 weeks later. Animals were 
euthanized with Euthasol (Virbac, Carros, France) administered by the attending veterinarian.

\section{Ovine sample collection}

Samples of abomasal lymph node, and the three sections of abomasal tissue were collected after euthanasia and were stored in RNAlater. Abomasums were washed contents were collected and mixed up to $2 \mathrm{~L}$ with water. $200 \mathrm{~mL}$ of abomasal sample was mixed with $200 \mathrm{~mL}$ of formalin for final adult worm counts. Contents were sifted through and adult worms were counted.

\section{Serum collection}

Blood was collected into 10-ml untreated vacutainer tubes (Tyco, Cork, Republic of Ireland) via jugular venipuncture and centrifuged at $750 \times g$ for 20 minutes at $4^{\circ} \mathrm{C}$. Serum was pipetted off the top of the blood clot and pooled by treatment group. The serum was aliquoted and frozen at $-20^{\circ} \mathrm{C}$ until use.

\section{Packed Cell Volume}

Blood was collected into 5-ml EDTA vacutainer tubes (Tyco, Cork, Republic of Ireland) via jugular venipuncture. Blood from these tubes were collected into StatSpin ${ }^{\mathrm{TM}}$ Glass Microhematocrit Tubes (HemoCue, Angelholm, Sweden), packed with clay, and centrifuged for 2 minutes using the StatSpin ${ }^{\circledR}$ CritSpin ${ }^{\mathrm{TM}}$ Microhematocrit Centrifuge (HemoCue, Angelholm, Sweden). PCV levels were measured using StatSpin CritSpin Model S120 Digital Microhematocrit Reader (HemoCue, Angelholm, Sweden). 


\section{Fecal Egg Count}

Fecal samples were collected weekly and $2 \mathrm{~g}$ from each sample was mixed with 28 $\mathrm{mL}$ modified McMaster Solution. Solids were separated from the solution using cheese cloth and the solution was saved for counting eggs. The solution with the eggs were pipetted onto McMaster Slides (Chalex Corporation, Issaquah, WA, USA) and eggs in all chambers were counted. To calculate eggs/gram the raw egg counts were multiplied by 50.

\section{Composition of vaccine used in study}

Peptides 1-4 were conjugated to KLH and synthesized by BioMatik (Wilmington, $\mathrm{DE}, \mathrm{USA}$ ). Each antigen-KLH was reconstituted by dissolving in $0.5 \mathrm{ml} 0.22 \mu \mathrm{m}$ filtered $8 \mathrm{M}$ Urea. $0.5 \mathrm{~mL} 0.03 \mathrm{uM}$ sterile-filtered water was added to bring the final concentration of the mixture to $10 \mathrm{mg} / \mathrm{ml}$. $62.5 \mu \mathrm{l}$ of each antigen (for a total of $625 \mu \mathrm{g} /$ antigen) was mixed together with $1000 \mu \mathrm{l}$ of sterile $10 \mathrm{X}$ PBS and $2250 \mu \mathrm{l}$ of $0.03 \mu \mathrm{m}$ sterile-filtered water. This mixture was layered over $6500 \mu$ ladjuvant, SEPPIC Montanide ISA 61 VG (Paris, France) in IKA DT-20 eco Tube with rotor-stator element (IKA, Staufen, Germany). The tube with contents was placed into the Ultra -Turrax ®Tube Drive Basic (IKA, Staufen, Germany), mixed at $1100 \mathrm{rpm}$ "speed 3" for 1 minute followed by mixing at $4000 \mathrm{rpm}$ "speed 9" for 3 minutes. The same process was repeated for the adjuvant only group, but the antigen volumes were replaced with $0.03 \mu \mathrm{m}$ sterile-filtered water. The mixtures were kept in their mixing tubes overnight at $4^{\circ} \mathrm{C}$ transferred to endotoxin-free vaccine vials for vaccination. 
Table 3. 1. Peptides used in vaccine and their amino acid sequences

\begin{tabular}{|l|l|}
\hline Peptide & Amino acid sequence (N to C terminus) \\
\hline $\mathbf{1}$ & LERAEERAEAGENKIVELC w/or w/out (KLH) \\
\hline $\mathbf{2}$ & VDESERVRKVMENRSFQDC w/or w/out (KLH) \\
\hline $\mathbf{3}$ & ADEVQRQLEEERKKREDAEC w/or w/out (KLH) \\
\hline $\mathbf{4}$ & EADRKYDEVARKLAMVC w/or w/out (KLH) \\
\hline
\end{tabular}

\section{Administration of Vaccine, Adjuvant Control, and Boosters}

Six SUF sheep were used per group. Vaccines and adjuvant controls were administered via intramuscular injection into neck muscle. The site of vaccination was sheared and wiped with isopropanol for 10 seconds before injection. The vaccine and adjuvant control were mixed before use and $1 \mathrm{~mL}$ of vaccine $(250 \mu \mathrm{g}$ total antigen) ladjuvant control was injected using a $20 \mathrm{G}$ needle. The sheep were monitored for signs of distress and discomfort intermittently for 12 hours. The sheep were then checked daily for the next 5 days. The same process was repeated for giving the booster vaccination and adjuvant control 4 weeks after initial vaccination.

\section{Peptide-specific ELISAs}

Unconjugated vaccine peptides were diluted to $1 \mathrm{mg} / \mathrm{ml}$ in DI water. $4 \mathrm{HBX}$ plates (ThermoFisher Scientific, Waltham, MA, USA) were coated with $100 \mu \mathrm{l}$ a mix of all 4 peptides diluted in $0.05 \mathrm{M}$ Carbonate/Bicarbonate buffer to a concentration of $2.5 \mu \mathrm{g} / \mathrm{ml}$ per peptide, and were incubated overnight at $4^{\circ} \mathrm{C}$. Wells were washed five times with PBS-T and blocked for 1 hour at room temperature with PBS-T + 3\% Skim Milk (PBS-B) (Kroger, Cincinnati, OH, USA). Plates were washed five times with PBS-T. Sheep serum was added at respective dilutions in PBS diluted down the plate by half for a final volume of $100 \mu \mathrm{l}$ per well. The plates were incubated at RT for 2 hours and washed with PBS-T 
five times. Mouse anti-sheep IgG:HRP conjugated antibody (Sigma-Aldrich, St. Louis, MO, USA) was diluted 1:2000 in PBS-B and incubated at RT for 1 hour. Wells were washed ten times with PBS-T. TMB substrate (ThermoFisher Scientific, Waltham, MA, USA) was added for 15 minutes and development was stopped using $2 \mathrm{M} \mathrm{H}_{2} \mathrm{SO}_{4}$. Absorbance was read at 450nm using Epoch BioTek Plate Reader (BioTek, Winooski, VT, USA).

\section{RNA extraction and cDNA synthesis}

50-80 mg of LN tissue was sectioned from sample in RNAlater (ThermoFisher Scientific, Waltham, MA, USA) and placed in a $5 \mathrm{ml}$ polypropylene tube. $1 \mathrm{~mL}$ RNA Bee was added and the section was homogenized using a tissue homogenizer. Samples were kept on ice before and after homogenization. Contents were transferred to $2 \mathrm{ml}$ microcentrifuge tube. $120 \mu \mathrm{l}$ chloroform:isoamyl alcohol was added and the tube was shaken vigorously for 15 seconds followed by rest on ice for 5 minutes. After resting, the samples were placed in a centrifuge and spun at $14000 \times \mathrm{g}$ for 15 mins at $4^{\circ} \mathrm{C}$. The aqueous solution was collected (top layer of the tube contents) and were mixed with equal parts ice-cold isopropanol. Contents were mixed gently and placed at $-20^{\circ} \mathrm{C}$ overnight. The next day, the tubes were centrifuged at $14000 \mathrm{xg}$ for 15 mins at $4^{\circ} \mathrm{C}$. The supernatant was removed and replaced with $500 \mu \mathrm{l} 75 \%$ ethanol for washing. The tubes were spun again $14000 \mathrm{xg}$ for 10 mins at $4^{\circ} \mathrm{C}$ and the wash step was repeated. Supernatant was removed and the RNA pellet was allowed to dry in an exhaust hood. The pellets were resuspended with 35-50 $\mu \mathrm{l}$ molecular grade water depending on the size of the pellet. RNA concentrations and $260 / 280$ ratios (above 1.8 is "pure" RNA) were determined using 
the Take3 addition of the BioTek Synergy H1 microplate reader (BioTek, Winooski, VT, USA). RNA was stored at $-80^{\circ} \mathrm{C}$ until use.

DNA was prepared using the qScript ${ }^{\mathrm{TM}}$ XLT cDNA SuperMix (Quantabio). $4 \mu \mathrm{I} 5 \mathrm{X}$ RT master mix was mixed with $1 \mu \mathrm{g}$ and incubated in a T100 Thermal Cycler (Bio-Rad, Hercules, CA, USA). The reaction was completed as $25^{\circ} \mathrm{C}$ for 5 minutes, $42^{\circ} \mathrm{C}$ for 60 minutes, $85^{\circ} \mathrm{C}$ for 5 minutes and infinite at $4^{\circ} \mathrm{C}$. cDNA samples were quantified with Take3 addition of the BioTek Synergy H1 microplate reader (BioTek, Winooski, VT, USA). cDNA samples were diluted using molecular grade water to $50 \mathrm{ng} / \mu \mathrm{l}$ and stored at $80^{\circ} \mathrm{C}$ until use.

\section{Gene expression}

Assays were run using CFX96 system (Bio-Rad, Hercules, CA, USA). Taqman Assay was made up of $1 \mu \mathrm{l}$ 20X TaqMan Gene expression assay (Applied Biosystems. Foster City, CA, USA), $2 \mu \mathrm{l}$ (100 ng) cDNA templates, $10 \mu \mathrm{l}$ 2X TaqMan Gene Expression Master Mix (Applied Biosystems. Foster City, CA, USA), and $7 \mu$ RNase-free water for a total volume of $20 \mu \mathrm{l}$ per reaction. The reaction was: $95^{\circ} \mathrm{C}$ for 10 minutes followed by 40 repeated cycles of $95^{\circ} \mathrm{C}$ for 15 seconds followed by $60^{\circ} \mathrm{C}$ for 20 seconds. Relative fold changes were determined using $\Delta \mathrm{Ct}$ values [Ct (test) - $\mathrm{Ct}$ (reference)] and derived using 2- $\Delta \Delta \mathrm{Ct}$ where the reference gene used for normalization was GAPDH. 
Table 3. 2. Forward and reverse primers used in qRT-PCR

\begin{tabular}{|c|c|c|c|}
\hline & $\mathbf{F}^{\prime}$ Primer $\left(\mathbf{5}^{\prime} \boldsymbol{\rightarrow} \mathbf{3}^{\prime}\right)$ & R Primer $\left(\mathbf{5}^{\prime} \rightarrow \mathbf{3}^{\prime}\right)$ & Accession Number \\
\hline GAPDH & CAGGAGCACGAGAGGAAGAG & AATGTATGGAGGTCGGGAGA & HM043737 \\
\hline GATA-3 & ATGAAACCGAAACCCGATG & GAACACAGACACCACGGAAG & NM_001252183.1 \\
\hline IL-4 & GCTGAACATCCTCACATCGAG & TTCTCAGTTGCGTTCTTTGG & M31736.1 \\
\hline T-bet & TACTACCGAAGCCAGGAAGC & AGAGTTCGCATGGAGTGGAA & DQ152994.1 \\
\hline IFNG & ATGACCTGTCGCCAAAATC & GCAGGCAGGAGAACCATTAC & NM_001009803.1 \\
\hline IL-10 & GAAACAGCACATTCCCAGAGT & GGATGAGGGTGGCATAGGT & FJ491732.1 \\
\hline IL-17A & GGAACACGAACTCCAGAAGG & ACTTGGCCTCCCAGATCA & LN835312.1 \\
\hline
\end{tabular}

GAPDH: Glyceraldehyde 3-phosphate dehydrogenase; IL-4: interleukin-4; T-bet: T-box expressed in T cells; IFNG: interferon gamma; Foxp3: forkhead box P3; IL-10: interleukin-10; IL17A: interleukin-17A.

\section{Statistical Analysis}

Two-way ANOVA with Tukey's multiple comparisons test were performed in GraphPad

Prism. When groups were compared to each other by weekly values (repeated values)FEC, PCV, antibody titre, Geisser-Greenhouse correction was applied. Significance was set at $p<0.05$. 


\section{$\underline{\text { Results }}$}

Table 3.3 describes the treatment groups in which group 1 is the vaccinated group, group 2 is the adjuvant only group, group 3 is the infection only group, and group 4 is the naïve group. Groups 1, 2, and 3, were infected with 10,000 L3 10 weeks post- initial vaccination, given 7 weeks to stay infected followed by deworming and a secondary infection of 10,000 L3 that was carried out 5 weeks (Figure 3.1). Packed cell volume and fecal egg counts were measured weekly to track infection levels. As expected, the naïve group maintained the highest PCV. All three infected groups followed the same trend of PCV and after reinfection, maintained the same PCV as the naïve group (Figure 3.2a). Fecal egg counts were not statistically significant between the infected groups, except for weeks 15 and 16 post-vaccination in which the adjuvant only group had a significantly lower FEC than the infection only group (Figure 3.2b). While not significant, the infection only group had higher FEC than either the vaccine or adjuvant groups. The same trend was seen in the abomasal adult worm counts. Naïve sheep stayed naïve through the whole experiment (Figure 3.2c).

A simple measurement of active immune response and recruitment of lymphocytes to the sire of infection is local lymph node hypertrophy. Lymph nodes from the lesser curvature of the abomasum were collected and weighed. Average total lymph node weight per sheep was significantly higher in all infected groups when compared to the naïve group (Figure 3.3a). The vaccinated sheep has significantly higher counts of lymph nodes compared to both infected and naïve groups, while the adjuvant only group had significantly more lymph nodes than the naïve group only (Figure $3.3 b$ ). Figure $3 c$ 
illustrates that although the infected group had lower number of lymph nodes, each lymph node had significantly greater mass than those in any of the other groups.

One of the goals of vaccination is to induce antibodies specific to the antigen used in vaccines. Figure 3.4 shows the average antibody titre of each group specific to a mix of all 4 antigens over the course of the experiment. As early as week 1 post vaccination, there is detectible specific antibody produced by animals that were vaccinated. After boosting, specific antibody titres reached their peak and leveled off for the remainder of the experiment. The other groups maintained the same level of antibody specific to antigens throughout the experiment. The lowest tested titre was reported (serum diluted 1:50- titre of 1.69897), as these groups did not have an increase in antibody levels.

After sacrificing the animals, abomasal lymph node samples were taken and kept in RNAlater until gene expression was run. GAPDH was run as the house keeping gene and all gene expression reported is corrected with GAPDH followed by the control (uninfected) group. Table 3.5 compares gene expression fold change between the groups. The infection only group had higher levels of Foxp3 compared to either the vaccinated or adjuvant only group $(P<0.05)$. IL-17A levels were higher in both the vaccinated and adjuvant only group compared to the infection group but were not different from each other $(P<0.05)$, illustrating an adjuvant effect. 


\section{Discussion}

Throughout the world, $H$. contortus plagues both goat and sheep industries. As of 2020 , the only commercially vaccine available is BarberVax and it is only available in New Zealand, South Africa, Australia, and the UK (by subscription). While this vaccine is mostly effective, it requires multiple boosters every season rather than inducing long-term protection. There have been many other anti-Hc vaccine experiments, but success rates have been highly variable. Based on our previous experiments and experiments throughout the literature, we developed and performed a vaccine experiment with Suffolk sheep- a known susceptible breed. Based on the FEC and adult worm count results, there was no protection induced by the vaccine. However, this vaccine did induce antibody production in the sheep that lasted throughout the whole experiment after one vaccination and one early boost.

As mentioned in previous chapters, the antigens selected for this vaccine were broadly based on STC antibody binding greatly to a protein band that was later identified via mass spec as Hc tropomyosin. Further, the specific peptides used in the vaccine were selected after performing an epitope mapping assay of Hc tropomyosin with STC antibody. Four peptides with the highest average binding value in this assay were selected for the vaccine and are listed in Table 1. Because peptides are poor antigens when administered alone in a vaccine, $\mathrm{KLH}$ was conjugated to the $\mathrm{C}$-terminus of each peptide during synthesis. $\mathrm{KLH}$ is a large protein isolated from the hemolymph of the mollusk Megathura crenulate. It is known to be a T-cell dependent antigen, which is important for priming $\mathrm{T}$ and $\mathrm{B}$ cells in an early immune response. These responses are also important for inducing proper antibody production and class switching (House, 2010). 
This vaccine experiment showed that Suffolk were able to produce antibody to the peptides used in this vaccine. Even with high titres specific to the vaccine antigens in the vaccine group, there was no difference in infection levels based on FEC and adult worm count between the vaccine, adjuvant only, and infection only groups.

IgG was the only antibody tested for this experiment. Although there was ample $\lg G$ specific to the peptides, the isotype may have played a role in lack of protection. $\lg G$ is generally a circulating antibody, which means it is found in the blood. For the antibody to bind its target, it must encounter it and for $\lg G$ to come in contact with the parasite, there would have had to have been blood in the abomasum. Under uninfected circumstances, there is not blood in the abomasum. However, once the host is infected and L4 and adults are established, their blood meals lead to release of blood into the abomasum; this is how BarberVax works. BarberVax induced antibodies against "hidden" gut antigens. Therefore, when L4 and adults take their blood meals, antibody can bind its target and inhibits blood metabolism. In the case of the vaccine from our study, the antibody is targeting tropomyosin which we identified in samples of L3 and XL3 homogenates. Because IgG is in the blood, low levels of $L 4$ and adult Hc may be important to release blood and prevent further establishment of Hc (Janeway et al., 2001).

To determine why this vaccine did not work, identifying the location of tropomyosin in all parasitic life stages of $\mathrm{Hc}$ will be imperative. If tropomyosin is only found in L3 stage, then another vaccine trial in which the animals are initially vaccinated and boostered followed by a low-dose infection (5,000 L3 to allow blood feeding and release of antibody into the gut) and a final challenge infection of $10,000 \mathrm{~L} 3$. While the goal of the vaccine is to induce protection before the animals encounters the parasite, vaccines must be finely 
tuned to allow the best chance of effectiveness. If animals can be given a low dose infection and can maintain that controlled level of infection to reduce the chance of being infected with more of the pathogen, then that may be a factor that has to be tested.

Another component of the vaccine that could have affected its potency is the adjuvant selection. The adjuvant used in this experiment was Montanide ISA 61 VG, a water-in-oil adjuvant designed for use in animals. Water-in-oil and oil-in-water adjuvants are used to induce both cellular and humoral response. ISA 61 VG was selected because it has been marketed to prolong the antibody response as well as induce a cellular response. RNA was extracted from samples of abomasal lymph nodes and qPCR was run on Th1 (tbet, ifng), Th2 (gata3, il4), Treg (foxp3, il10) and Th17 (il17a) genes. There was no significant difference in the groups between Th1 and Th2 groups, but foxp3 was significantly upregulated in the infected only group. /17a was significantly upregulated in both the vaccinated and adjuvant group compared to the infection only group but was not different between the two groups. These data indicate that the infection only group may have a higher population of Treg cells in the lymph node which may be reducing the ability of Th2 cells to expand.

Shepherd et al, found that both STC and SUF monocytes co-cultured with L3 had early increased levels of inflammatory markers. However, after 15 hours, STC saw a decrease in these markers and an increase in Th2 cytokines while SUF Th1 expression remained high, suggesting STC had switched monocyte phenotype from Th1 towards Th2 and SUF maintained a Th1 profile(Shepherd, 2019). These results indicate that early Th1-type response may be important but switching to a Th2 response may be the key in their ability to clear Hc early. While these experiments were shorter term than the vaccine 
trial, others have also found that Th2 response is important in clearing $\mathrm{Hc}$ infections $(\mathrm{H}$. S. Gill et al., 1993; Gill et al., 2000; Lacroux et al., 2006; Terefe et al., 2007; Bowdridge et al., 2013; MacKinnon et al., 2015; Jacobs et al., 2016; Middleton et al., 2020)

Future studies using the same antigens for vaccination would benefit from exploring the use of different adjuvants such as Alum. Alum is known to induce a strong antibody response (Tritto et al., 2009). In previous Hc vaccine studies the adjuvants QuilA, Alum, Adju-Phos, and Diethylaminoethyl (DEAE)-dextran have been tested for their efficacies. These studies have all utilized hidden gut antigens so testing them with an external antigen may result in different protections. In this initial vaccine study, the reason for using the adjuvant we used was find a balance between humoral and cellular responses.

In summary, this vaccine trial demonstrated the ability of Suffolk lambs to develop a specific antibody response to peptides after vaccination. This study also illustrated a need for selecting different antigens or adjuvants could improve the efficacy of a vaccine against $H c$. Gene expression of abomasal lymph nodes revealed an adjuvant effect. This effect was an increase in il17a expression. However, the vaccine did not elicit protection from $\mathrm{Hc}$ infection. The sheep industry continues to lose money by disease caused by $H$. contortus infection. Therefore, continuing to expand antigen discovery efforts may be imperative. 


\section{Literature Cited}

Bowdridge, S., K. MacKinnon, J. C. McCann, A. M. Zajac, and D. R. Notter. 2013. Hairtype sheep generate an accelerated and longer-lived humoral immune response to Haemonchus contortus infection. Vet. Parasitol. 196:172-178.

doi:10.1016/j.vetpar.2013.01.008.

Fawzi, E. M., M. E. González-Sánchez, M. J. Corral, J. M. Alunda, and M. Cuquerella. 2015. Vaccination of lambs with the recombinant protein $\mathrm{rHc} 23$ elicits significant protection against Haemonchus contortus challenge. Vet. Parasitol. 211:54-59. doi:10.1016/j.vetpar.2015.04.029.

Gadahi, J. A., M. Ehsan, S. Wang, Z. Zhang, Y. Wang, R. Yan, X. Song, L. Xu, and X. Li. 2016. Recombinant protein of Haemonchus contortus 14-3-3 isoform 2 ( $\mathrm{rHcftt}-2$ ) decreased the production of IL-4 and suppressed the proliferation of goat PBMCs in vitro. Exp. Parasitol. 171:57-66. doi:10.1016/j.exppara.2016.10.014.

Gill, H. S., K. Altmann, M. L. Cross, and A. J. Husband. 2000. Induction of T helper 1and T helper 2-type immune responses during Haemonchus contortus infection in sheep. Immunology. 99:458-463. doi:10.1046/j.1365-2567.2000.00974.x.

Gill, H. S., G. D. Gray, D. L. Watson, and A. J. Husband. 1993. Isotype-specific antibody responses to Haemonchus contortus in genetically resistant sheep. Parasite Immunol. 15:61-67. doi:10.1111/j.1365-3024.1993.tb00585.x.

González-Sánchez, M. E., M. Cuquerella, and J. M. Alunda. 2018. Vaccination of lambs against Haemonchus contortus with the recombinant rHc23. Effect of adjuvant and antigen dose. P. L. Ho, editor. PLOS ONE. 13:e0193118. doi:10.1371/journal.pone.0193118.

House, R. 2010. Fundamentals of clinical immunotoxicology. In: Methods in Molecular Biology: Immunotoxicity Testing. Humana Press, Totowa, NJ, USA.

Jacobs, J. R., K. N. Sommers, A. M. Zajac, D. R. Notter, and S. A. Bowdridge. 2016. Early IL-4 gene expression in abomasum is associated with resistance to Haemonchus 
contortus in hair and wool sheep breeds. Parasite Immunol. 38:333-339. doi:10.1111/pim.12321.

Janeway, C. A., P. Travers, M. Walport, and M. J. Shlomchik. 2001. The distribution and functions of immunoglobulin isotypes. Immunobiol. Immune Syst. Health Dis. 5th Ed. Available from: https://www.ncbi.nlm.nih.gov/books/NBK27162/

Kandil, O. M., K. A. Abdelrahman, H. A. Shalaby, S. H. M. Hendawy, N. M. T. A. El Ezz, S. A. Nassar, and J. E. Miller. 2017. Evaluation of crude larval protein and recombinant somatic protein 26/23 (rHcp26/23) immunization against Haemonchus contortus in sheep. Vet. World. 10:758-763. doi:10.14202/vetworld.2017.758-763.

Lacroux, C., T. H. C. Nguyen, O. Andreoletti, F. Prevot, C. Grisez, J.-P. Bergeaud, L. Gruner, J.-C. Brunel, D. Francois, P. Dorchies, and P. Jacquiet. 2006. Haemonchus contortus (Nematoda: Trichostrongylidae) infection in lambs elicits an unequivocal Th2 immune response. Vet. Res. 37:607-622. doi:10.1051/vetres:2006022.

MacKinnon, K. M., S. A. Bowdridge, I. Kanevsky-Mullarky, A. M. Zajac, and D. R. Notter. 2015. Gene expression profiles of hair and wool sheep reveal importance of Th2 immune mechanisms for increased resistance to Haemonchus contortus. J. Anim. Sci. 93:2074-2082. doi:10.2527/jas.2014-8652.

Magalhães de Matos, A. F. I., C. O. R. Nobre, J. P. Monteiro, C. M. L. Bevilaqua, W. D. Smith, and M. Teixeira. 2017. Attempt to control Haemonchus contortus in dairy goats with Barbervax $\AA$, a vaccine derived from the nematode gut membrane glycoproteins. Small Rumin. Res. 151:1-4. doi:10.1016/j.smallrumres.2017.03.016.

Middleton, D., J. J. Garza, S. P. Greiner, and S. A. Bowdridge. 2020. Neutrophils rapidly produce Th2 cytokines in response to larval but not adult helminth antigen. Parasite Immunol. 42:e12679. doi:10.1111/pim.12679.

Piedrafita, D., S. Preston, J. Kemp, M. de Veer, J. Sherrard, T. Kraska, M. Elhay, and E. Meeusen. 2013. The effect of different adjuvants on immune parameters and protection following vaccination of sheep with a larval-specific antigen of the gastrointestinal 
nematode, Haemonchus contortus. PloS One. 8:e78357.

doi:10.1371/journal.pone.0078357.

Shepherd, E. A. 2019. Characterization of Ovine Monocytes in Response to Haemonchus contortus Larvae in vitro and a Novel Role of Interleukin-13 Inducing Larval Paralysis [Ph.D.]. West Virginia University, United States -- West Virginia.

Available from:

https://search.proquest.com/pqdtglobal/docview/2401413094/abstract/F85EFDAB1A95 4F16PQ/1

Terefe, G., C. Lacroux, O. Andreoletti, C. Grisez, F. Prevot, J. P. Bergeaud, J. Penicaud, V. Rouillon, L. Gruner, J. C. Brunel, D. Francois, J. Bouix, P. Dorchies, and P. Jacquiet. 2007. Immune response to Haemonchus contortus infection in susceptible (INRA 401) and resistant (Barbados Black Belly) breeds of lambs. Parasite Immunol. 29:415-424. doi:10.1111/j.1365-3024.2007.00958.x.

Tritto, E., F. Mosca, and E. De Gregorio. 2009. Mechanism of action of licensed vaccine adjuvants. Vaccine. 27:3331-3334. doi:10.1016/j.vaccine.2009.01.084.

Vervelde, L., N. Bakker, F. N. J. Kooyman, A. W. C. A. Cornelissen, C. M. C. Bank, A. K. Nyame, R. D. Cummings, and I. van Die. 2003. Vaccination-induced protection of lambs against the parasitic nematode Haemonchus contortus correlates with high IgG antibody responses to the LDNF glycan antigen. Glycobiology. 13:795-804. doi:10.1093/glycob/cwg107. 
$\underline{\text { Tables and figures }}$

Table 3. 3. Vaccine trial groups

\begin{tabular}{|c|c|c|c|c|}
\hline Group & $\underline{\mathbf{N}=}$ & $\underline{\text { Adjuvant }}$ & $\underline{\text { Peptide Mixture }}$ & $\frac{\underline{\text { Hc (10,000 }}}{\underline{\mathbf{L 3}}}$ \\
\hline 1 (Vaccinated) & 6 & + & + &,++ \\
\hline 2 (Adjuvant Only) & 6 & + & &,++ \\
\hline 3 (Infection Only) & 6 & & &,++ \\
\hline 4 (Naive) & 6 & & & \\
\hline
\end{tabular}

6 Suffolk sheep were used in each group. Adjuvant + peptide mixture (the vaccine) was administered to group 1. At the same time, adjuvant was administered to group 2. Groups 1, 2, and 3 were given two oral challenges of 10,000 L3 H. contortus. Group 4 remained naïve and without any vaccine treatment.

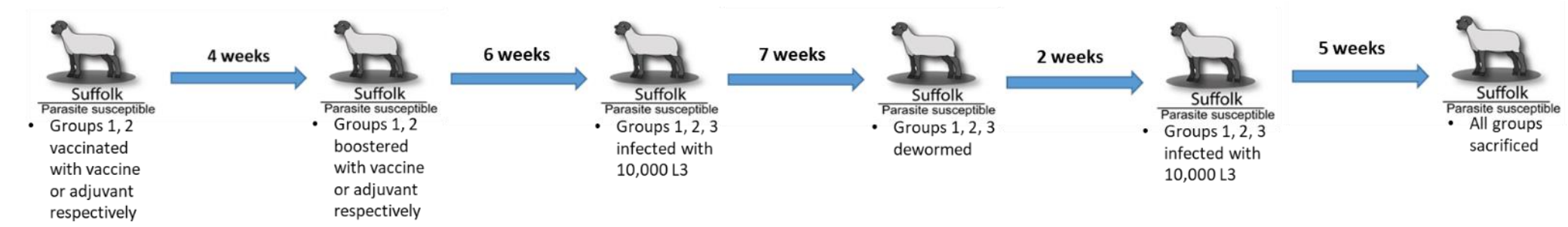

Figure 3. 1. Vaccination and challenge schedule for vaccine trial.

This schematic shows the schedule of vaccinations by week and by group. Groups 1 and 2 were vaccinated at day 0.4 weeks later, the same sheep were boostered with the same vaccines. After 6 weeks, Groups 1,2, and 3 were give an oral gavage of 10,000 L3 and this infection persisted for 7 weeks. These animals were dewormed and two weeks later were challenged with 10,000 L3. 5 weeks later, all animals were sacrificed. 
a.

\section{Packed Cell Volume}

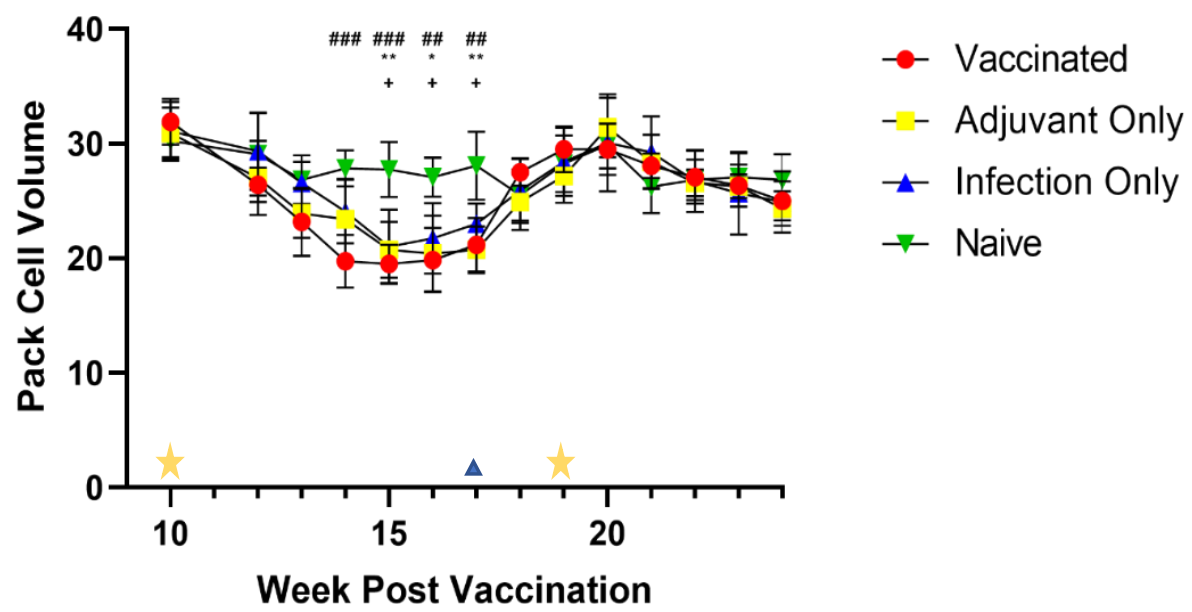

Fecal Egg Count

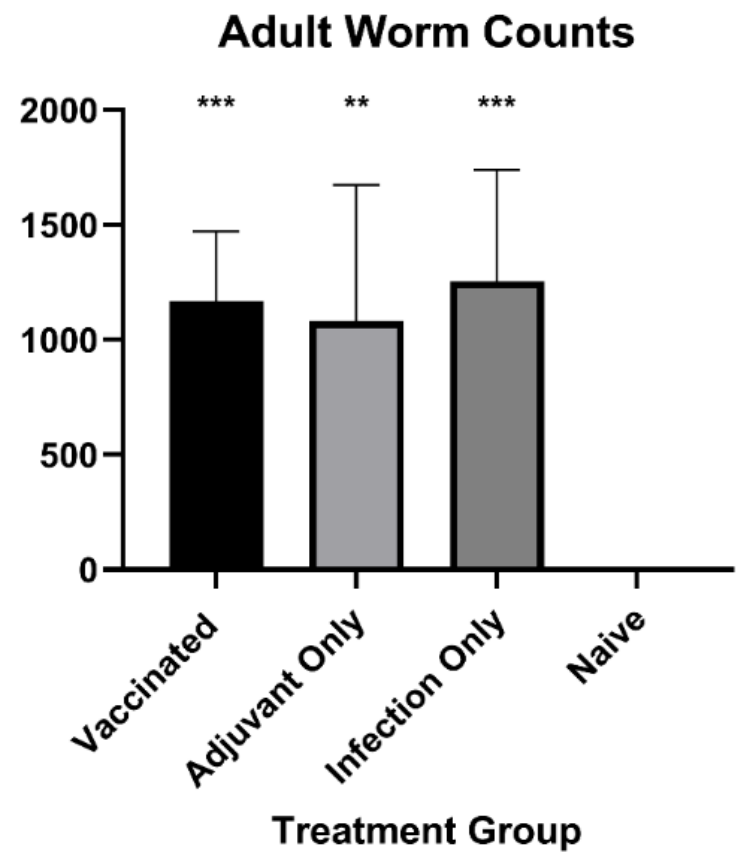

Figure 3. 2. Weekly and final infection parameters.

(a) Weekly packed cell volumes were used to monitor for anemia caused by infection. Yellow star shapes indicate week of infection; blue triangle indicates week of deworming. (b) Weekly fecal egg counts were taken and performed in triplicate per animal (\# denotes significance of vaccinated vs naïve, * denotes significance of adjuvant only vs naïve, + denotes significance of infection only vs naïve, a denotes difference of adjuvant vs infection only). (c) Adult worm counts in the abomasum were determined after sacrifice. $\left({ }^{*}: \mathrm{P}<0.05,{ }^{* *}\right.$ : $\mathrm{P}<0.01,{ }^{* * *}$ : $\mathrm{P}<0.001,{ }^{* * *}$ : $\left.\mathrm{P}<0.0001\right)$ 
a.

Average total lymph node weight

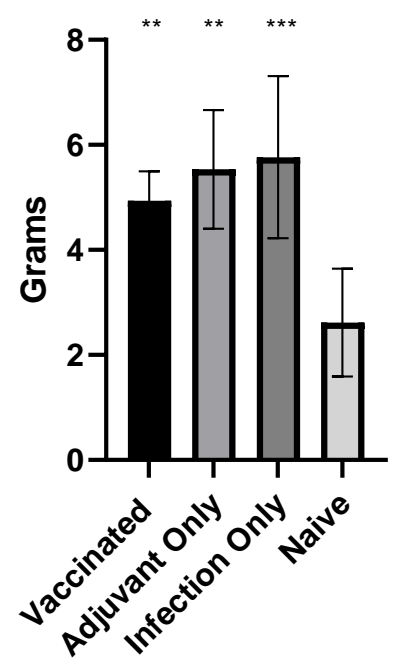

Treatment Group b.

Abomasal lymph node count
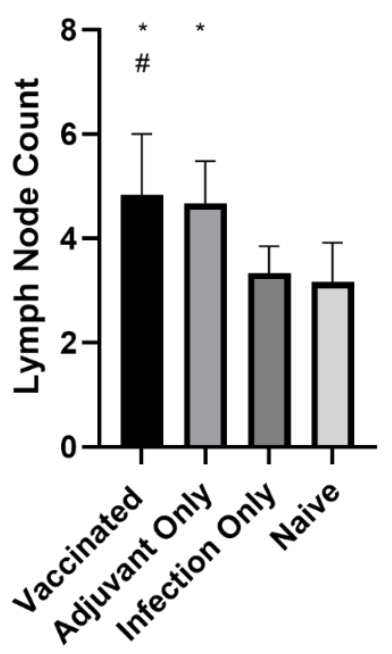

Treatment Group c.

Average mass per lymph node

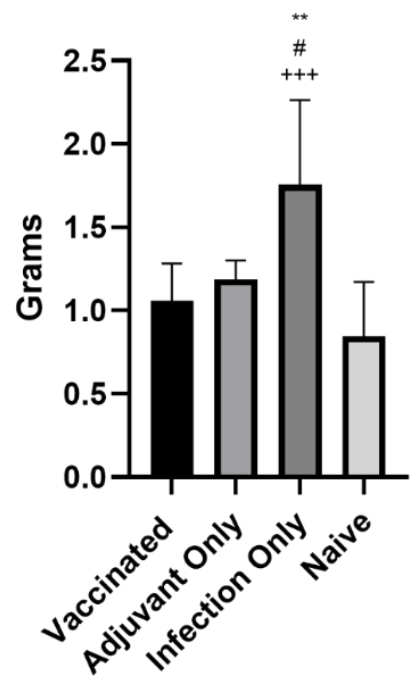

Treatment Group

Figure 3. 3. Abomasal lymph node weight and counts.

After sacrifice, abomasal lymph nodes were removed, counted and weighed. (a) Vaccinated, adjuvant, and infection groups all had significantly higher total lymph node mass (per animal) compared to the naïve group $\left({ }^{* *}: P<0.01,{ }^{* * *}: P<0.001\right)$. (b) Lymph nodes were removed and counted; * denotes significant difference of group vs naïve ( $p<$ $0.05)$, \# denotes significant difference of vaccinated vs infection only $(P<0.05)$. (c) weight per lymph node was calculated by dividing the lymph node count by total weight; ${ }^{* \star}$ denotes significant difference of infection only vs vaccine $(P<0.01)$, \# denotes significant difference of infection only vs adjuvant only $(P<0.05),+++$ denotes significant difference of infection only vs naive $(P<0.001)$ 


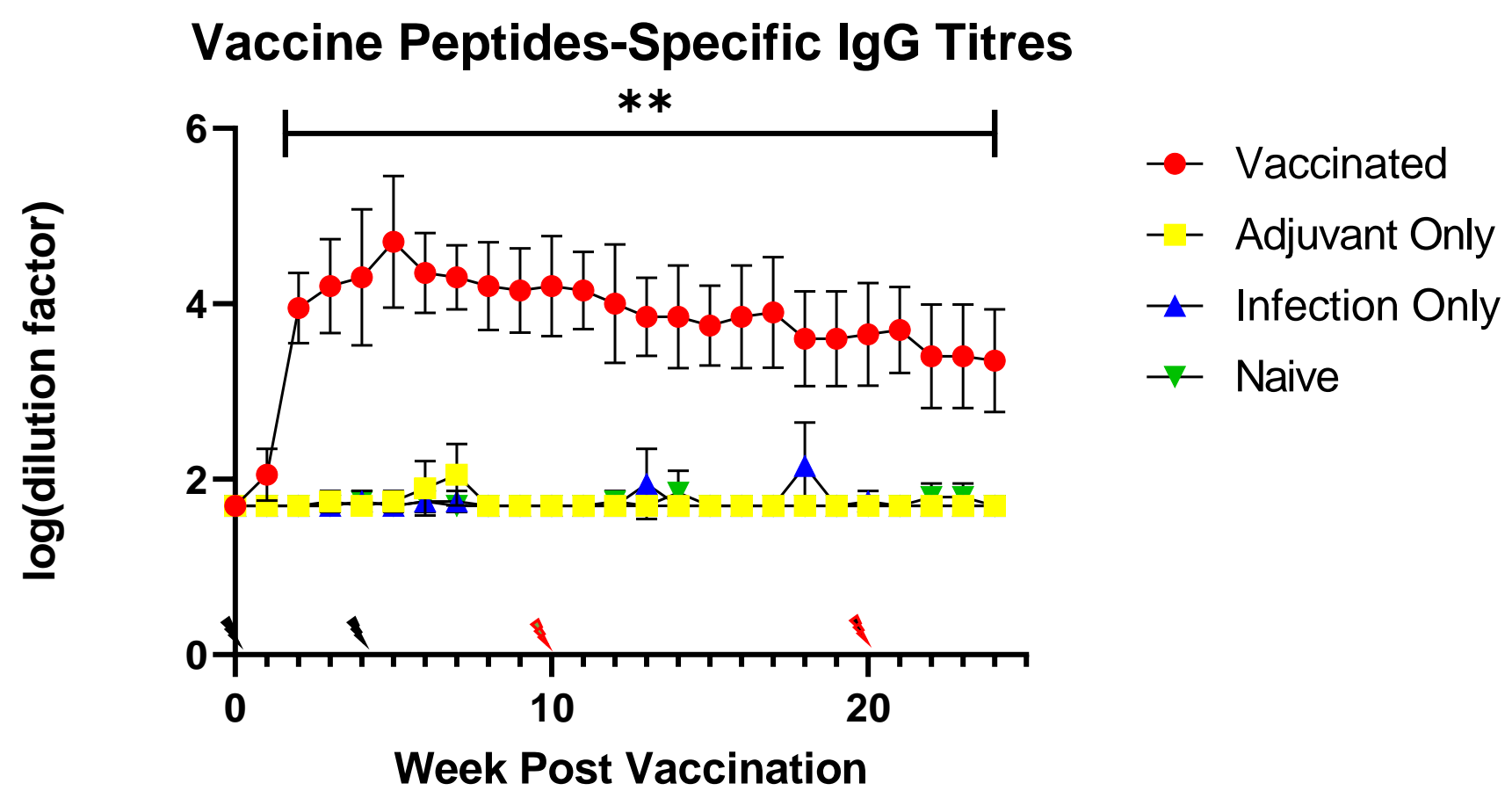

Figure 3. 4. Vaccine peptides- specific IgG.

ELISA were performed by coating high-binding plates with a mixture of all 4 peptides used in the vaccine. The primary antibody used was individual sheep serum and the secondary antibody used was mouse anti-sheep lgG:HRP. The lowest dilution tested was 1:50, explaining the lowest log (dilution factor) at 1.69. Weeks in which the appropriate groups were vaccinated are marked with a black bolt and the weeks of challenge infection are marked with a red bolt. Starting at week 2post vaccination and lasting to sacrifice, vaccinated lambs had significantly higher levels of peptide-specific IgG compared to all groups $(P<0.01)$. 
Table 3. 4. Gene expression of abomasal lymph node sections.

\begin{tabular}{|c|c|c|c|}
\hline & Vaccinated & Adjuvant only & Infection only \\
\hline gata3 & $2.731 \pm 1.023$ & $1.989 \pm 0.489$ & $1.245 \pm 0.344$ \\
\hline il4 & $4.589 \pm 1.998$ & $2.425 \pm 0.379$ & $3.543 \pm 1.241$ \\
\hline tbet & $4.744 \pm 2.097$ & $4.138 \pm 1.721$ & $2.612 \pm 1.961$ \\
\hline ifng & $2.268 \pm 0.602$ & $3.349 \pm 0.572$ & $4.446 \pm 1.040$ \\
\hline foxp3 & $4.708 \pm 1.249$ & $6.952 \pm 1.187$ & $9.230 \pm 2.158^{\mathrm{a}}$ \\
\hline il10 & $1.668 \pm 0.979$ & $1.157 \pm 0.087$ & $1.962 \pm 1.125$ \\
\hline il17a & $8.474 \pm 2.491^{\mathrm{b}}$ & $9.077 \pm 2.831^{\mathrm{b}}$ & $2.491 \pm 0.437$ \\
\hline
\end{tabular}

Abomasal lymph nodes were collected at the time of sacrifice. $50 \mathrm{mg}$ of the largest lymph node collected from each sheep was used gene expression analysis. Fold change is reported \pm SEM. Fold change (FC) was calculated using $\Delta$ ct relative to housekeeping gene GAPDH and $\Delta \Delta$ ct relative to naïve sheep. Different superscript letters indicate significance difference from those unlabeled in shared row. $P<0.05$ 


\section{Chapter 5: Discussion}

\section{Background}

The major goal of this research was to identify vaccine candidates of Haemonchus contortus and use them in a vaccine trial. This was done through protein binding assays (western blots), candidate identification, epitope mapping assays, and in vivo vaccine trial which included analysis of efficacy via parasitological parameters and molecular assays.

As populations across the globe increase, access to nutritious food also needs to increase. Agricultural industries are working alongside scientists to try to make growing food and livestock as efficiently as possible. Climate change is one of the largest threats to agricultural industry. Changing climates make growing food more difficult as climate disasters including floods, droughts, fires, and storms become more severe, more frequent, and more difficult to predict. In the sheep industry, increased world temperatures and humidity across the globe make $\mathrm{Hc}$ infections more likely to be an issue in areas where it wasn't before. As mentioned throughout, $\mathrm{Hc}$ is one of the greatest threats to the sheep industry. Hc infections lead to decreased productivity of sheep, and increased costs in lost lambs and treatments. Therefore, an increase in the number of regions that $\mathrm{Hc}$ thrive would be devastating for the sheep industry, those that rely on lamb for income, and those that rely on lamb meat for nutrition.

A major issue surrounding $H c$ is its ability to develop resistance to multiple anthelmintic drugs. One method to combat $\mathrm{Hc}$ is the development of a vaccine. Although BarberVax exists, it requires multiple boosters. This not only increases cost, but also requires extensive time to administer the vaccine. BarberVax is composed of multiple native antigens, meaning they are extracted from adult $\mathrm{Hc}$ homogenate. Thus far, there 
have not been successful protocols for growing adult $\mathrm{Hc}$ in vitro from egg stage. This means that lambs and sheep are continuously infected and sacrificed to maintain populations of $\mathrm{Hc}$ for protein extraction. To reduce the need for sheep in the chain of vaccine production, one of the goals of this study was to identify a protein that could be produced synthetically.

\section{Limiting Factors}

Vaccine trials designed to prevent $H c$ in sheep have been largely unfruitful. Some of the difficulties associated with sheep studies include host specific studies, antigen identification, and antigen production. Unlike mice used in initial vaccine studies, sheep are largely outbred. This is both a positive and a negative. Because they are outbred, they are more representative of sheep populations. However, having inbred animals and the tools to produce inbred animals makes studying specific functions of a particular molecule on a whole system more achievable. Another factor that contributes to the lack of advances in sheep studies has been the lack of sheep-specific products, such as antibodies specific for sheep proteins. However, in recent years, these products have become increasingly more available. These issues are also applied to the search of molecular based products specific to Hc.

Another limiting factor of studying $\mathrm{Hc}$ in its host is the availability of sheep; the gestation period of a sheep 147 days and the weaning generally occurs at 60 days after birth before a lamb can be used in an experiment (Sheep Production and Management: reproduction in sheep). Most sheep are bred once a year and produce an average of 1.3 live lambs per ewe (USDA-APHIS-VS-CEAH-NAHMS, 2014). This largely limits the amount of time in which an experiment can be performed and has the potential to limit 
the number of sheep available for use. Alternative animal models of $\mathrm{Hc}$ infection to test responses before using sheep are available but not practical. Jirds are gerbil- like animal that can host $H c$ infections, but the parasite does not develop past L4 and establishment of the parasite is too low for experimentation. Also, without complete development, eggs would not be shed in the feces, thus monitoring infections would be difficult (Conder et al., 1992).

Another concern in sheep studies is the use of the animal after it is sacrificed. $H$. contortus infection does not prevent sheep from being used as food. In a normal infection experiment with $H c$, the animals would be sacrificed and could be butchered for profit and food. Depending on the treatment, there is a withdrawal period between when an animal is vaccinated or medicinally treated and when it can enter the food system. In terms of vaccine experiments, novel components may not have been evaluated for their effect on meat quality or safety. When these animals are sacrificed, their carcass cannot be used for food and thus, these experiments may be less attractive and lucrative to some researchers.

\section{Explorations and Future Directions}

Research originating in our lab showed that both SUF and STC antibody bound L3 better than XL3 and L4s based on larval binding assays. One of the main differences between these life stages is the intact L3 cuticle of the L3 stage (Garza et al., 2017). This led to the studies working to identify $\mathrm{Hc}$ antigens recognized by either SUF or STC antibodies. We hypothesized that there were antigen(s) found in L3 cuticles that contributed to an early immune response. St. Croix are known to be resistant to $H c$ infection. It was unsurprising to find STC antibody bound more proteins and had more 
intense band development. However, the intensity of IgG binding of $35 \mathrm{kDa}$ band was unexpected. Whatever proteins were part of the $35 \mathrm{kDa}$ band were not bound by Suffolk $\lg G$.

To ensure that the high binding results of the St. Croix immunoblot compared to the Suffolk blot were not due to more antibody in the St. Croix serum, ELISAs were run to measure antibody in the serum. The first ELISA performed was total ovine immunoglobulin. These results showed that the Suffolk had significantly more total immunoglobulin than the St. Croix (19.417 $\mathrm{mg} / \mathrm{ml}$ vs $15.8317 \mathrm{mg} / \mathrm{ml}$, respectively). While this measured total immunoglobulins, ELISAs were also performed to comparatively measure $H$. contortus- specific IgG in each serum sample used in the immunoblot. Once again, Suffolk serum had significantly higher levels of IgG towards Cuticle, L3, and XI3(the targeted antibody used in the immunoblot) than the St. Croix. These results indicate that although the Suffolk had a more antibody towards the proteins, they were not as highly specific to proteins as St. Croix IgG. These results led us to hypothesize that although the Suffolk can produce antibody towards larvae homogenate, they may not be identifying proteins that lead to protection. These results also are indicative that antibodies produced by Suffolk may not be protective.

The $35 \mathrm{kDa}$ band was excised and sent for mass spec identification. Before proteins are analyzed with mass spectrometry, they are digested with different enzymes to cut the protein into smaller peptides at certain amino acids. After digestion with trypsin, the peptides were analyzed via mass spectrometry based on their size and charge. Mascot database was used to identify the proteins and Scaffold (a proteome software) was used to validate the identities. Based on the protein identification report received from 
University of Nebraska- Lincoln, "Peptide identifications were accepted if they could be established at greater than $80.0 \%$ probability by the Peptide Prophet algorithm with Scaffold delta-mass correction(Keller et al., 2002). Protein identifications were accepted if they could be established at greater than $99.0 \%$ probability and contained at least 2 identified peptides. Protein probabilities were assigned by the Protein Prophet algorithm (Nesvizhskii et al., 2003)."

The analysis identified the $35 \mathrm{kDa}$ protein as tropomyosin domain containing protein (GenBank: CDJ92091.1). Further investigation of tropomyosin domain containing protein using the BLAST feature of NCBI showed strong overlapping of $\mathrm{Hc}$ tropomyosin domain containing protein with other invertebrate tropomyosin. These results led to studying the protein as a potential vaccine candidate. In other invertebrate species, tropomyosin has been identified as a main allergen (shellfish and cockroaches) and has been investigated as a vaccine antigen for other species such as the red poultry mite, ticks, and other parasites (Taylor et al., 1996; Hartmann et al., 1997; Cao and Liu, 1998; Reese et al., 1999; Ayuso et al., 2002; Sereda et al., 2010; Wai et al., 2014).

However, the mass spectrometry results provided a list of 198 other proteins that the band could contain. Most of the proteins identified during mass spec were not $35 \mathrm{kDa}$, which reduced the number of proteins investigated during these experiments. The list of proteins identified also means that although tropomyosin has been identified as an antigen of other species, the other proteins may have been bound by sheep IgG in the 35 $\mathrm{kDa}$ band. A western blot was performed using anti- Charybdis feriata tropomyosin antibody to bind $H c$ tropomyosin in the protein sample and confirm its presence at the correct molecular weight after protein separation. These results did show that 
tropomyosin was there. While we were able to visualize tropomyosin via western blot, we were not able to visualize the specific location of tropomyosin within the larval body.

Identifying the location of tropomyosin within different life staged of $\mathrm{Hc}$ will be key if this protein is to be used in future vaccine experiments. Transmission electron microscopy can be utilized to determine location of specific proteins within a biological structure. This is done my labeling the protein with a metal, such as gold. The protein labeled with gold-labeled antibody will appear as black dots against the rest of the structure. Knowing the location of the protein within the structure will provide a better understanding of whether the immune system has the potential to access to the protein in vivo.

Several studies could be performed to confirm the identity of tropomyosin as an antigen bound by STC antibody. These experiments could use synthetically produced tropomyosin or tropomyosin isolated from $\mathrm{HcL} 3$ homogenate. In vitro produced-Hc tropomyosin could be either bound to a plate for use in an ELISA, or the protein could be bound by STC serum via western blot. These experiments could also be done using native $H c$ tropomyosin isolated via pulldown column. This would be achieved by binding anti-tropomyosin antibody to a column and eluting $H c$ protein through the column. This would allow all other proteins to run through the column and $\mathrm{Hc}$ tropomyosin could then be eluted from the specific antibody. Further, comparing antibody binding between in vitro-produced tropomyosin or native tropomyosin could be valuable information for future vaccine studies. These proteins could also be used to stimulate cells in vitro and compare their abilities to induce proliferation. 
Further investigations of other potential vaccine antigens should utilize immunoprecipitation assays. These assays use protein affinity, such as Protein $A$, of $\lg G$ to immobilize antibody to a column (Sjöquist and Stålenheim, 1969). In terms of this experiment, sheep antibody would be bound to a column and solubilized Hcprotein would be slowly passed through the column to allow antibody-antigen binding. After the conjugates have bound, unbound protein can be washed through and the antibodyantigen complex can be eluted and antigens specifically bound by the antibody could be identified. This also allows for different types of antigens to bind antibody, such as glycogens, saccharides or lipids, not just proteins. Although this method requires multiple steps, it would allow multiple antigens, again not just proteins, to be isolated at once.

Although tropomyosin was bound highly by STC IgG, we observed other proteins bound by $\lg G$ and $\lg A$ that were not identified. To improve the efficacy of a future vaccine, it would be imperative to identify other antigens bound by $\lg G$ and $\lg A$. Increased levels of IgA have been associated with lower fecal egg counts in sheep (Amarante et al., 2005; Bowdridge et al., 2013; Hernández et al., 2016). Therefore, identifying IgA-bound antigens has the potential to enhance the investigations of new putative vaccine candidates.

This research focused on $\mathrm{L} 3$ of $\mathrm{Hc}$ because previous research has shown an ability of St. Croix immune system to respond early in vivo, which would be to the L3. Also, preventing L3 establishment would also prevent further development other life stages and thus prevent infection. However, it may be more beneficial to target different life stages either in addition to L3 or exclusively. Once they enter the abomasum, L3 or exsheathed L3 move in and out of the lumen of the abomasum where they molt into L4 within two to 
three days. After 10 days post-infection, L4 develop buccal lancets that can then pierce the lumen and release blood for consumption (Nicholls et al., 1985). These observations mean that the $L 3$ is not present as $L 3$ for very long in the abomasum and thus targeting other life stages may also be imperative to study. As mentioned, BarberVax targets adult Hc enzymes that metabolize blood. Although BarberVax does not induce long-lasting protection, it may be worthwhile to mix BarberVax with different adjuvants such as Alum or oil-emulsion adjuvant to see if protection could be prolonged or enhanced after one vaccination. It would also be advantageous to study and understand the correlates of protection induced by BarberVax so that those units of the immune response could be amplified to improve the vaccine.

Other research has found that there are other breeds of "resistant" sheep. The mechanisms of resistance vary between these breeds. While not all mechanisms of resistance have been elucidated, STC challenge experiments have shown that $\mathrm{Hc}$ are unable to establish in the abomasum indicating a targeted immune response to L3. Another resistant breed is Texel sheep. Studies measuring FEC and adult worm burden after infection have shown reduced fecal egg count, but adult worms still establish in the abomasum. After investigations, Garza and Weaver (unpublished data) showed that cells mixed with antibody bound the genital pores of adult female Hc, blocking release of eggs and reducing environmental contamination. These examples mean that different breeds of resistant sheep immune systems may recognize different antigens. Therefore, screening of these antigens via immunoblot or through column separation with different breed serum could lead to many other vaccine candidates that should be explored. 
One of the most important future experiments include identification of antigenic peptides. This study has the potential to provide multiple putative vaccine candidates. Although it is understood that a Th2 response is necessary to provide protection against $H$. contortus, more insight into what the immune system is recognizing or building an adaptive response to would be illuminating. A series of experiments exploring not only what antibody is binding, but what also what cells are recognizing have the potential to reveal many unknown vaccine candidates. Understanding the differences in breed immune responses could also benefit the sheep industry overall, as different resistant breeds' immune mechanisms are different from each other. This is apparent in the previously discussed unpublished Garza and Weaver research showing different PBMC and serum binding site preference between Texel and St. Croix. Collecting serum from producers or other universities that have different resistant and susceptible breeds would also provide an opportunity for further collaborations and new data. This experiment could be achieved through an immunoblot with Haemonchus contortus protein separated via gel electrophoresis followed by binding of different serums and finally a secondary antibody and developer. This experiment could also be accomplished using a column that binds sheep antibody followed by a flow through of $\mathrm{H}$. contortus protein and finally separation via gel electrophoresis.

Exploration of other vaccine candidates has the potential to identify more easily producible proteins as well. As mentioned in chapter 3, production of tropomyosin domain containing protein was attempted only to amplify a non- $H$. contortus gene after vector insertion. However, if other vaccine candidates are identified and are smaller or better documented, then they may be easier to produce in vitro. Selection of a protein that is 
easier to produce in vitro or having whole tropomyosin produced in vitro would also eliminate the need to keep lambs infected for native protein, as they do with BarberVax. Another advantage of recombinant proteins is that based on previous $H$. contortus vaccine experiments recombinant proteins are more protective than peptides (Boisvenue et al., 1991; Purcell et al., 2007; Kandil et al., 2017; González-Sánchez et al., 2018). This is often the case, as peptides are small and need to be conjugated to a large carrier protein to become more antigenic for vaccine use (Rappuoli et al., 2019). Whole recombinant proteins also have an advantage of Determining the location of the peptides within the protein structure provides information on the immune system's ability to bind these peptides used in the vaccine. Even if antibody is produced to the proteins, if they are not accessible to the antibody, they would be worthless.

Another factor to consider during vaccination is the environment in which the pathogen would be targeted by vaccine-induced antibody. In the case of $H$. contortus, the parasite lives and is therefore targeted in a harsh environment- the abomasum or true stomach. There, the $\mathrm{pH}$ highly acidic at a $\mathrm{pH}$ of $2-4$. This low $\mathrm{pH}$ has the potential to denature proteins or alter their confirmation. Antibody development after vaccination is to the peptides (or protein in other cases) included in the vaccine. When released into the abomasum, the low $\mathrm{pH}$ has the potential to alter the binding region of antibody, altering its ability to bind its target protein. While our data showed that circulating antibody was able to bind the vaccine peptides, these antibodies were isolated from blood, not the abomasum. Therefore, in future experiments, it may also be beneficial to collect antibody from the abomasal mucosa and determine its ability to bind its target. Understanding how antibody binding is affected by $\mathrm{pH}$ could also be tested in vitro. Isolated serum could be 
incubated in different pH buffers and their binding capabilities could be tested in culture with L3 or to peptides via ELISA.

Although Suffolk were able to produce antibody to the vaccine peptides, the immune response induced by the adjuvant was not appropriate for protection against $H$. contortus. Therefore, future vaccine experiments should include multiple adjuvants to select the best in terms of this infection. As several studies have shown, resistant breeds mount Th2 responses against $\mathrm{Hc}$ and thus, a Th2 response should be the goal of the vaccine adjuvant. However, other studies have also shown low recruitment of neutrophils early in the abomasum. Combined with recent finding that Suffolk neutrophils stimulated with HcLA in vitro are able produce IL-4, these data suggest that an adjuvant that induces cellular recruitment may be a positive addition to the vaccine (Middleton et al., 2020).

Previous studies have revealed an inability of Suffolk lambs and wool composite lambs to produce an early Th2 response, like St. Croix sheep. Instead, high levels of inflammatory genes are upregulated early and did not level off to allow a Th2 response (Bowdridge et al., 2015; Shepherd, 2019). Gene expression of the abomasal lymph nodes from this vaccine experiment animals showed that there was neither Th1 or Th2 response induced by any of the treatments (vaccination or adjuvant only). However, the adjuvant seemingly induced il17a gene expression. I/17a is a cytokine produced by Th17 cells which are described as proinflammatory cells and has not been associated with reduced parasitic infection. This adjuvant (Montanide ISA $61 \mathrm{VG}$ ) was chosen to induce both a long-lived antibody response, but also to potentially increase the cellular response. Gene expression from the infection only group did reveal an interesting increase in foxp3 expression, a gene associated with $\mathrm{T}$ regulatory cells. These data may suggest that the 
local lymph node environment may be preventing a switch to Th2 response. Selecting adjuvants that induce a stronger Th2 response to overcome a consistent Th1 response or Treg response may be a better adjuvant selection for future vaccine trials. Alum is a common Th2-inducing adjuvant and could be used in future vaccine trials against $\mathrm{Hc}$. Alum has also been associated with increased recruitment of neutrophils, monocytes and eosinophils (Calabro et al., 2011). These cell types are recruited to the site of infection during an effective immune response against $\mathrm{Hc}$ and thus using Alum has the potential to increase immunity during vaccination.

Further, while parasitological parameters are important in parasite vaccine trials, it is also important to understand why the vaccine did or did not work. To understand the results of the parasitological parameters, cell types, gene expression, and protein abundance at the site of infection could all be indicators vaccine effectiveness. Therefore, in a future vaccine trial, snap-freezing tissue for immunohistochemistry would provide an opportunity to understand the local cytokine levels beyond gene expression. It will also be important to understand the effects of the vaccine on meat quality and withdrawal period- are there traceable amounts of the vaccine in the food parts of the carcass? Without this knowledge, these vaccines would not be viable even if they were effective.

\section{$\underline{\text { Conclusions }}$}

These studies have shown that there are large disparities between St. Croix and Suffolk antibody development to specific $\mathrm{Hc}$ proteins during infection. While this is unsurprising, an immunoblot showed how different antibodies produced by the different breeds was; specifically, St. Croix IgG bound one Hc protein exceptionally well, while Suffolk IgG did not bind it at all. This protein was identified as tropomyosin domain 
containing protein. These results led to further investigations of specific antigenic epitopes of this protein for a putative use in vaccine. Four new epitopes were chosen via epitope mapping for a vaccine trial. Suffolk sheep were selected to use for this trial, as they are a susceptible breed that would be the target of this vaccine in a production system. The vaccine was composed of a cocktail of the four peptides from the epitope mapping experiment and Montanide ISA 61 VG adjuvant. This water-in-oil adjuvant induces a strong cellular response and long-lasting antibodies. Weekly antibody analysis showed elevated levels of peptide-specific antibodies week two after vaccination and through the end of the trial in the vaccinated sheep. However, the antibodies were not protective, as all infected groups had statistically same fecal egg counts (weekly measures of infection) and adult worm burdens. There was an adjuvant effect of increased il17a gene expression. Increased IL-17A could have contributed to the lack of protection, as it is an inflammatory cytokine. These results illustrate a need for experimenting with different adjuvants to induce different immune responses. Although these experiments were not successful in protecting the animals, they build a roadmap for future antigen discovery and vaccine trial methods. 


\section{Literature Cited}

Amarante, A. F. T., P. A. Bricarello, J. F. Huntley, L. P. Mazzolin, and J. C. Gomes. 2005. Relationship of abomasal histology and parasite-specific immunoglobulin $A$ with the resistance to Haemonchus contortus infection in three breeds of sheep. Vet. Parasitol. 128:99-107. doi:10.1016/j.vetpar.2004.11.021.

Ayuso, R., S. B. Lehrer, and G. Reese. 2002. Identification of continuous, allergenic regions of the major shrimp allergen Pen a 1 (tropomyosin). Int. Arch. Allergy Immunol. 127:27-37. doi:10.1159/000048166.

Boisvenue, R. J., M. I. Stiff, L. V. Tonkinson, and G. N. Cox. 1991. Protective studies in sheep immunized with cuticular collagen proteins and peptides of Haemonchus contortus. Parasite Immunol. 13:227-240. doi:10.1111/j.1365-3024.1991.tb00278.x.

Bowdridge, S. A., A. M. Zajac, and D. R. Notter. 2015. St. Croix sheep produce a rapid and greater cellular immune response contributing to reduced establishment of Haemonchus contortus. Vet. Parasitol. 208:204-210. doi:10.1016/j.vetpar.2015.01.019.

Bowdridge, S., K. MacKinnon, J. C. McCann, A. M. Zajac, and D. R. Notter. 2013. Hairtype sheep generate an accelerated and longer-lived humoral immune response to Haemonchus contortus infection. Vet. Parasitol. 196:172-178. doi:10.1016/j.vetpar.2013.01.008.

Calabro, S., M. Tortoli, B. C. Baudner, A. Pacitto, M. Cortese, D. T. O'Hagan, E. De Gregorio, A. Seubert, and A. Wack. 2011. Vaccine adjuvants alum and MF59 induce rapid recruitment of neutrophils and monocytes that participate in antigen transport to draining lymph nodes. Vaccine. 29:1812-1823. doi:10.1016/j.vaccine.2010.12.090.

Cao, J., and S. Liu. 1998. [Immunization of mice with native tropomyosins from Schistosoma japonicum and Oncomelania hupensis]. Zhongguo Ji Sheng Chong Xue Yu Ji Sheng Chong Bing Za Zhi. 16:401-405. 
Conder, G. A., S. S. Johnson, A. D. Hall, M. W. Fleming, M. D. Mills, and P. M. Guimond. 1992. Growth and Development of Haemonchus contortus in Jirds, Meriones unguiculatus. J. Parasitol. 78:492-497. doi:10.2307/3283650.

Garza, J., S. P. Greiner, and S. A. Bowdridge. 2017. Serum-mediated Haemonchus contortus larval aggregation differs by larval stage and is enhanced by complement -. $\begin{array}{llll}\text { Parasite } & \text { Immunol. } & \text { Available } & \end{array}$ https://onlinelibrary.wiley.com/doi/abs/10.1111/pim.12409

González-Sánchez, M. E., M. Cuquerella, and J. M. Alunda. 2018. Vaccination of lambs against Haemonchus contortus with the recombinant rHc23. Effect of adjuvant and antigen dose. P. L. Ho, editor. PLOS ONE. 13:e0193118. doi:10.1371/journal.pone.0193118.

Hartmann, S., R. Adam, T. Marti, C. Kirsten, S. Seidinger, and R. Lucius. 1997. A 41-kDa antigen of the rodent filaria Acanthocheilonema viteae with homologies to tropomyosin induces host-protective immune responses. Parasitol. Res. 83:390-393. doi:10.1007/s004360050269.

Hernández, J. N., A. Hernández, M. J. Stear, M. Conde-Felipe, E. Rodríguez, D. Piedrafita, and J. F. González. 2016. Potential role for mucosal $\lg A$ in modulating Haemonchus contortus adult worm infection in sheep. Vet. Parasitol. 223:153-158. doi:10.1016/j.vetpar.2016.04.022.

Kandil, O. M., K. A. Abdelrahman, H. A. Shalaby, S. H. M. Hendawy, N. M. T. A. El Ezz, S. A. Nassar, and J. E. Miller. 2017. Evaluation of crude larval protein and recombinant somatic protein 26/23 (rHcp26/23) immunization against Haemonchus contortus in sheep. Vet. World. 10:758-763. doi:10.14202/vetworld.2017.758-763.

Keller, A., A. I. Nesvizhskii, E. Kolker, and R. Aebersold. 2002. Empirical statistical model to estimate the accuracy of peptide identifications made by MS/MS and database search. Anal. Chem. 74:5383-5392. doi:10.1021/ac025747h. 
Middleton, D., J. J. Garza, S. P. Greiner, and S. A. Bowdridge. 2020. Neutrophils rapidly produce Th2 cytokines in response to larval but not adult helminth antigen. Parasite Immunol. 42:e12679. doi:10.1111/pim.12679.

Nesvizhskii, A. I., A. Keller, E. Kolker, and R. Aebersold. 2003. A statistical model for identifying proteins by tandem mass spectrometry. Anal. Chem. 75:4646-4658. doi:10.1021/ac0341261.

Nicholls, C. D., D. L. Lee, and M. J. Sharpe. 1985. Scanning electron microscopy of biopsy specimens removed by a colonoscope from the abomasum of sheep infected with Haemonchus contortus. Parasitology. 90:357-363. doi:10.1017/S0031182000051052.

Purcell, A. W., J. McCluskey, and J. Rossjohn. 2007. More than one reason to rethink the use of peptides in vaccine design. Nat. Rev. Drug Discov. 6:404-414. doi:10.1038/nrd2224.

Rappuoli, R., E. De Gregorio, and P. Costantino. 2019. On the mechanisms of conjugate vaccines. Proc. Natl. Acad. Sci. 116:14-16. doi:10.1073/pnas.1819612116.

Reese, G., R. Ayuso, and S. B. Lehrer. 1999. Tropomyosin: An Invertebrate PanAllergen. Int. Arch. Allergy Immunol. 119:247-258. doi:10.1159/000024201.

Sereda, M. J., S. Hartmann, D. W. Büttner, R. Volkmer, M. Hovestädt, N. Brattig, and R. Lucius. 2010. Characterization of the allergen filarial tropomyosin with an invertebrate specific monoclonal antibody. Acta Trop. 116:61-67. doi:10.1016/j.actatropica.2010.05.010.

Sheep Production and Management: reproduction in sheep. Available from: https://aces.nmsu.edu/sheep/sheep_reproduction/breeding_habits.html

Shepherd, E. A. 2019. Characterization of Ovine Monocytes in Response to Haemonchus contortus Larvae in vitro and a Novel Role of Interleukin-13 Inducing Larval Paralysis [Ph.D.]. West Virginia University, United States -- West Virginia. Available from: https://search.proquest.com/pqdtglobal/docview/2401413094/abstract/F85EFDAB1A95 $4 \mathrm{~F} 16 \mathrm{PQ} / 1$ 
Sjöquist, J., and G. Stålenheim. 1969. Protein a from Staphylococcus Aureus: IX. Complement-fixing activity of Protein A-IgG complexes. J. Immunol. 103:467-473.

Taylor, M. J., R. E. Jenkins, and A. E. Bianco. 1996. Protective immunity induced by vaccination with Onchocerca volvulus tropomyosin in rodents. Parasite Immunol. 18:219225. doi:10.1046/j.1365-3024.1996.d01-93.x.

USDA-APHIS-VS-CEAH-NAHMS. 2014. Lambing Management Practices on U.S. Sheep Operations, 2011. APHIS USDA. Available from: https://www.aphis.usda.gov/animal_health/nahms/sheep/downloads/sheep11/Sheep11_ is_Lambing.pdf

Wai, C. Y. Y., N. Y. H. Leung, M. H. K. Ho, L. J. Gershwin, S. A. Shu, P. S. C. Leung, and K. H. Chu. 2014. Immunization with Hypoallergens of Shrimp Allergen Tropomyosin Inhibits Shrimp Tropomyosin Specific IgE Reactivity. PLOS ONE. 9:e111649. doi:10.1371/journal.pone.0111649. 